\title{
Un audífono binaural inspirado en el reflejo olivococlear medial contralateral
}

Tesis doctoral Alejandro Hernández Martín

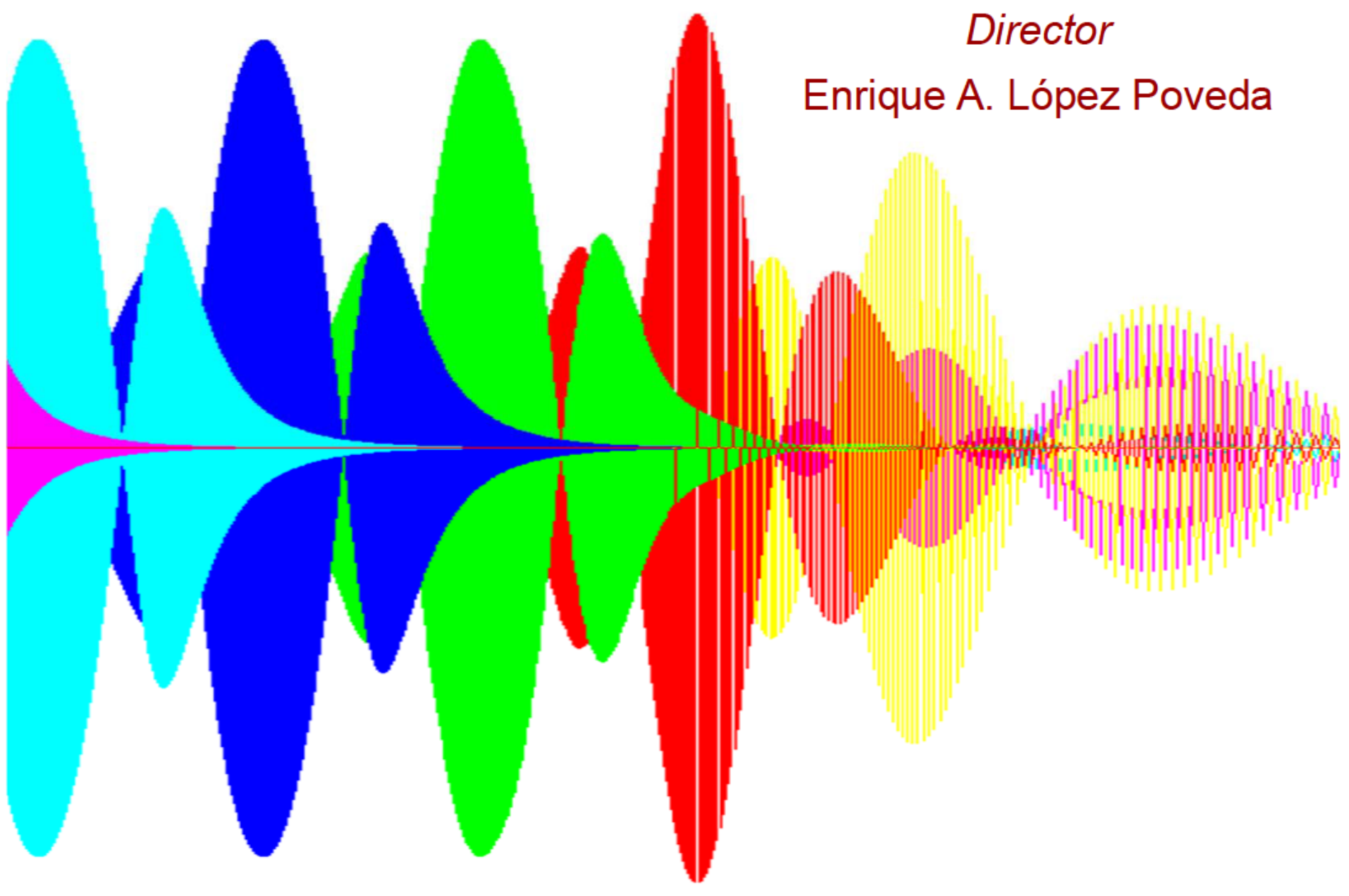

Universidad de Salamanca Junio 2020 



\section{Un audífono binaural inspirado en el reflejo olivococlear medial contralateral}

Tesis doctoral

Alejandro Hernández Martín

Director

Enrique A. López Poveda

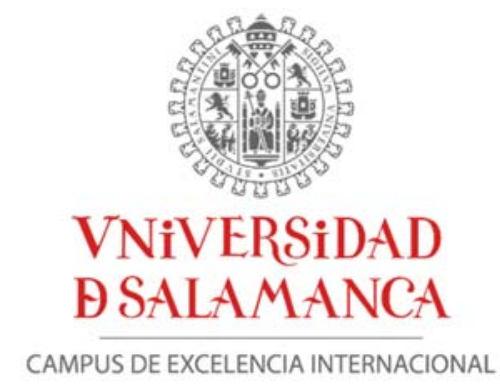

Junio de 2020 

D. Enrique Alejandro López Poveda, con DNI 07.953.786-H, profesor titular del Departamento de Cirugía de la Universidad de Salamanca e investigador del Instituto de Neurociencias de Castilla y León,

\section{CERTIFICA}

Que la tesis doctoral titulada "Un audífono binaural inspirado en el reflejo olivococlear medial contralateral" ha sido realizada por D. Alejandro Hernández Martín (DNI 76.074.700-S) bajo mi dirección.

La tesis aborda el problema de cómo ayudar a las personas que usan audífonos para que se comuniquen mejor en ambientes ruidosos. Propone un nuevo método binaural para procesar y amplificar los sonidos, denominado 'audífono MOC', inspirado en el reflejo olivococlear medial. Demuestra que los sonidos ipsilaterales y contralaterales modulan la amplificación del sonido aportada por este nuevo audífono de forma similar a cómo el reflejo olivococlear medial natural modula la amplificación en la cóclea sana. La tesis demuestra, además, que cuando varias personas hablan a la vez, los individuos hipoacúsicos reconocen mejor el habla con este nuevo audífono que usando un audífono convencional en cada oído.

En conjunto, la tesis presenta una obra original, de gran calidad, que reúne los requisitos formales y el rigor científico y académico necesario para que sea defendida y optar al grado de Doctor. 



\section{Solicitud de Mención de Doctorado Industrial}

D. Enrique Alejandro López Poveda, con DNI 07.953.786-H, profesor de la Universidad de Salamanca, y director de la tesis doctoral titulada "Un audífono binaural inspirado en el reflejo olivococlear medial contralateral" realizada por D. Alejandro Hernández Martín (DNI 76.074.700-S).

\section{EXPONE}

1. Que la tesis aborda el problema de cómo mejorar los audífonos para que las personas que los usan comprendan mejor el habla en ambientes ruidosos. Propone un nuevo método binaural para procesar y amplificar los sonidos inspirado el reflejo olivococlear medial. Demuestra que las personas hipoacúsicas reconocen mejor el habla enmascarado por otro hablante con este nuevo método que cuando usan un audífono convencional en cada oído.

2. La tesis se enmarca en el contrato de investigación (Art. 83) titulado "Procesamiento binaural de sonidos para implantes cocleares" firmado entre la empresa MED-EL GmbH y la Universidad de Salamanca, con plazo de ejecución 15/04/2013 a 31/08/2022.

3. El método de procesamiento de sonido propuesto en la tesis, o alguna variación de éste, podría materializarse en un nuevo tipo de audífono binaural, así como inspirar el diseño de nuevos audífonos e implantes auditivos. La tesis tiene, por tanto, interés industrial.

Y, por estos motivos,

\section{SOLICITA}

1. Que se otorgue a la tesis la Mención Industrial.

2. Que el contenido de la tesis se mantenga confidencial en el repositorio de la Universidad de Salamanca durante el mayor tiempo posible. 



\section{Resumen}

La pérdida de audición, que afecta 466 millones de personas en todo el mundo, deteriora la comunicación y la interacción social de las personas que la padecen. Para estas personas, el uso de audífonos puede ser una gran ayuda, ya que estos dispositivos mejoran la audibilidad de los sonidos suaves y la percepción de la sonoridad. Sin embargo, en situaciones cotidianas donde una persona está hablando en presencia de otros sonidos, los usuarios de audífonos tienen grandes dificultades para entender el habla. Esto podría deberse a que las personas con pérdida auditiva, que sufren un deterioro de sus células ciliadas externas cocleares, carecen de los beneficios 'desenmascarantes' que proporciona el reflejo olivococlear medial (MOCR). Este control reflejo, que el cerebro auditivo ejerce sobre la respuesta mecánica coclear, posiblemente facilita la escucha en ruido al reducir la adaptación de la respuesta al ruido de las fibras del nervio auditivo. Con el objetivo de mejorar la percepción del habla en ruido de los usuarios de audífonos, en la presente tesis se ha diseñado, implementado y evaluado un algoritmo de compresión de amplitud multicanal inspirado en el MOCR contralateral, denominado audífono MOC. Se trata de un audífono binaural en formato software donde la compresión que se aplica sobre los sonidos varía en el tiempo en función del sonido ipsilateral (compresión no instantánea) y contralateral (control contralateral de la compresión). Se demuestra que, de manera similar al efecto del MOCR natural en la compresión coclear, la compresión en cada canal del audífono MOC cambia dinámicamente dependiendo de las características de los sonidos ipsilaterales y contralaterales. La evaluación objetiva de la inteligibilidad del habla en personas con hipoacusia neurosensorial bilateral simétrica muestra que, en comparación al uso de dos audífonos funcionalmente independientes entre sí (audífono STD), el audífono binaural MOC mejora de 1-2 dB la inteligibilidad del habla en presencia de otro hablante. Este hallazgo implica que los 72 millones posibles usuarios de audífonos podrían mejorar entre un 20 y $40 \%$ el reconocimiento de frases en reuniones, fiestas o lugares de trabajo, donde los ruidos son otras personas hablando. En conclusión, el procesamiento binaural MOC, que simula los efectos del MOCR contralateral en el procesamiento de sonidos, puede mejorar la percepción del habla en ruido al reducir los efectos nocivos asociados a la compresión que aplican los audífonos tradicionales. 


\section{Abstract}

Hearing loss affects 466 million people around the world. It impairs verbal communication and hinders social interaction. For most people with hearing loss, hearing aids can be helpful, as they improve the audibility of soft sounds and the perception of loudness. Hearing-aid users, however, continue to struggle understanding speech in noisy environments, even with current devices. We hypothesize this could be partly due to hearing loss reducing, even removing, the 'antimasking' effects provided by the medial olivocochlear reflex (MOCR). The MOCR allows the brain to control cochlear mechanical compression and possibly facilitates the recognition of speech in noise by reducing the adaptation of auditory nerve fibers to background noise. To improve the recognition of speech in noise for hearing-aid users, we have designed, implemented, and tested a hearingaid algorithm inspired by the contralateral MOCR, termed the 'MOC hearing aid'. It consists of a binaural, multichannel compressor where the compression in each frequency channel of each ear varies dynamically in time depending upon ipsilateral (non-instantaneous compression) and contralateral (contralateral control of compression) sounds. We show that, similar to how sound activation of the MOCR changes cochlear compression, the compression in each frequency channel of the MOC hearing aid changes depending on the characteristics of ipsilateral and contralateral sounds. We also show that compared to using two conventional compressors without contralateral control of compression (one per ear), the MOC hearing aid can improve the reception threshold for sentences in competition with a single talker by 1-2 dB SNR. These findings suggest that the 72 million hearing-aid users or candidates could recognize 20 to $40 \%$ more sentences in meetings, parties, or workplaces where background noise consists of other talkers. Most importantly, they suggest that binaural sound processing inspired by the contralateral MOCR can improve the recognition of speech in noise by reducing the negative effects of compression as applied by conventional hearing aids. 


\section{Agradecimientos}

En primer lugar, me gustaría agradecer a Enrique A López-Poveda, director de la tesis, el tiempo y el esfuerzo empleado en mi formación profesional y personal. Su ejemplo me acompañará toda la vida. Me encuentro especialmente agradecido por la oportunidad de participar en su proyecto sobre la estrategia MOC, un trabajo muy enriquecedor y satisfactorio. Además, quisiera agradecer al resto de compañeros de laboratorio su ayuda en las cuestiones más técnicas (Almudena y Peter), su colaboración en la recolección de datos (Mila) y su predisposición para el debate científico (Fernando y Miriam). También, quiero dar las gracias a todos los compañeros del INCYL por las charlas en pasillos y en estancias para el café. Todos vosotros habéis conseguido que este trabajo sea una pasión y no una obligación. Por ello: gracias.

En segundo lugar, me gustaría expresar mi gratitud a MED-EL, por la financiación de nuestra investigación. También quiero dar las gracias a los participantes por su colaboración. Ellos han hecho posible los hallazgos que se presentan en este trabajo.

Por otra parte, quisiera agradecer su apoyo a mi madre, a mi hermana, a mi madrina, a mis abuelos Ramón y Celestina y al resto de mi familia. Su confianza me da fuerzas para afrontar cualquier dificultad. También, me siento realmente agradecido con la familia que uno elige, especialmente con el grupo 2 por su compromiso en la búsqueda de la verdad, y, en general, con todas aquellas personas que han influido en que hoy sea quien soy.

Finalmente quiero agradecer a mi compañera de viaje, su apoyo, consejos, amor, y sobre todo su dedicación para que nuestros caminos en un futuro sean uno solo.

Quisiera dedicar este trabajo a todos los mencionados y a todas las personas que lucharon contra el COVID-19. Espero que algún día nuestra investigación pueda mejorar la vida de las personas con pérdida de audición y así poder dejar el mundo en mejores condiciones de lo que lo encontramos. El que da, no debe volver a acordarse; pero el que recibe nunca olvidará.

Este trabajo ha sido financiado por el Ministerio de Economía y Competitividad (ref. BFU201565376-P) y por MED-EL GmbH (Innsbruck, Austria). 


\section{Abreviaturas y acrónimos}

Entre paréntesis se indica el término inglés del que procede el acrónimo, en su caso.

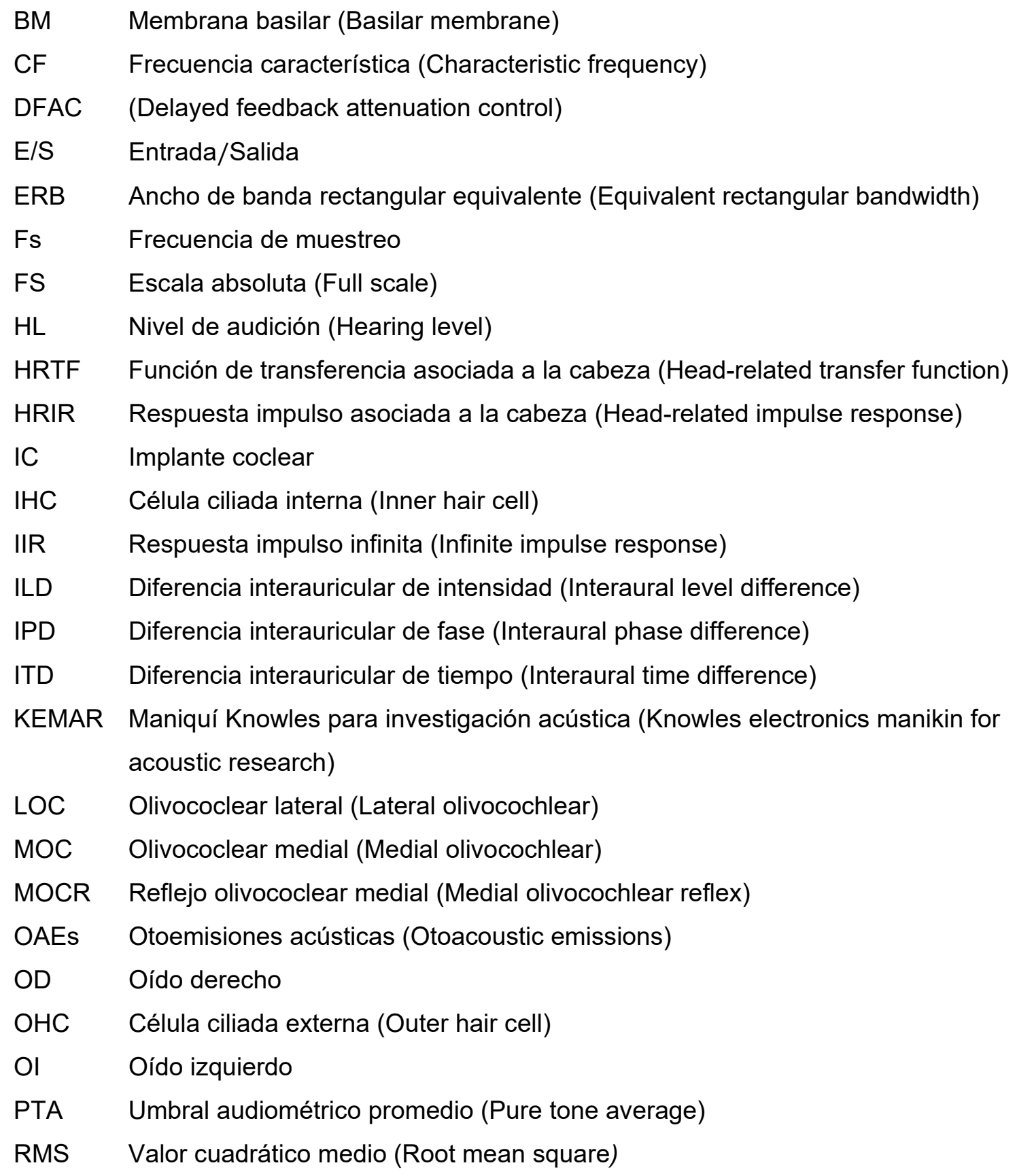


SHL Pérdida auditiva del habla (Speech hearing loss)

SNR Relación señal/ruido (Signal-to-noise ratio)

SPL Nivel de presión sonora (Sound pressure level)

SRT Umbral de recepción verbal (Speech reception threshold)

SSN Ruido con espectro del habla (Speech shaped noise)

STD Audífono binaural estándar consistente en emplear dos audífonos idénticos (uno en cada oído) funcionalmente independientes entre sí.

VC Control de volumen (Volume control) 


\section{Parámetros}

Se muestran, a continuación, los principales parámetros usados en el texto.

\begin{tabular}{lll}
\hline Parámetros & Definición & Unidades \\
\hline $\mathrm{M}$ & Máxima amplificación o ganancia & $\mathrm{dB}$ \\
$\mathrm{T}$ & Umbral de compresión & $\mathrm{dB} F \mathrm{~S}$ \\
$\mathrm{R}$ & Relación de compresión & $\mathrm{dB} / \mathrm{dB}$ \\
$\tau_{\mathrm{AT}}$ & Tiempo de ataque & $\mathrm{s}$ \\
$\tau_{\mathrm{RT}}$ & Tiempo de relajación & $\mathrm{S}$ \\
$\tau_{\mathrm{a}}$ & Constante rápida de integración MOC & $\mathrm{S}$ \\
$\tau_{\mathrm{b}}$ & Constante lenta de integración MOC & $\mathrm{S}$ \\
$\Gamma_{\mathrm{min}}$ & Mínima ganancia MOC & $\mathrm{dB}$ \\
$\Gamma_{\mathrm{max}}$ & Máxima ganancia MOC & $\mathrm{dB}$ \\
$\mathrm{E}_{0}$ & Energía correspondiente a la mitad de la máxima atenuación & $\mathrm{dB} \mathrm{FS}$ \\
$\beta$ & Pendiente de función sigmoidal de control MOC & $\mathrm{dB} \mathrm{FS}$ \\
$\mathrm{f}_{\mathrm{c}}$ & Frecuencia central & $\mathrm{Hz}$ \\
$\mathrm{BW}$ & Ancho de banda & $\mathrm{Hz}$ \\
$\mathrm{Fs}$ & Frecuencia de muestreo & $\mathrm{Hz}$ \\
$\mathrm{VC}$ & Control de volumen & $\%$ \\
$\mathrm{X}_{\mathrm{g}}$ & Intensidad de entrada a la que se aplica la ganancia NAL-RP & $\mathrm{dB} \mathrm{FS}$ \\
$\mathrm{O}_{\mathrm{m}}$ & Intensidad de salida máxima & $\mathrm{dB} \mathrm{FS}$ \\
\hline
\end{tabular}




\section{Contenido}

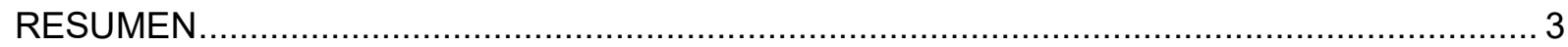

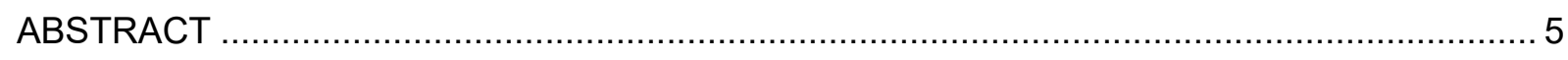

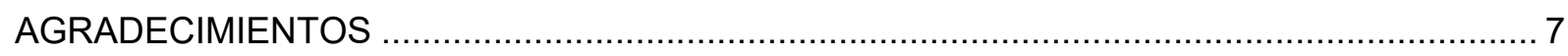

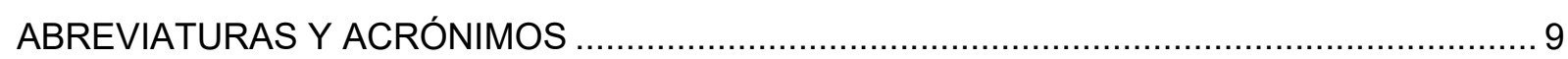

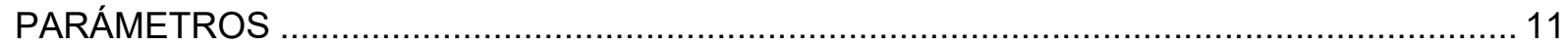

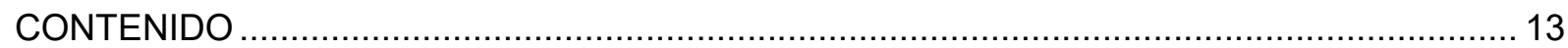

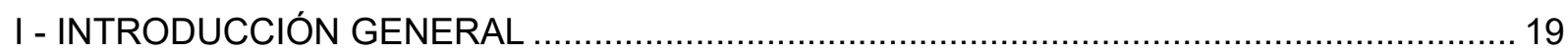

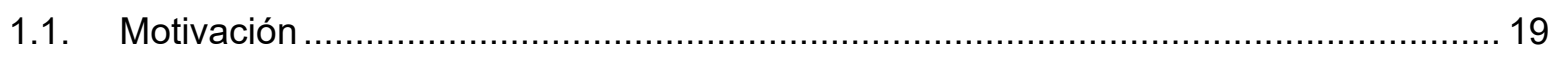

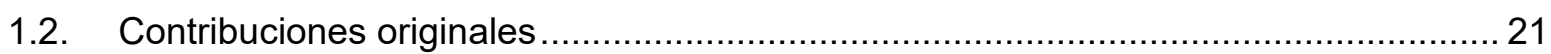

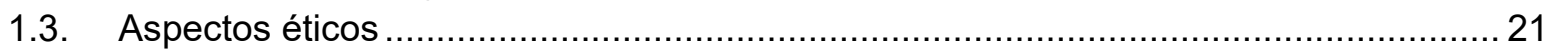

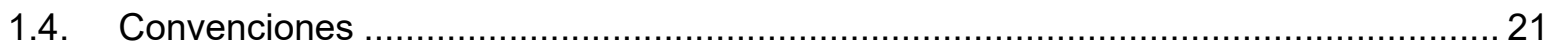

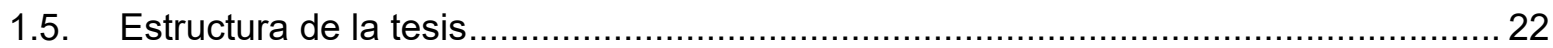

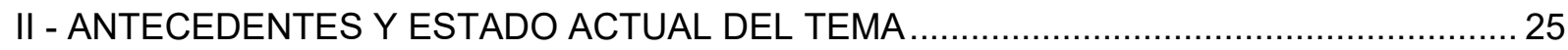

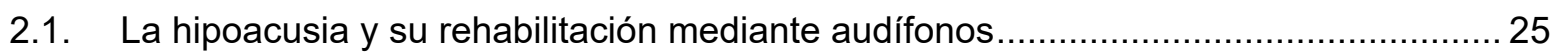

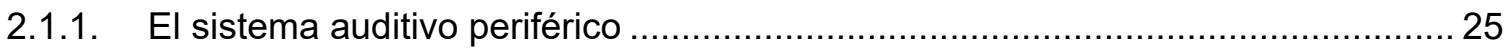

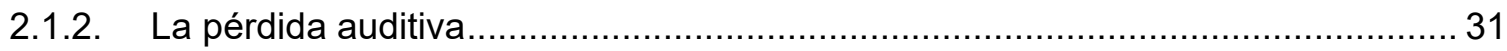

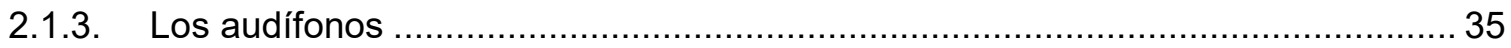

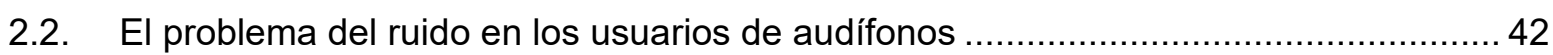

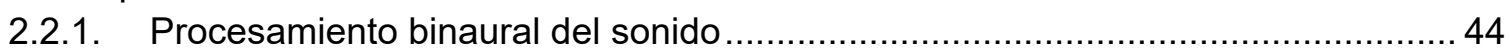

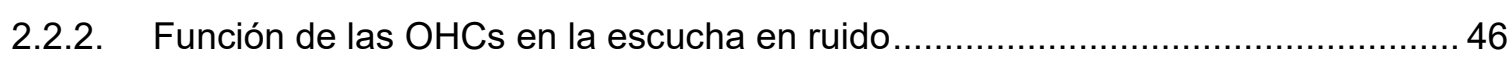

2.3. Un nuevo audífono binaural inspirado en el MOCR contralateral ............................... 50

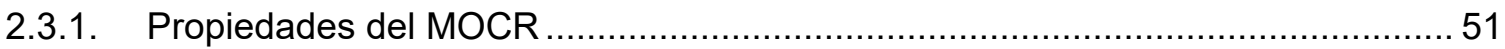

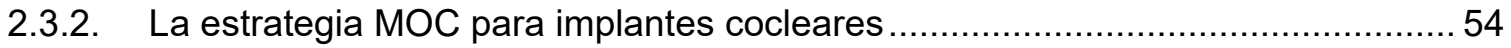

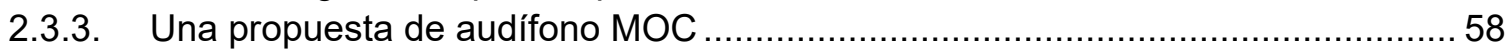

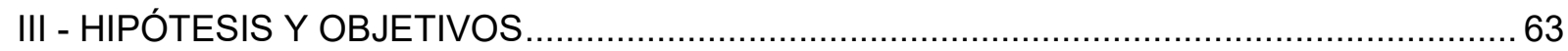

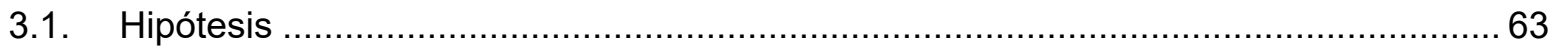

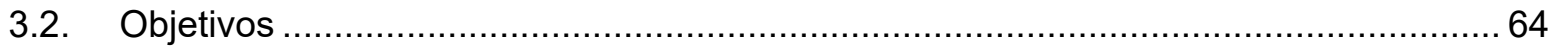

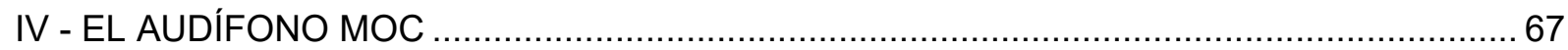

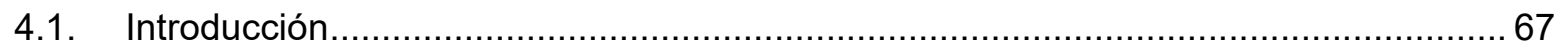

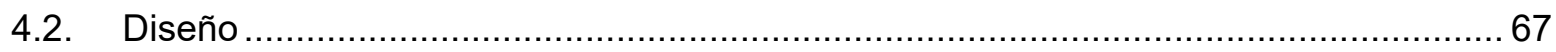

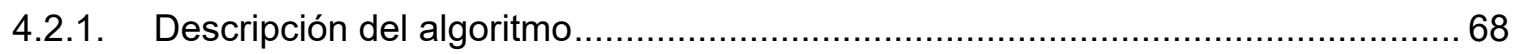




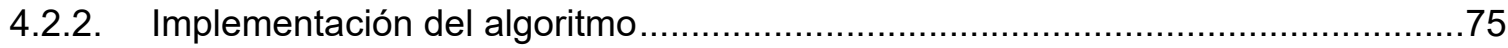

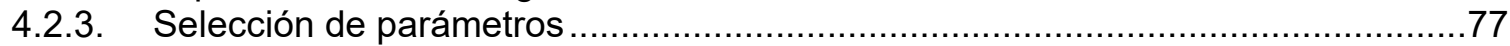

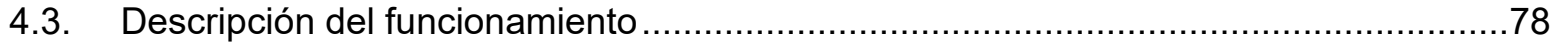

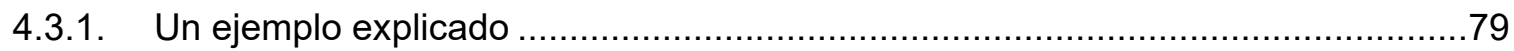

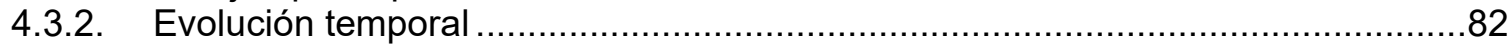

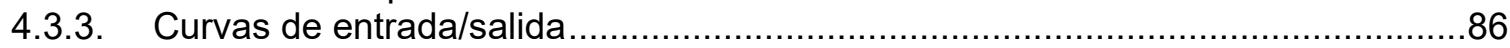

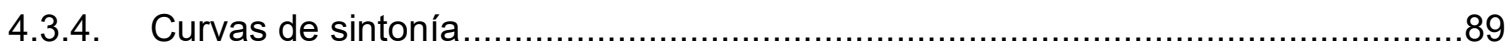

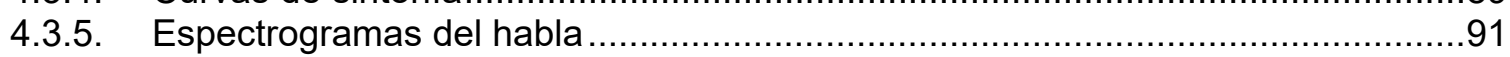

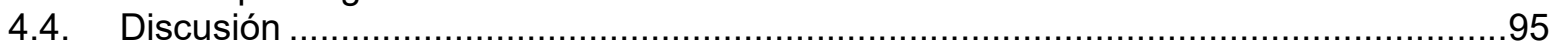

4.4.1 Compresión binaural y dinámica inspirada en el MOCR ....................................96

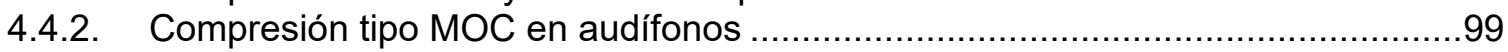

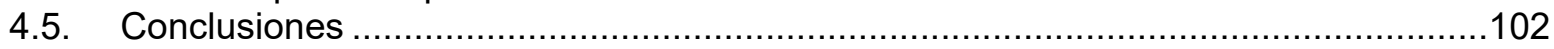

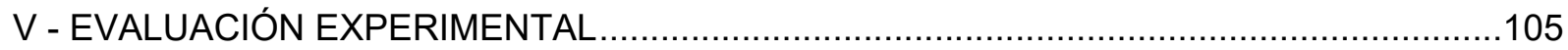

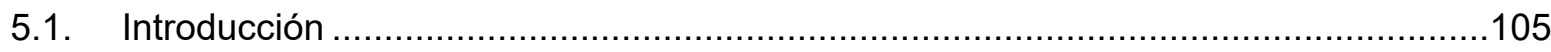

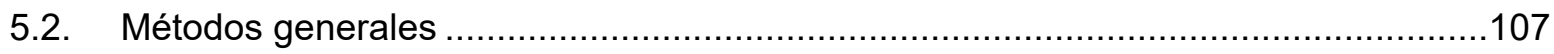

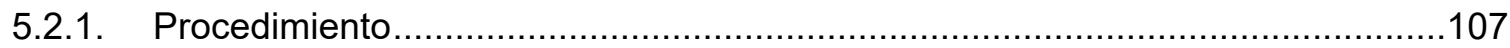

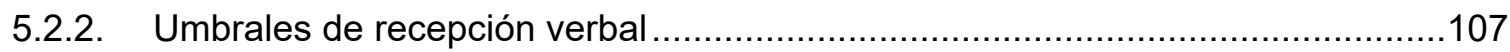

5.2.3. Orden de presentación de las condiciones ....................................................108

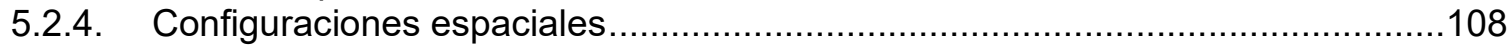

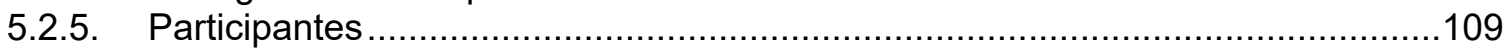

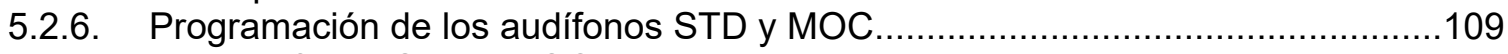

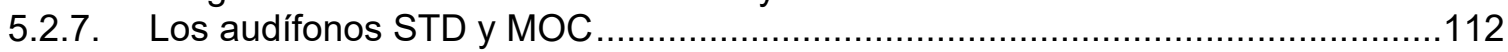

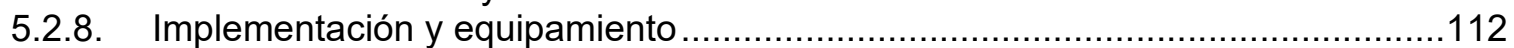

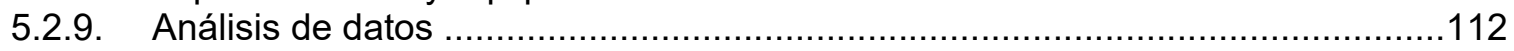

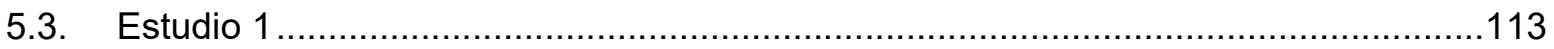

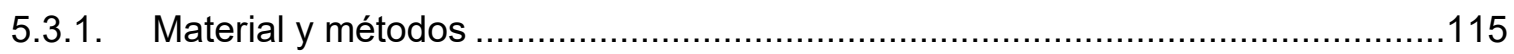

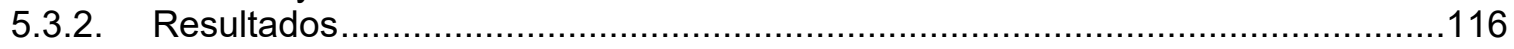

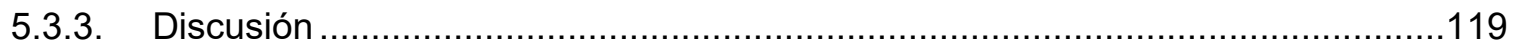

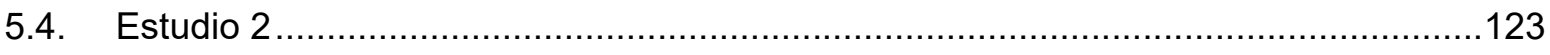

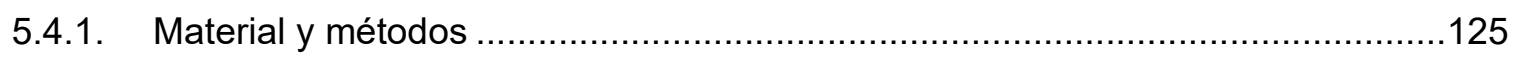

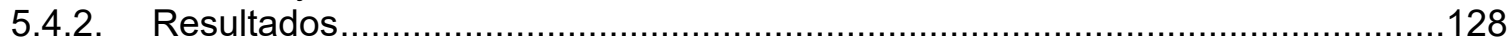

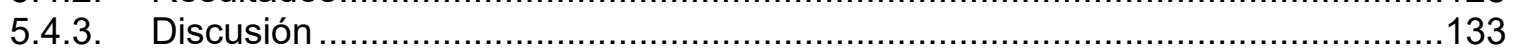

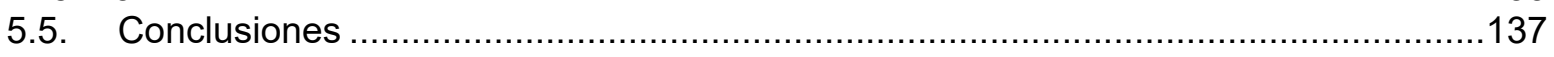

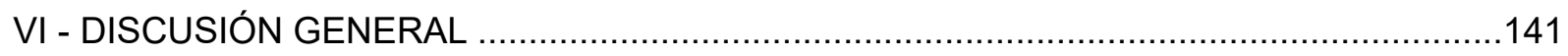

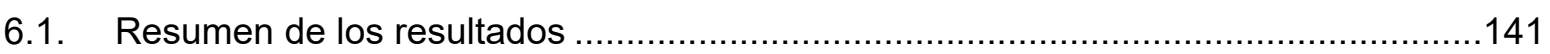

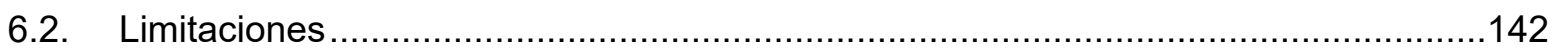

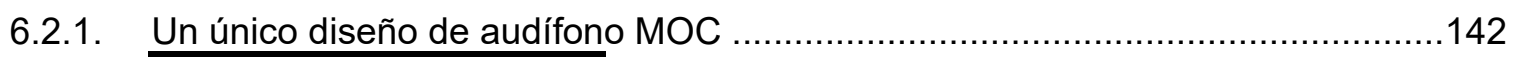

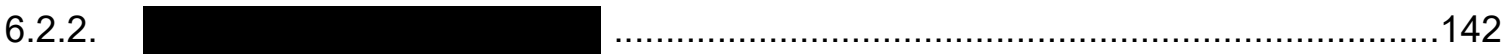

6.2.3. Dependencia de la inhibición de la pérdida auditiva .......................................143

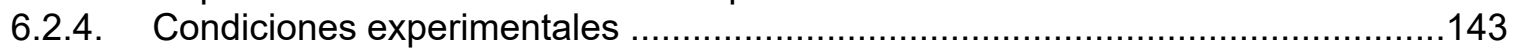

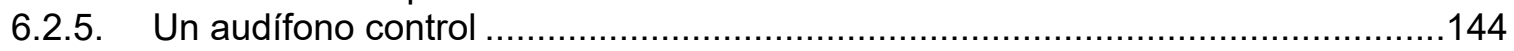

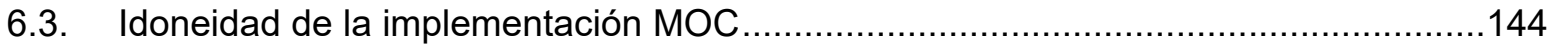

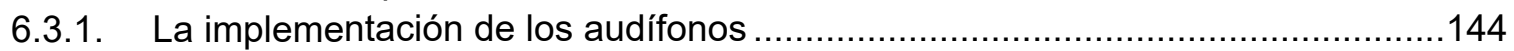

6.3.2. El efecto de la inhibición sobre la inteligibilidad ............................................ 145

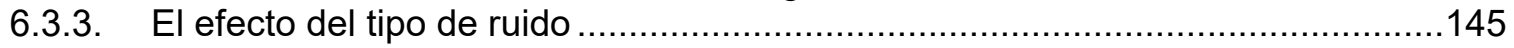

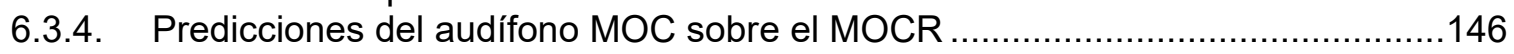




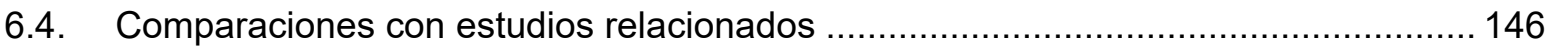

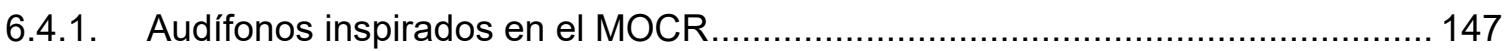

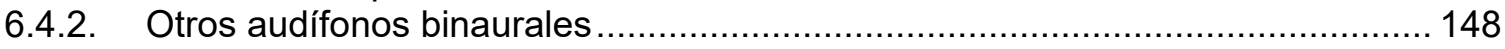

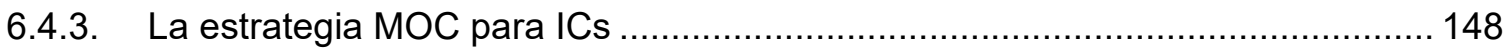

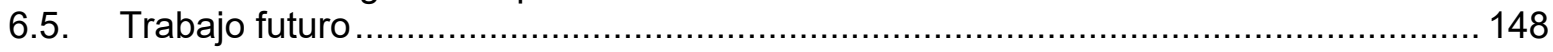

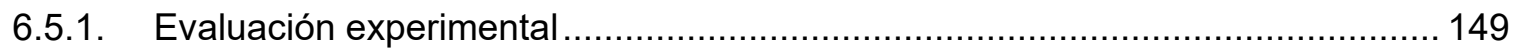

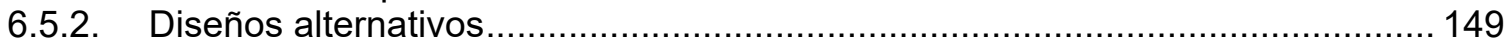

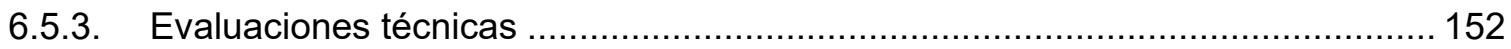

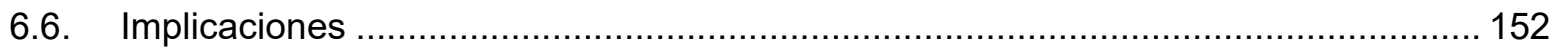

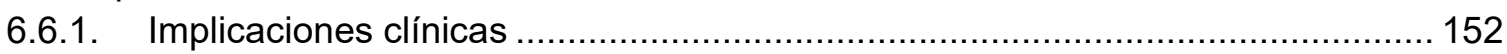

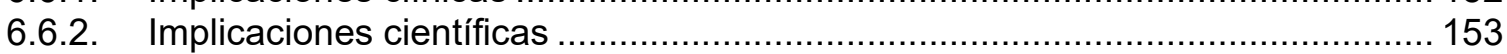

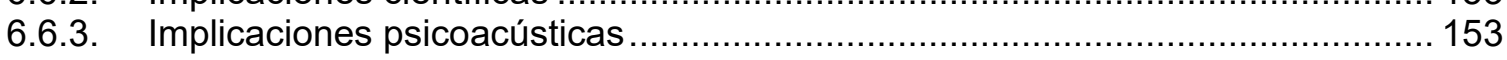

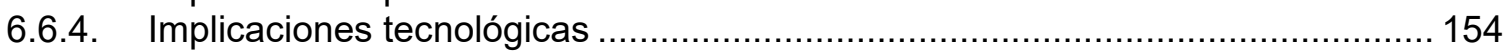

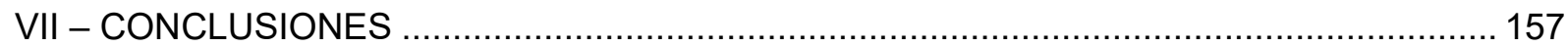

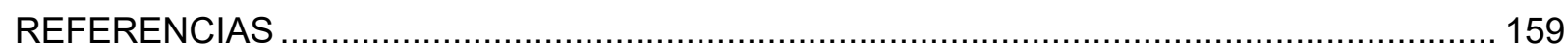

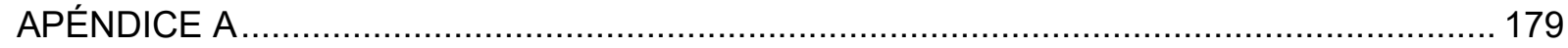

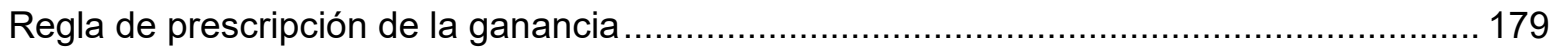

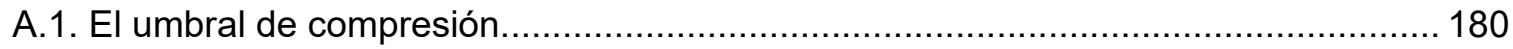

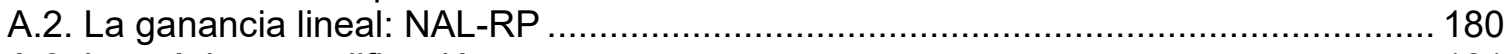

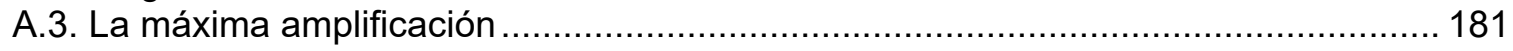

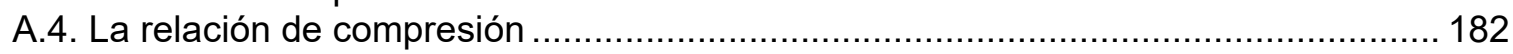

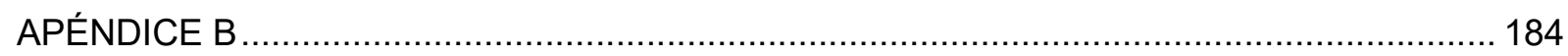

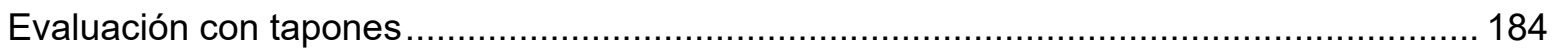

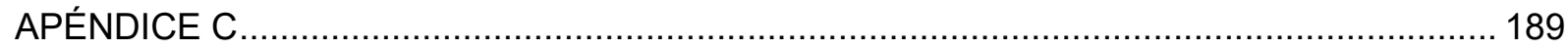

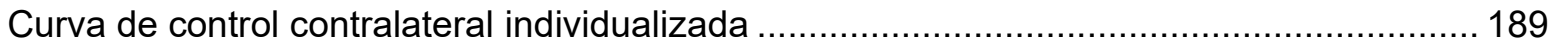





$$
\begin{aligned}
& \text { I - INTRODUCCIÓN } \\
& \text { GENERAL }
\end{aligned}
$$




\section{I - Introducción general}

\subsection{Motivación}

En todo el mundo, 466 millones de personas padecen pérdida de audición incapacitante. Estas cifras van en aumento y se estima que 900 millones de personas sufrirán pérdida de audición en 2050 (Organización Mundial de la Salud, 2018). La pérdida de audición reduce la capacidad de comunicación, lo que limita el acceso a los servicios y genera sentimientos de soledad, aislamiento y frustración (Palmer et al., 2016). El impacto social y económico de la pérdida auditiva es grande (Organización Mundial de la Salud, 2018). Afortunadamente, en la mayoría de los casos, las pérdidas de audición pueden tratarse con audífonos. Desgraciadamente, sin embargo, los usuarios de audífonos aún tienen grandes dificultades para entender el habla en ambientes acústicos ruidosos, como restaurantes o lugares de trabajo (Kochkin, 2002; LopezPoveda et al., 2017b). Esta tesis tiene como objetivo principal mejorar la inteligibilidad del habla en ruido de los usuarios de audífonos gracias a un procesamiento binaural inspirado en el control reflejo (involuntario) que el cerebro ejerce sobre la mecánica coclear de cada oído a través del haz eferente olivococlear.

Los audífonos comprimen el amplio rango de niveles sonoros del entorno al rango más estrecho de niveles sonoros que percibe el usuario. La compresión se hace por bandas de frecuencias (compresión multicanal) para restaurar la percepción normal de la sonoridad y la sensibilidad frente a los sonidos débiles (Walker y Dillon, 1982; Dillon, 1996; Kates, 2010; Popelka et al., 2016). Los compresores amplifican los sonidos de baja intensidad más que los sonidos de alta intensidad, lo que reduce el contraste espectro-temporal de las señales procesadas (Plomp, 1988). Este efecto es crítico para los oyentes con discapacidad auditiva, pues puede acentuar las dificultades que ya sufren para comprender el habla en presencia de otros sonidos fluctuantes (Festen y Plomp, 1990), como, por ejemplo, otro hablante. Si, además, la compresión se aplica de forma independiente en cada oído, se altera la información binaural generada por el efecto sombra de la cabeza (Byrne y Noble, 1998; Musa-Shufani et al., 2006; Wiggins y Seeber, 2011, 2012). Este último efecto también es crítico ya que las personas hipoacúsicas, a la hora de 
entender el habla en ruido, se benefician menos de la separación espacial señal-máscara que las personas normoyentes (Bronkhorst y Plomp,1989). Por tanto, solo se puede esperar un beneficio limitado del uso de audífonos bilaterales que amplificarán tanto el habla como el ruido, distorsionando así la profundidad de modulación, las diferencias interauriculares de intensidad (ILDs, del inglés interaural level differences) y la relación señal/ruido (SNR, del inglés signal-tonoise ratio).

En la audición binaural, la compresión de la oscilación mecánica del órgano de Corti de los dos oídos probablemente se acopla y se ajusta dinámicamente a través del reflejo olivococlear medial (MOCR, del inglés medial olivocochlear reflex) (Guinan y Cooper, 2003; Backus y Guinan, 2006). Se cree que la activación de MOCR desenmascara los sonidos al reducir la adaptación de la respuesta al ruido de las fibras del nervio auditivo (Liberman y Guinan, 1998; Guinan, 2006; Chintanpalli et al., 2012), y que este efecto desenmascarante posiblemente facilita el reconocimiento del habla en ruido (Kim et al., 2006; Brown et al., 2010; Clark et al., 2012), aunque la evidencia es controvertida (véase Marrufo-Pérez et al., 2018; Lopez-Poveda, 2018). El MOCR ejerce su control sobre la mecánica coclear a través de las células ciliadas externas (OHCs, del inglés outer hair cells). Los usuarios de audífonos con frecuencia sufren de una pérdida y/o una disfunción de las $\mathrm{OHCs}$ que produce una reducción o ausencia de compresión mecánica coclear (Ruggero et al., 1990; Lopez-Poveda et al., 2009; Lopez-Poveda y Johannesen, 2012) y, por lo tanto, posiblemente también una reducción de los efectos y beneficios del MOCR. Según lo expuesto, la hipótesis general del presente trabajo es que un audífono con un procesamiento binaural de la compresión inspirado en el MOCR mejorará la inteligibilidad del habla en ruido de los usuarios de audífonos.

En esta tesis se presenta un audífono binaural, que denominaremos "audífono MOC", cuyo diseño se inspira en el MOCR contralateral. Se describe su funcionamiento y se compara con el del MOCR natural. Se propone que esta comparación sirva como criterio a la hora de elegir los parámetros del audífono $\mathrm{MOC}$; es decir, a la hora de programarlo. Una vez configurado el audífono MOC, se presenta una primera evaluación experimental dirigida a investigar si el audífono restaura adecuadamente la audibilidad. Finalmente, se investiga experimentalmente el rendimiento del audífono $\mathrm{MOC}$ en ambiente ruidoso comparando la inteligibilidad de personas hipoacúsicas con el audífono MOC frente a un audífono convencional de referencia (audífono estándar o STD). Como se verá, el audífono MOC con parámetros apropiados puede ser beneficioso para preservar una percepción binaural natural del entorno acústico y reducir parcialmente los efectos nocivos de la compresión. 


\subsection{Contribuciones originales}

Las principales aportaciones de la tesis son las siguientes:

1. Un algoritmo de compresión multicanal dinámica del rango dinámico con control contralateral inspirado en el MOCR contralateral (audífono MOC).

2. La implementación en formato software de un prototipo del audífono MOC adecuado para su evaluación experimental.

3. La demostración de que un audífono MOC de acción rápida, en comparación con un audífono STD, restaura la audibilidad sin deteriorar la inteligibilidad del habla en ruido estacionario.

4. La demostración de que un audífono MOC de acción rápida, en comparación con un audífono STD, mejora 1-2 dB en promedio los umbrales de recepción verbal del habla enmascarada por otro hablante (ruido fluctuante).

5. La demostración de que la selección de los parámetros temporales del audífono MOC es un aspecto crítico tanto para reproducir los efectos del MOCR contralateral como para obtener una mejora en el reconocimiento del habla en ruido.

6. La demostración de que el funcionamiento de un audífono comercial comparte características con el MOCR ipsilateral.

7. El diseño de una regla de prescripción de ganancia no lineal para el audífono MOC.

\subsection{Aspectos éticos}

Todos los procedimientos experimentales llevados a cabo durante esta tesis fueron aprobados por el Comité de Bioética de la Universidad de Salamanca. Todos los voluntarios dieron su consentimiento para participar antes de incluirlos en el estudio.

\subsection{Convenciones}

En esta tesis, se define el plano horizontal como un plano paralelo al suelo que divide la cabeza en dos a la altura de los ojos. En este plano, se define el azimut (o ángulo azimutal) como el ángulo desde el eje dorsoventral en el sentido de las agujas del reloj. Es decir, fuentes de sonido 
ubicadas en azimuts de $0^{\circ}, 90^{\circ}, 180^{\circ}$ y $270^{\circ}$ se encontrarían frente al oyente, a la derecha del oyente, detrás del oyente, y a la izquierda del oyente, respectivamente.

\subsection{Estructura de la tesis}

En el apartado II (Antecedentes y estado actual del tema), se presenta un contexto amplio sobre la rehabilitación de la pérdida auditiva mediante audífonos y nuestra propuesta para mejorar el rendimiento de los audífonos en entornos ruidosos. Estos conocimientos se complementan con una breve introducción de la fisiología de la audición, de la mecánica coclear y del sistema eferente MOC. En el apartado III se detallan las hipótesis y los objetivos de la tesis. Seguidamente, en el apartado IV (El audífono MOC), se detalla el algoritmo del audífono MOC, junto a una descripción de su funcionamiento. En esta misma sección, se comparan, en la medida de lo posible, las características del funcionamiento del audífono MOC frente a las del MOCR natural. En el apartado V (Evaluación experimental), se compara objetivamente la inteligibilidad del habla de personas con pérdida de audición cuando usan el audífono MOC y el audífono STD. Por último, en el apartado VI (Discusión general), se analizan los resultados, discutiendo las posibles limitaciones del audífono MOC y de las evaluaciones realizadas, y comparándolos con otros estudios similares. Además, se plantean nuevos retos, así como posibles soluciones para algunas de las dificultades que han surgido durante el desarrollo del trabajo. 


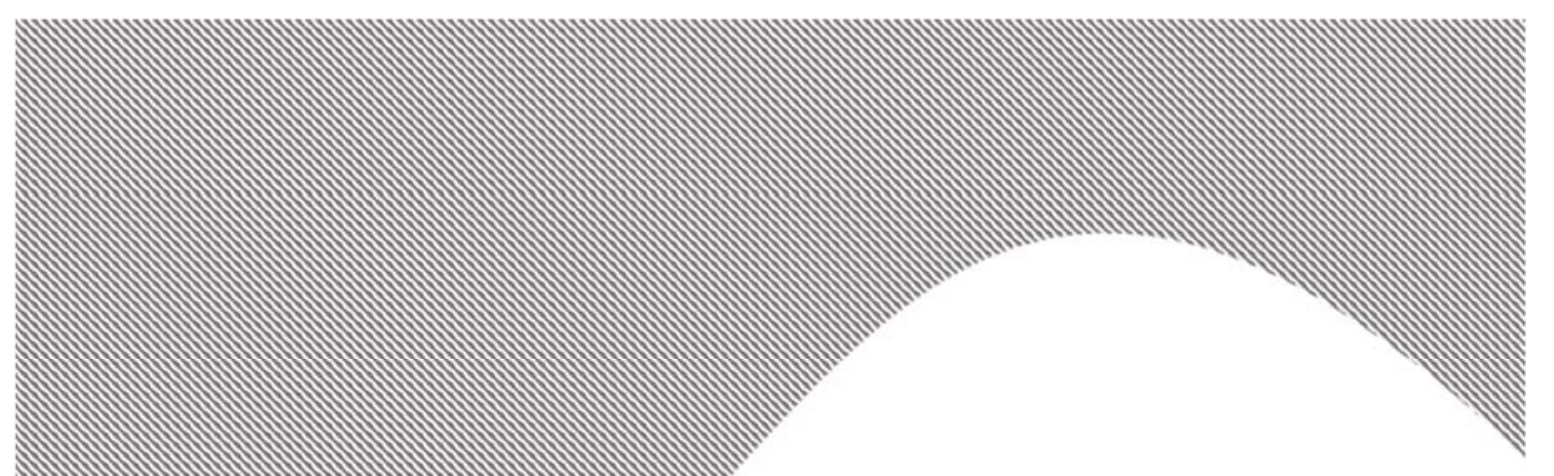

II - ANTECEDENTES Y ESTADO ACTUAL DEL TEMA 
II - Antecedentes y estado actual del tema 


\section{II - Antecedentes y estado actual del tema}

\subsection{La hipoacusia y su rehabilitación mediante audífonos}

En la mayoría de los casos, la rehabilitación de la audición en personas con pérdida auditiva neurosensorial se realiza por medio de audífonos (Moore, 2007), dispositivos electrónicos que amplifican el sonido a la entrada del canal auditivo (Walker y Dillon, 1982; Kates, 2008; Popelka et al., 2016). El principal objetivo de un audífono es restaurar la pérdida de sensibilidad auditiva producida por el daño coclear mientras mantiene una escucha cómoda de los sonidos intensos (Moore, 1996). Desafortunadamente, los usuarios de audífonos tienen grandes dificultades para entender el habla en ambientes acústicos ruidosos, como restaurantes, reuniones o lugares de trabajo (Kochkin 2002; Lopez-Poveda et al. 2017b).

En esta tesis se presenta una propuesta de procesamiento binaural de sonidos cuyo objetivo principal es mejorar la percepción del habla en ruido de los usuarios de audífonos. Para entender en profundidad este trabajo es necesario establecer un conjunto de conocimientos básicos. A continuación, se explica brevemente el proceso de transducción en el sistema auditivo, recalcando la importancia de la respuesta mecánica de la cóclea y cómo su deterioro conduce a una pérdida de audición. Una vez se define la hipoacusia y se describen sus principales efectos sobre la percepción auditiva, se explica cómo los audífonos actuales tratan de restaurar la audición normal y hasta qué punto lo consiguen.

\subsubsection{El sistema auditivo periférico}

El sistema auditivo de los mamíferos es capaz de detectar y analizar sonidos en un extenso rango de frecuencias e intensidades gracias a las exquisitas propiedades de la transducción mecano-eléctrica que tiene lugar en la cóclea (Oxenham y Bacon, 2003). 
En el oído externo, las ondas sonoras que alcanzan el pabellón auricular son transmitidas hasta el tímpano por medio del conducto auditivo externo. El sonido procedente de una única fuente sonora llega a cada oído con características diferentes debido a su interacción (por difracción, resonancia, interferencia, etc.) con todos los "obstáculos físicos humanos" (cabeza, torso, orejas, etc.). El efecto conjunto de todos esos factores que alteran la onda acústica desde que se genera en la fuente de sonido hasta que llega al tímpano se resume en la función de transferencia asociada a la cabeza o HRTF (del inglés head-related transfer function) (Wightman y Kistler, 1993, 2005).

En el oído medio, la vibración de la membrana timpánica se transmite por la cadena de huesecillos (yunque, martillo y estribo) hasta la ventana oval de la cóclea, en contacto con el estribo. Dentro de la cóclea, las vibraciones se propagan en un medio acuoso, denominado perilinfa. La cadena de huesecillos magnifica la presión acústica, lo que permite adaptar la impedancia de la transición aire-liquido. Por otra parte, cuando se presenta un sonido muy intenso se activa el reflejo acústico del oído medio (o reflejo estapedial). Este contrae el músculo del estribo e incrementa la rigidez de la cadena de huesecillos y, por tanto, reduce la energía que se trasmite al oído interno. Además de la transmisión por la vía aérea (por el oído medio), el sonido puede alcanzar el oído interno por estructuras esqueléticas, de ahí al líquido céfaloraquídeo y desde este a la perilinfa a través del acueducto coclear.

En el oído interno, los patrones de vibración se transforman en pulsos eléctricos. Las diferencias de presión entre la rampa timpánica (que se inicia en la ventana oval) y la vestibular (que termina en la ventana redonda) crean ondas que se propagan a lo largo de la membrana basilar (BM, del inglés basilar membrane). La onda que se propaga por la BM es conocida como 'onda viajera'. La amplitud de esta onda crece a medida que se propaga desde la base hasta el ápex coclear, describe un máximo y decrece rápidamente. El punto de máxima amplitud de la onda viajera varía desde la base hasta el ápex de la cóclea en función del espectro del sonido, lo que permite a la cóclea actuar como un analizador de frecuencias. Este efecto es conocido comúnmente como cocleotopía (Von Békésy, 1960). El órgano de Corti ubicado sobre la BM alberga los receptores auditivos, las células ciliadas (Figura 2.1). Las oscilaciones del órgano de Corti desplazan los cilios de estas células con relación a la membrana tectoria, lo que provoca una despolarización de las células ciliadas y, en consecuencia, la emisión de potenciales de acción por parte de las neuronas del ganglio espiral. Las fibras nerviosas aferentes que inervan las células ciliadas internas (IHCs, del inglés inner hair cells) constituyen el 95\% del nervio auditivo. Por ello, las IHCs son consideradas el principal transductor auditivo. Por otra parte, las OHCs 
tienen la capacidad de contraerse y expandirse activamente en respuesta a estímulos eléctricos y químicos, una propiedad denominada electro-motilidad (Brownell,1990). El movimiento contráctil de las $\mathrm{OHCs}$ modula el desplazamiento de la BM y cumple el papel de amplificador coclear (Ashmore et al., 2010).

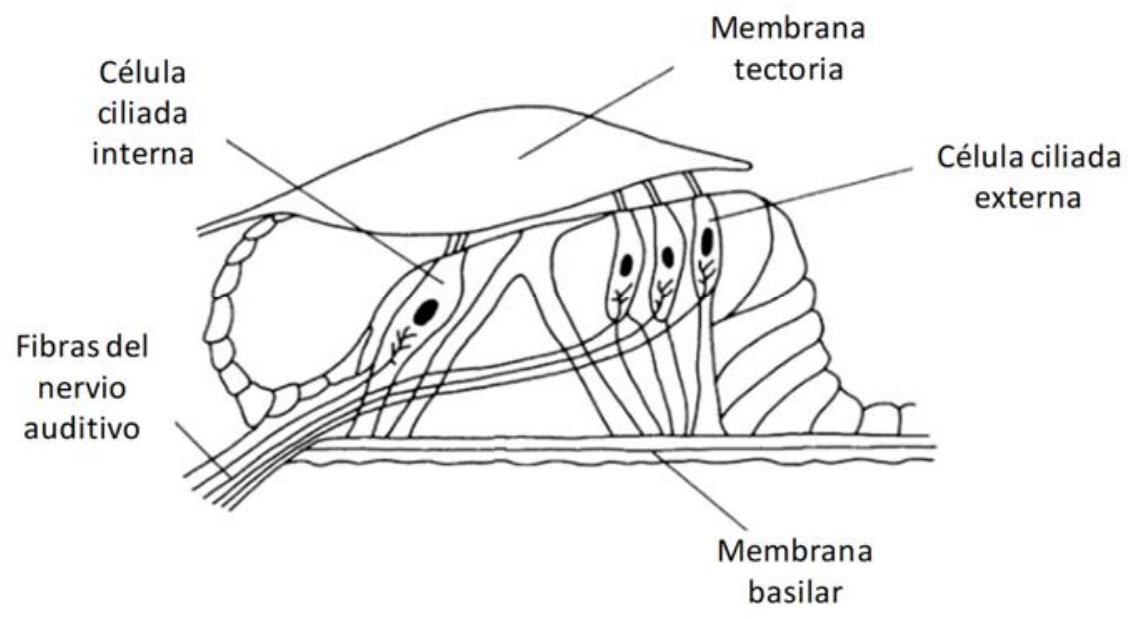

Figura 2.1. Diagrama esquemático del órgano de Corti. Figura adaptada de Ainsworth (1976).

Las IHCs codifican las oscilaciones mecánicas de la BM en impulsos eléctricos que son enviados al cerebro auditivo a través del nervio auditivo. La información acústica en el nervio auditivo asciende hasta la corteza auditiva, pasando por los núcleos cocleares, el complejo olivar superior, el colículo inferior y el núcleo geniculado medial (Malmierca y Merchán, 2004, Lee y Sherman, 2011; Webster y Fay, 2013). El sistema auditivo tiene, además, una vía descendente (eferente) que conecta los núcleos neuronales auditivos centrales con la cóclea. Esta vía eferente permite al sistema auditivo central controlar la respuesta de la mecánica coclear de forma dinámica durante la escucha (Guinan, 2006; Lopez-Poveda, 2018).

La ausencia, la alteración o la disfunción de alguno de los elementos que forman parte del proceso de transducción puede dar lugar a una pérdida de audición. Por ejemplo, una mala conducción del sonido a través del oído medio, una pérdida total o parcial de células ciliadas, una pérdida o disfunción de cilios, o una alteración de la homeostasis coclear, entre otros muchos factores, pueden elevar los umbrales audiométricos dando lugar a una pérdida de audición. En general, la pérdida de audición es un problema complejo en el que pueden intervenir uno o varios factores de forma combinada. No obstante, estudios en animales señalan que las cualidades del 
sistema auditivo están en gran parte ligadas al correcto funcionamiento de un mecanismo activo presente en la mecánica coclear (Rhode, 1971; Rhode y Robles, 1974; Robles y Ruggero, 2001).

\section{La mecánica coclear}

En un oído sano, cada punto de la BM posee una alta sensibilidad frente a un rango estrecho de frecuencias (Figura 2.2). Es decir, la oscilación coclear mecánica a niveles sonoros bajos está muy sintonizada en torno a una frecuencia denominada frecuencia característica ( $C F$, del inglés characteristic frequency). Dado que la oscilación mecánica de cada región coclear esta sintonizada en frecuencia, su funcionamiento se asemeja al de un filtro acústico. Por esta razón, suele utilizarse el término de filtro coclear. Para frecuencias próximas a la CF, se necesita menos nivel sonoro para producir una misma velocidad de oscilación en una cóclea sana que en la misma cóclea post-mortem (Figura 2.2A). Esto es porque en la cóclea sana, las OHCs amplifican la oscilación mecánica frente a los sonidos de baja intensidad y de frecuencias próximas a la CF. Esta amplificación coclear $^{1}$, sin embargo, depende del nivel sonoro del estímulo acústico. A niveles sonoros de 30-80 dB SPL (del inglés sound pressure level), las curvas de E/S de la Figura 2.3 muestran que la respuesta crece de forma no lineal, compresiva (pendiente $<1$ $\mathrm{dB} / \mathrm{dB}$ ), al incrementar la intensidad del estímulo. En el rango de niveles sonoros de $20-30 \mathrm{~dB}$ $\mathrm{SPL}$, sin embargo, la amplificación es aproximadamente constante (invariante con el nivel sonoro) y toma el valor máximo. La compresión coclear hace que un amplio rango de niveles de presión sonora del estímulo acústico sea representado por un rango de respuestas de la BM más estrecho (Rhode, 1971; Sellick et al.,1982; Robles et al., 1986; Ruggero, 1992). La amplificación coclear en un punto particular de la BM es mínima a niveles de presión sonora altos, al igual que sucede cuando las frecuencias de estimulación se alejan de la CF.

\footnotetext{
${ }^{1}$ La amplificación coclear se define, aquí, como el cociente (en dB) entre la velocidad (o el desplazamiento) de oscilación de la BM en una cóclea sana relativo a la oscilación de la cóclea muerta (o dañada) para tonos puros de frecuencia igual a la CF.
} 

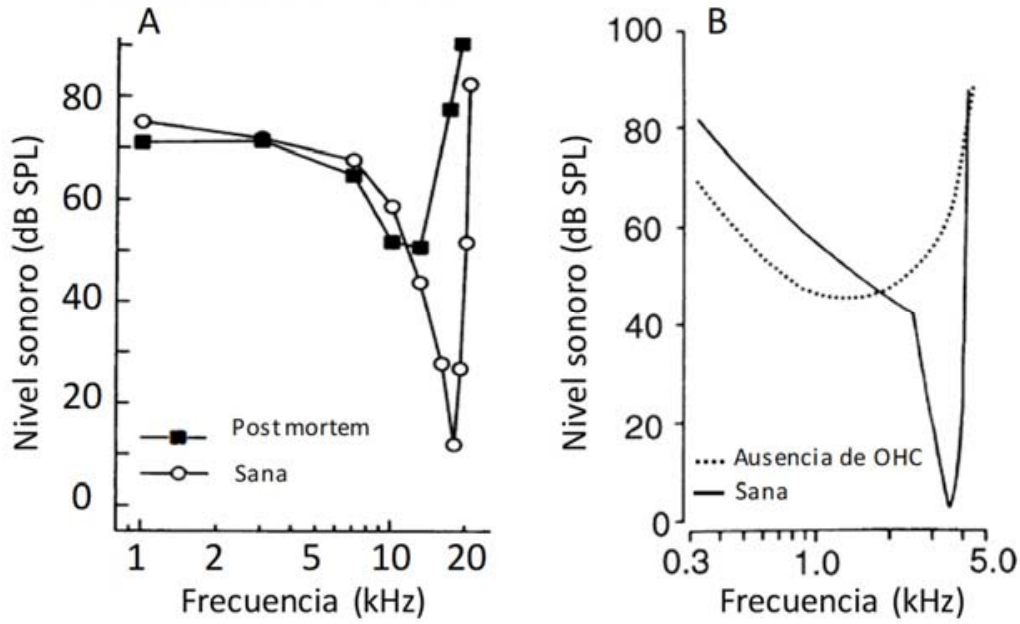

Figura 2.2. Curvas de sintonización medidas en un punto de la $B M(\mathbf{A})$ y en una fibra del nervio auditivo (B). Las curvas muestran el nivel de presión sonora al cual se produce la misma respuesta (A: velocidad o desplazamiento de oscilación de la BM o B: respuesta neuronal del nervio auditivo) en función de la frecuencia del estímulo. Adaptadas de Sellick et al. (1982) y Liberman et al. (1986), respectivamente. Obsérvese que amplificación coclear depende de las células ciliadas externas.

Los registros post-mortem demuestran la existencia de un mecanismo, comúnmente denominado mecanismo activo o amplificador coclear, que produce una gran sensibilidad, una estrecha sintonización y una respuesta compresiva (Figura 2.2A). Estas características del amplificador coclear, vistas en la respuesta del nervio auditivo, también se deterioran por la reducción o la ausencia de OHCs (Figura 2.2B). La pérdida o disfunción de las OHCs puede estar asociada a la edad, la exposición a sonidos intensos, fármacos ototóxicos, infecciones, alteraciones metabólicas, e incluso a una disfunción de la estría vascular (Gratton et al., 1996). Como se muestra en la Figura 2.2B y en la Figura 2.3, la disfunción de OHCs reduce la sensibilidad y la sintonización espectral de la respuesta mecánica coclear, y, por tanto, los filtros cocleares se hacen más anchos. Además, los efectos no lineales vistos sobre las curvas de E/S de BM se reducen o desaparecen. Obsérvese en la Figura 2.3 cómo la disfunción de OHCs reduce la compresión coclear. Por tanto, la respuesta coclear activa o el amplificador coclear depende fuertemente de la integridad de las OHCs 


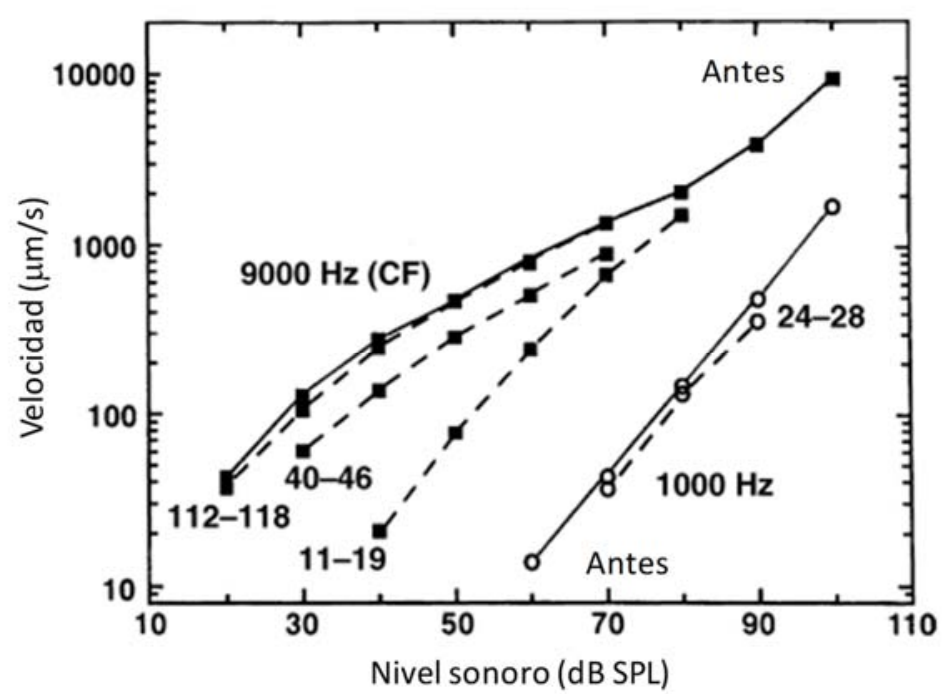

Figura 2.3. Curvas de entrada/salida para un punto de la membrana basilar ( $C F=9 \mathrm{kHz}$ ) inmediatamente antes (líneas continuas) y después (líneas discontinuas) de una inyección intravenosa de furosemida que inhibe la actividad de las células ciliadas externas. La desactivación de las células ciliadas externas demuestra su contribución al mecanismo activo coclear. Cada curva muestra la velocidad de oscilación de la membrana basilar en función del nivel de presión sonora del estímulo. En este caso, el estímulo es un tono puro de frecuencia igual $(9000 \mathrm{~Hz}$, cuadrados negros) o mucho menor (1000 Hz, círculos blancos) a la CF. Los números indican los minutos tras la inyección. Figura adapatada de Ruggero y Rich, 1991.

Por otro lado, en oídos sanos, la sensibilidad y la sintonización de la cóclea no son fijas; varían según el estado de activación de las fibras eferentes del haz MOC (del inglés medial olivocochlear), que actúan sobre las OHCs modulando la ganancia del amplificador coclear. El haz MOC es un conjunto de fibras nerviosas con origen en neuronas del complejo olivar superior que inervan tanto la cóclea ipsilateral como la contralateral (Figura 2.4). Los eferentes MOC terminan directamente sobre la membrana basolateral de las OHCs. La activación de los eferentes MOC hiperpolariza las OHCs, inhibiendo la electromotilidad (Frolenkov, 2006) y, como consecuencia, su efecto amplificador, reduciendo así la amplitud de vibración del órgano de Corti (Murugasu y Russell, 1996; Cooper y Guinan, 2006). Los eferentes MOC pueden activarse de manera refleja (involuntaria) mediante sonidos ipsilaterales y contralaterales (Lilaonitkul y Guinan, 2009a), dando lugar al denominado reflejo olivococlear medial (MOCR). El MOCR comienza a activarse con niveles sonoros de 20 dB SPL (Aguilar et al., 2013), y su efecto aumenta a medida que crece el nivel sonoro (Backus y Guinan, 2006), lo que implica que el sistema eferente MOC está actuando activamente durante la mayoría de las situaciones de escucha. 


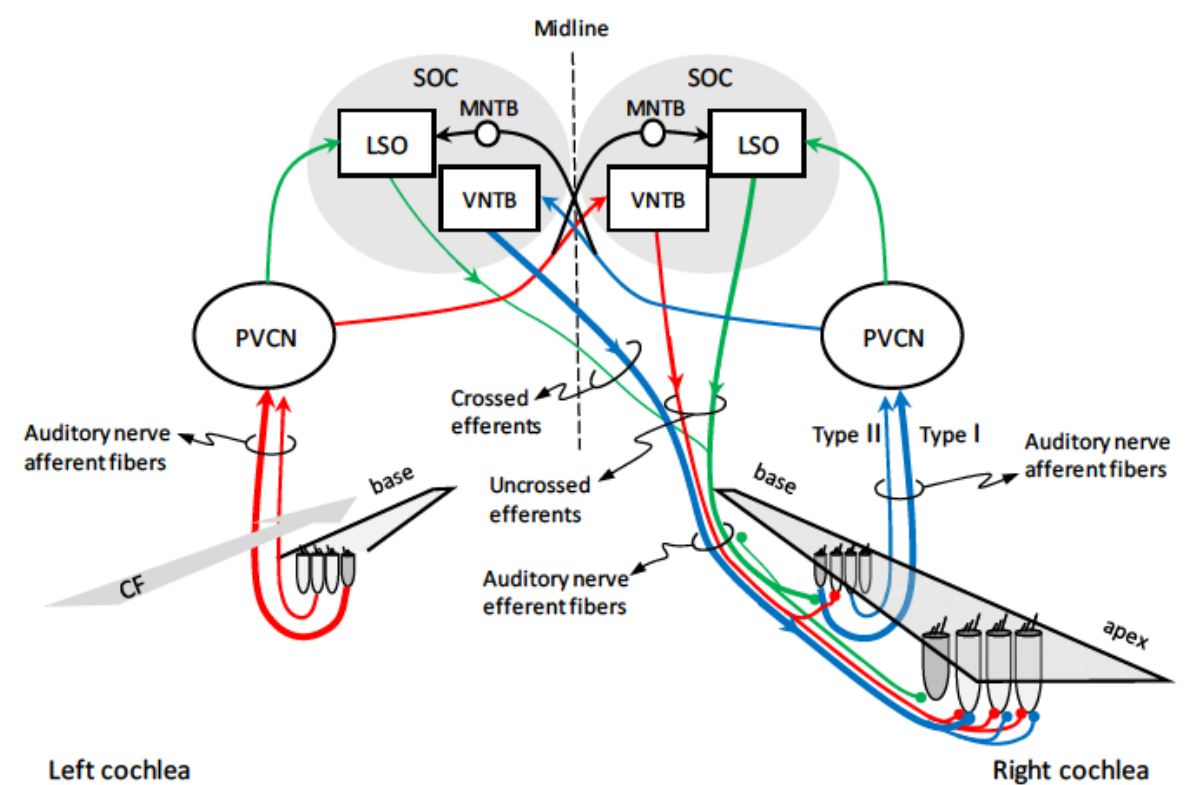

Figura 2.4. Esquema del sistema eferente olivococlear. Vías para la activación de los eferentes mediales (MOC) y laterales (LOC) a la cóclea derecha. Las líneas rojas y azules ilustran las vías para la activación de los reflejos MOC contralaterales e ipsilaterales, respectivamente. Las líneas verdes ilustran las vías para la activación del reflejo LOC. El grosor de cada línea ilustra aproximadamente la densidad de inervación. Abreviaturas: LSO, oliva superior lateral; MNTB, núcleo medial del cuerpo trapezoide; PVCN, núcleo coclear posteroventral; SOC, complejo olivar superior; VNTB, núcleo ventral del cuerpo trapezoide; CF, frecuencia característica.

En resumen, la pérdida o la disfunción de OHCs (afección incluida dentro de las hipoacusias neurosensoriales) deteriora el amplificador coclear (o mecanismo activo de la cóclea) y altera el control que el cerebro ejerce sobre la mecánica coclear en cada oído. En este trabajo se presenta un procesamiento de señal para usuarios de audífonos (personas con hipoacusia neurosensorial) inspirado en el reflejo MOC contralateral.

\subsubsection{La pérdida auditiva}

El umbral absoluto de audición (o umbral de audibilidad) se define como el mínimo nivel de presión sonora necesario para detectar un sonido en ausencia de otras fuentes sonoras. Cuando el estímulo es un tono puro, el umbral de audición para jóvenes sin patología auditiva (personas normoyentes) decrece gradualmente a medida que se incrementa la frecuencia del tono desde $20 \mathrm{~Hz}$ hasta 3-4 kHz (donde la sensibilidad auditiva es máxima) para crecer gradualmente desde estas frecuencias hasta aproximadamente $20 \mathrm{kHz}$, excepto a $8-9 \mathrm{kHz}$, donde el umbral presenta un pico (Figura 2.5). La diferente sensibilidad auditiva a diferentes frecuencias se debe a la 
acción combinada de resonancias producidas por el canal auditivo y el pabellón auricular, la mayor eficacia de transmisión de frecuencias en torno a 1-2 kHz del oído medio, y una menor ganancia del amplificador coclear a frecuencias bajas que a frecuencias altas (Cheatham y Dallos, 2001).

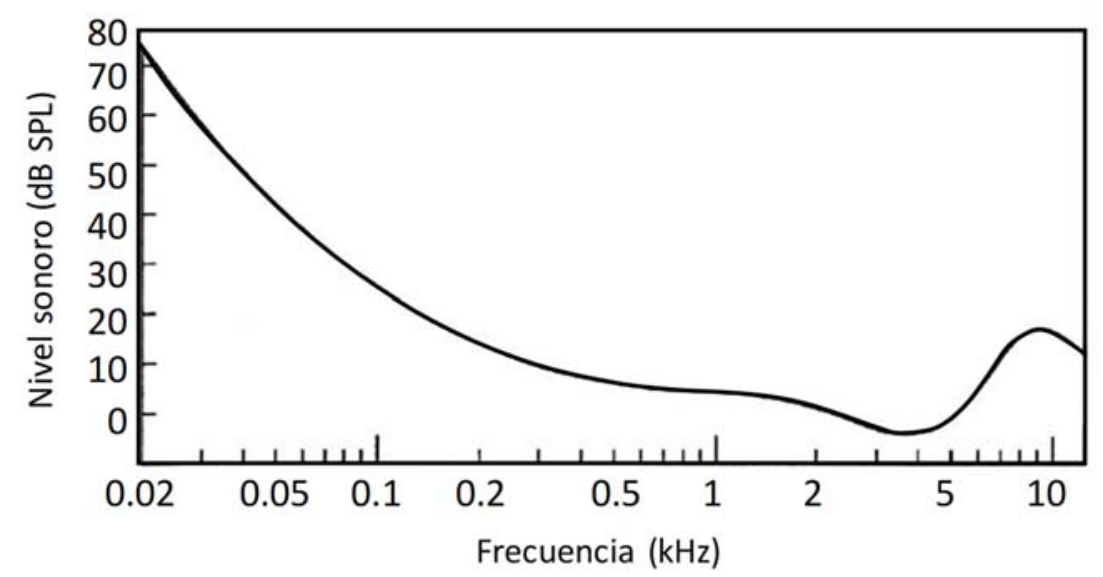

Figura 2.5. Umbrales de audibilidad de jovenes normoyentes en campo libre.

En audiología, la pérdida de audición se determina a partir del umbral de detección de tonos puros y se expresa relativa al umbral correspondiente de normoyentes. Sus unidades son los decibelios de nivel de audición ( $\mathrm{dB} \mathrm{HL}$, del inglés $\mathrm{dB}$ hearing level) y se representan en función de la frecuencia a través del audiograma (Figura 2.6). Se considera que una persona tiene pérdida de audición cuando su umbral audiométrico en alguna frecuencia supera los 20-25 dB HL. La pérdida de audición suele clasificarse en grados según el promedio de los umbrales audiométricos (PTA, del inglés Pure Tone Average) en las frecuencias de $500 \mathrm{~Hz}, 1 \mathrm{kHz}$ y $2 \mathrm{kHz}$ (a veces se promedia también el umbral a $4 \mathrm{kHz}$ ), aunque existen otras clasificaciones más recientes (Bisgaard, et al., 2010). Estas clasificaciones pueden orientar sobre la relevancia de la deficiencia auditiva de una forma aproximada (Figura 2.6). 


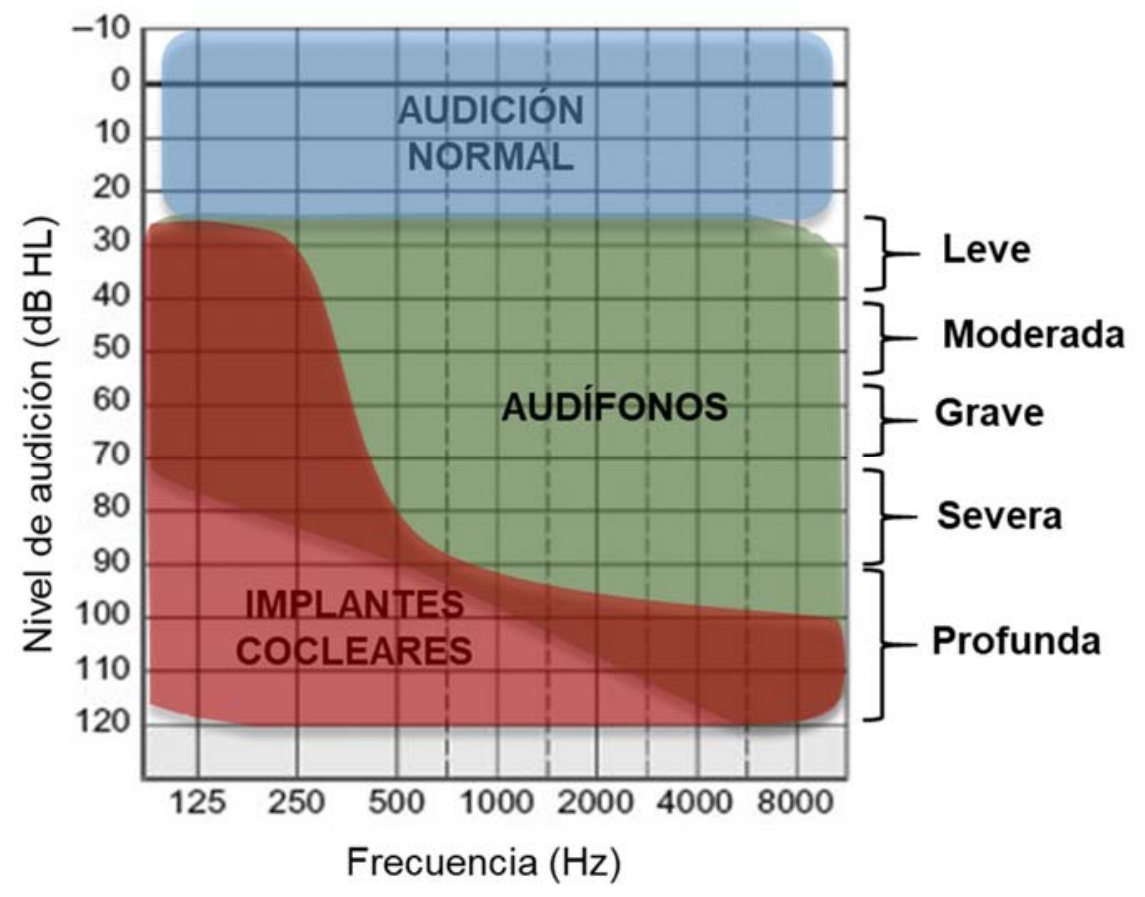

Figura 2.6. El audiograma representa el grado de pérdida de audición en función de la frecuencia. En la parte derecha se muestra la clasificación de la pérdida auditiva. En color se ilustra la prescripción de prótesis auditivas (implantes cocleares y audífonos) en función del grado de pérdida

El audiograma tonal permite diferenciar entre pérdidas de audición de origen conductivo o neurosensorial. La estimulación con tonos se puede realizar por vía ósea (con un vibrador colocado en el hueso temporal del cráneo) y aérea (con auriculares). La estimulación táctil de las vibraciones (vía ósea) consigue transmitir los sonidos directamente a la cóclea, puenteando la transmisión del sonido por el oído externo y medio. Dado que la pérdida de transmisión no se refleja por vía ósea, cuando los umbrales audiométricos de sendos procedimientos son similares la pérdida de audición es de origen neurosensorial. Con frecuencia, la pérdida conductiva puede tratarse con medicamentos para curar infecciones o mediante cirugía. La hipoacusia neurosensorial, por el contrario, afecta a la cóclea, las células ciliadas y/o las estructuras neurales, aunque es común que las $\mathrm{OHCs}$ sean las primeras en deteriorarse, como sucede en la mayoría de los casos de presbiacusia (o pérdida de audición asociada con envejecimiento). Normalmente, no es posible corregir (o curar) una pérdida auditiva neurosensorial con un tratamiento médico o una intervención quirúrgica y, por tanto, el tratamiento más común es el audífono. Cuando la pérdida auditiva neurosensorial es profunda, el tratamiento es el implante coclear (Figura 2.6). 
La pérdida de audición neurosensorial está asociada comúnmente a una percepción anormal de la sonoridad (Figura 2.7). La hipoacusia neurosensorial reduce la sensibilidad a bajas intensidades sin alterar el umbral al que los sonidos se vuelven incómodamente fuertes. Se produce así una reducción del rango dinámico de audición. El rango audible resultante es conocido como rango dinámico residual. La reducción del rango dinámico hace que la sonoridad crezca más "rápido" de lo normal al aumentar la intensidad del sonido, un efecto denominado reclutamiento de la sonoridad (Steinberg y Gardner, 1937; Moore y Glasberg, 2004; Marozeau y Florentine, 2007). Es posible que la pérdida o disfunción de las OHCs contribuya al reclutamiento. Como se verá más adelante, el rango dinámico residual y el reclutamiento de la sonoridad condicionan cómo se aplica la ganancia en un audífono en función de la intensidad del sonido.

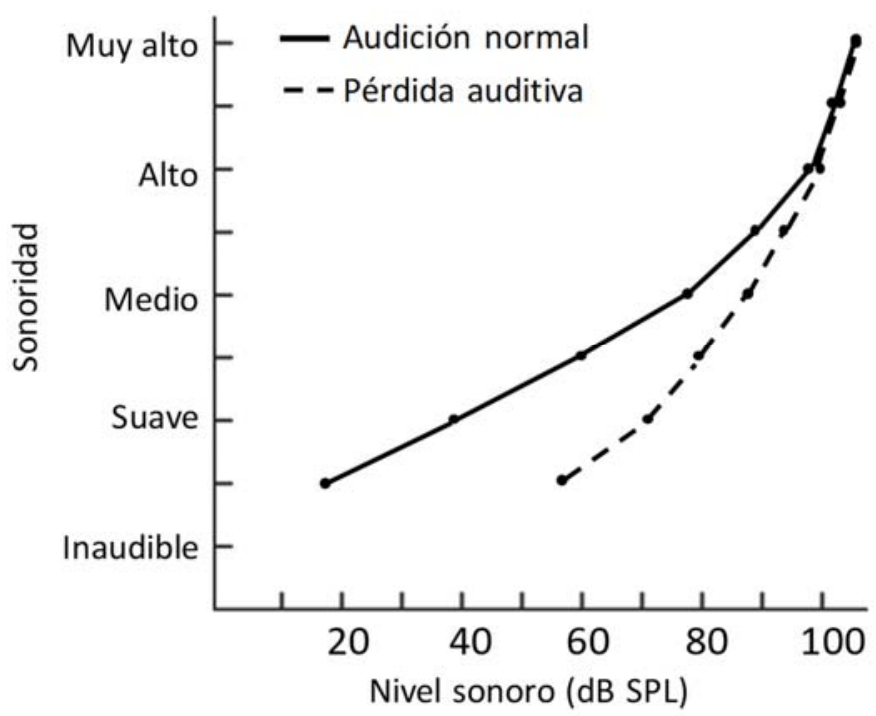

Figura 2.7. Ejemplo de curva de sonoridad en personas con audición normal y con pérdida auditiva. Se ilustra cómo la sonoridad crece al aumentar la intensidad del sonido de forma anómala en personas con pérdida auditiva.

Cabe destacar que no solo la disfuncionalidad del mecanismo activo coclear (por pérdida o disfunción de las OHCs) puede producir pérdida de audición con sus consecuentes alteraciones de la percepción auditiva. La pérdida o la disfunción parcial de IHCs también puede producir pérdida de audición. De hecho, se estima que en promedio el $65 \%$ de la pérdida auditiva se debe a una pérdida o disfunción de las OHCs y el $35 \%$ restante a una pérdida o disfunción de las IHCs, aunque los porcentajes pueden variar de unas personas a otras, e incluso invertirse en pacientes con una misma pérdida de audición (Lopez-Poveda y Johannesen, 2012; Johannesen et al., 2014). Por otro lado, la pérdida de sinapsis entre las IHCs y las fibras del nervio auditivo (condición denominada sinaptopatía coclear) o la pérdida de fibras nerviosas (denominada desaferenciación o desinervación auditiva) podría alterar la percepción auditiva sin alterar los 
umbrales audiométricos (véase, por ejemplo, Kujawa y Liberman, 2009; Bramhall et al., 2017; véanse las revisiones de Lopez-Poveda, 2014; Plack et al., 2014; Bramhall et al., 2019).

\subsubsection{Los audífonos}

En la mayoría de los casos, la pérdida auditiva neurosensorial se trata por medio de audífonos, dispositivos electrónicos que amplifican el sonido a la entrada del canal auditivo. En concreto, un audífono es un compresor de amplitud no-instantáneo multicanal, tal y como se explica a continuación.

El funcionamiento básico de un audífono se realiza en bloques, a través de una serie de etapas de procesamiento (Levitt, 1987; Kates, 2008; Popelka et al., 2016). Un micrófono recoge la señal acústica en formato analógico, que se transforma en una señal digital y se envía a un procesador digital de señales. Este procesador modifica la señal digital en función del perfil auditivo del usuario (como se describe más adelante) e incluso puede incorporar otras estrategias de procesamiento adicionales como filtros de reducción de ruido, clasificación del entorno acústico y/o intensificadores del habla (Kates 2008; Launer et al., 2016; Kollmeier y Kiessling, 2018). Finalmente, la señal digital procesada se convierte de nuevo en una señal analógica que se emite en forma de sonido amplificado por un altavoz.

\section{Procesamiento básico}

La señal procesada por el audífono se amplifica en función de la intensidad y la frecuencia de la señal entrante, con el fin de compensar parcialmente la pérdida de audición del usuario. Como los usuarios de audífonos tienen un rango dinámico menor que las personas normoyentes y sufren reclutamiento de la sonoridad, el audífono aporta menos ganancia o menos amplificación a los sonidos de alta intensidad que a los sonidos de baja intensidad. De este modo, el audífono comprime el amplio rango de intensidades sonoras captado por el micrófono en un rango más estrecho de intensidades sonoras a la salida del audífono, adecuándose al rango dinámico residual del usuario (Figura 2.8). En condiciones naturales de escucha, la intensidad del sonido fluctúa constantemente, lo que exige que el audífono ajuste continuamente la ganancia que aporta para compensar la pérdida de audición del usuario. Sin embargo, la ganancia necesaria se aplica progresivamente en el tiempo (ganancia dinámica o no-instantánea) para no introducir excesiva distorsión, mantener una escucha cómoda y proteger al oyente de los cambios abruptos de intensidad. Además, dado que los umbrales audiométricos de cada usuario varían en función 
de la frecuencia, el audífono aplica una ganancia diferente en cada canal de frecuencia para restaurar la audibilidad sobre todo el espectro de frecuencias.

En el contexto del presente trabajo, este procesamiento que acabamos de describir se denominará procesamiento (o audífono) estándar (STD).

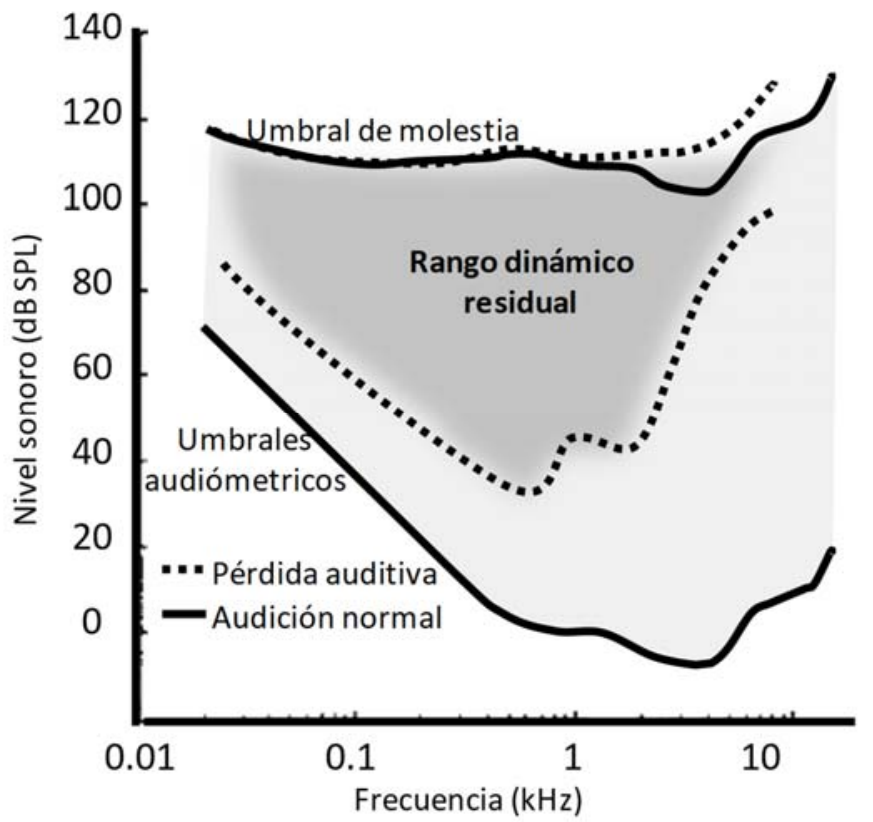

Figura 2.8. Representación esquemática de la reducción del rango dinámico de audición en personas con pérdida auditiva. La pérdida auditiva aumenta los umbrales audiométricos (mínimo nivel sonoro audible) mientras mantiene los umbrales de molestia (mínimo nivel sonoro que produce una sensación auditiva de malestar). El objetivo principal de un audífono es adaptar la intensidad del sonido que recoge un micrófono sobre el rango dinámico residual del usuario. Para ello los audífonos aplican compresión multicanal.

\section{La compresión}

En general, la amplificación o ganancia que aplica un audífono a la señal que recoge su micrófono se reduce a medida que aumenta la intensidad sonora de dicha señal. A este incremento no lineal de la ganancia se le conoce también como compresión porque su efecto es comprimir un amplio rango de intensidades a la entrada del audífono en un rango más estrecho a la salida, adecuado al rango dinámico residual del usuario. La compresión se aplica sobre las señales de entrada a través de las curvas de ganancia-intensidad (Figura 2.9).

En las curvas de ganancia-intensidad y curvas de E/S típicas (Walker y Dillon, 1982; Kuk, 2002; Kates, 2008; Launer et al., 2016), por debajo de una cierta intensidad de entrada, denominada umbral de compresión $(\mathrm{T})$, la mayoría de los compresores aplican amplificación lineal. En este rango de intensidades, la amplitud de salida es directamente proporcional a la de entrada por un factor $\mathrm{M}$ (en dB), conocido como máxima amplificación. Para intensidades de entrada por encima del umbral de compresión, la ganancia se reduce a medida que aumenta la intensidad de entrada y la pendiente de la curva de $\mathrm{E} / \mathrm{S}$ del audífono es menor que $1 \mathrm{~dB} / \mathrm{dB}$, demostrando el 
comportamiento compresivo del audífono. Al inverso de la pendiente de la curva de E/S en el segmento compresivo por encima del umbral de compresión se le denomina relación de compresión $(R)$ y se expresa en unidades de $\mathrm{dB} / \mathrm{dB}$. En otras palabras, la relación de compresión $R$ indica el cambio en el nivel sonoro de la señal de entrada requerido para lograr $1 \mathrm{~dB}$ de cambio en la salida (Figura 2.9).

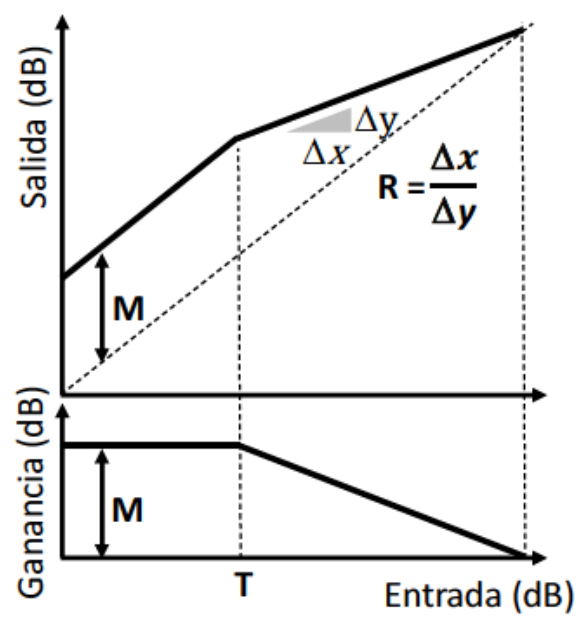

Figura 2.9. Las curvas de entrada/salida y de ganancia/intensidad en un audífono representan cómo varía la intensidad sonora de salida y la ganancia en función de la intensidad sonora de entrada, respectivamente. M: máxima amplificación. T: umbral de compresión, definido como el nivel sonoro de la señal de entrada a partir del cual la ganancia comienza a disminuir. $R$ : relación de compresión. $\Delta y$ representa el incremento en la intensidad de salida para un incremento dado de la intensidad de entrada $(\Delta \mathrm{x})$, en la sección no-lineal (compresiva) de la curva de entrada salida.

Como el sonido del micrófono o los ruidos ambiente de baja intensidad pueden ser molestos, algunos audífonos aplican expansión (operación opuesta a la compresión) con el fin de evitar amplificar los ruidos de baja intensidad (Kuk, 2002; Kates, 2008; Launer et al., 2016). También existen curvas de E/S que suavizan la transición lineal-compresión por medio de un parámetro adicional (Giannoulis et al., 2012). Otras, incluso introducen un segmento lineal a altas intensidades tal y como sucede en las curvas de E/S de la membrana basilar (Dillon, 1996) o bien un segmento muy compresivo para limitar la máxima salida del audífono (Walker y Dillon, 1982; Kuk, 2002; Launer et al., 2016).

La pérdida de audición es la principal referencia a la hora de ajustar los parámetros de la curva de ganancia-intensidad de un compresor.

\section{El ajuste de la ganancia}

El ajuste de las curvas de ganancia-intensidad de un audífono en función del perfil auditivo del usuario del audífono viene dado por las reglas de prescripción de ganancia. Entre ellas, cabe destacar las reglas NAL-NL1 (Byrne et al., 2001), NAL-NL2 (Keidser et al., 2011, 2012), CAMEQ2-HF (Moore et al., 2010), y DSL (Scollie et al., 2005). En general, el objetivo de estas reglas de prescripción de ganancia es garantizar la audibilidad en un amplio rango de niveles sonoros. 
El ajuste de la ganancia pierde relevancia una vez se consigue preservar la audibilidad (LopezPoveda et al., 2017b). Por esto, los diferentes procedimientos propuestos tras asegurar la audibilidad se centran más en unos aspectos de la percepción auditiva que en otros, como pueden ser la sonoridad, la comodidad en la escucha o la inteligibilidad del habla.

Existen otros aspectos importantes a la hora de determinar la prescripción de la ganancia; por ejemplo, cómo crece o decrece la ganancia en función de la frecuencia (van Buuren et al., 1996) o cómo la cantidad relativa de amplificación a baja y alta frecuencia puede tener efectos adversos sobre la sonoridad (Fletcher y Munson 1933; Steinberg y Gardner, 1937; Persson et al.,1990) y la inteligibilidad del habla (Hogan y Turner,1998; Vickers et al., 2001; Baer et al., 2002).

\section{Canales de frecuencia}

Los audífonos convencionales aplican una ganancia especifica ( $\mathrm{y}$ una curva de $\mathrm{E} / \mathrm{S}$ ) a cada rango de frecuencia del sonido, en función de la pérdida de audición del usuario a cada región de frecuencia. Para ello, por conveniencia, el espectro del sonido se divide en canales de frecuencia. Se necesitan al menos 4 o 5 canales para ajustar la ganancia a cualquier audiograma (Trine y Van Tasell, 2002). Algunos audífonos comerciales pueden tener hasta 22 canales de frecuencia, aunque típicamente tienen de 10 a 20 canales (Salorio-Corbetto et al., 2020). También los audífonos pueden agrupar los canales de frecuencia en bandas de frecuencia a la hora de ajustar la ganancia. Por lo tanto, procesan la señal por diferentes canales, pero aplican una misma configuración o ganancia a todos los canales de una misma banda de frecuencias.

Teóricamente, un mayor número de canales facilitaría una mayor resolución espectral. Sin embargo, no existe evidencia real que lo demuestre. De hecho, el uso de demasiados canales muy compresivos reduce el contraste temporal y espectral de las componentes del habla; reduciendo así la inteligibilidad del habla (Plomp, 1988) y la calidad del sonido (van Buuren et al., 1999). El número de canales no tiene un efecto significativo sobre la inteligibilidad del habla cuando la máscara es un hablante o un balbuceo (Salorio-Corbetto et al., 2020). En cambio, cuando el ruido tiene el espectro del habla, el reconocimiento silábico mejora al aumentar el número de canales de 4 a 8 (Yund y Buckles, 1995). No obstante, estas observaciones deben considerarse con precaución ya que las técnicas experimentales y los procesadores de sonidos utilizados pueden ser muy diferentes de unos estudios a otros. 


\section{El rango de frecuencias}

No todas las frecuencias del espectro audible tienen la misma importancia para la percepción del habla. Las ponderaciones de importancia de las diferentes regiones del espectro propuestas por algunos modelos de inteligibilidad, como el índice de articulación (AI) o el índice de inteligibilidad del habla (SII), sugieren que la información útil del habla solo se extiende hasta $6 \mathrm{kHz}$ (Kryter, 1962; ANSI, 1997). Estas ponderaciones sugieren que la comprensión del habla no debería verse afectada al extender el ancho de banda de un audífono más allá de $6 \mathrm{kHz}$. Se ha demostrado, sin embargo, que la amplificación de la señal por encima de $8 \mathrm{kHz}$ mejora la localización de las fuentes sonoras (Best et al., 2005), que es la habilidad subyacente necesaria para organizar el entorno de escucha y, por tanto, puede mejorar la inteligibilidad del habla en ruido (Vickers et al., 2001; Baer et al., 2002). Un estudio reciente así lo ha demostrado (Zadeh et al., 2019).

\section{El ancho banda de cada canal}

Los filtros auditivos de un oído deteriorado son más anchos que los de un oído normal (Moore, 2007). Presumiblemente, esto aumenta la susceptibilidad a que el habla sea enmascarada ${ }^{2}$ por una fuente de ruido, especialmente en baja frecuencia (Moore, 2007). Con el objetivo de restaurar la pérdida de sensibilidad de cada región coclear, aumentar la selectividad frecuencial y reducir los efectos de enmascaramiento, sería adecuado tener un gran número de canales de frecuencia con anchos de banda muy estrechos. Esto resulta poco práctico tanto en términos de tiempo computacional como de calidad del sonido. Además, de poco serviría procesar los sonidos a través de canales estrechos si los filtros cocleares del usuario del audífono siguen siendo más anchos de lo normal. Dadas estas limitaciones, lo más conveniente es procesar los sonidos por canales de frecuencias con anchos de banda similares a los del sistema auditivo sano (Fletcher, 1940). Generalmente, para establecer el ancho de banda de cada filtro, los audífonos siguen una distribución logarítmica acorde al ancho de banda rectangular equivalente (ERB, del inglés equivalent rectangular bandwidth) de los filtros auditivos (Moore y Glasberg, 1983).

\footnotetext{
${ }^{2}$ Enmascaramiento: efecto auditivo que se produce cuando sólo se percibe un sonido al presentar a la vez (o próximos en el tiempo) dos o más sonidos que son audibles por separado. En este caso se dice que el sonido percibido enmascara a los otros.
} 


\section{La velocidad de compresión}

Con el fin de evitar introducir excesiva distorsión, mantener una escucha cómoda y proteger al usuario de los cambios abruptos de intensidad, la ganancia en un audífono se aplica de forma no instantánea. Es decir, cuando se produce una variación en la intensidad de la señal de entrada que exige un cambio en el valor de la ganancia, el audífono 'suaviza' el cambio de ganancia progresivamente en el tiempo. Típicamente, la dinámica de la ganancia se consigue con un filtro de suavizado o detector de nivel programado con dos constantes de tiempo denominadas tiempo de ataque $\left(\tau_{\mathrm{AT}}\right)$ y tiempo de relajación $\left(\tau_{\mathrm{RT}}\right)$.

El tiempo de ataque se define como el intervalo de tiempo que emplea un compresor no instantáneo en estabilizar la ganancia cuando existe un incremento en la intensidad de entrada. Por su parte, el tiempo de relajación es el intervalo de tiempo empleado para estabilizar la ganancia cuando hay un decremento en la intensidad de entrada. Existe un convenio propuesto por el Instituto Americano de Estándares Nacionales (ANSI, 2003) para normalizar estos valores

(Figura 2.10).

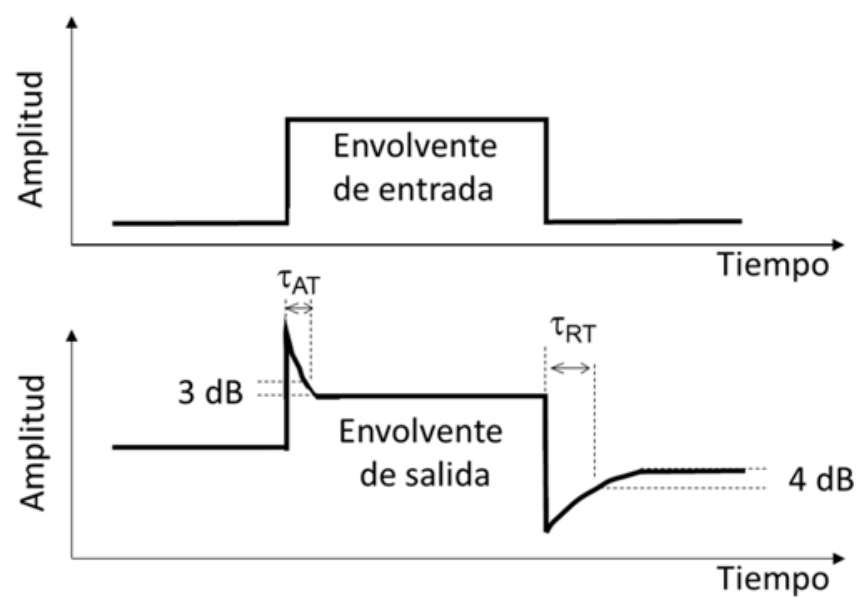

Figura 2.10. Efectos de sobreimpulso ('overshoot') y subimpulso ('undershoot') producidos por los tiempos de ataque y relajación, respectivamente, a la salida de un audífono no instantáneo en respuesta a un tono puro con un salto en su nivel sonoro. ANSI (2003) define el tiempo de ataque como el tiempo que tarda la señal de salida en conseguir estar dentro de los $3 \mathrm{~dB}$ del estado estacionario cuando se produce un salto abrupto en la intensidad de entrada de 55 a 90 dB SPL. El tiempo de relajación se define como el tiempo que tarda la señal de salida en estar dentro de los $4 \mathrm{~dB}$ del estado estacionario cuando se produce una caída abrupta de intensidad desde 90 a $55 \mathrm{~dB}$ SPL.

Existe una gran controversia acerca de los valores óptimos de las constantes de tiempo de un compresor, especialmente del tiempo de relajación (Moore, 2008). Cuando los tiempos de ataque y relajación son cortos (entre 5 y $200 \mathrm{~ms}$ ), el audífono se considera un compresor 'silábico' o de acción rápida, en el que la compresión cambia sílaba a sílaba. En cambio, cuando la constante de relajación es del orden de segundos, el audífono funciona como un controlador automático de volumen o un compresor de acción lenta. Algunos compresores incorporan tiempos de relajación múltiples, automáticos y/o adaptativos como solución de compromiso. Este es el caso del dual- 
front end (Moore y Glasberg, 1988) o del adaptive dynamic range optimization (ADRO) (Blamey, 2005) (véase Giannoulis et al., 2013).

La velocidad de compresión puede modular (distorsionar) las características temporales de la señal (Levitt et al., 1987). La compresión de acción rápida reduce el contraste espectro-temporal de forma efectiva, los mínimos del espectro se amplifican y los máximos se atenúan a lo largo del tiempo. En cambio, los compresores de acción lenta aplican ganancias más planas espectralmente y más estacionarias (más constantes) temporalmente. Aplicando una compresión más lineal se respeta en mayor medida la calidad del sonido, se mantiene el contraste y se reduce la distorsión espectral. Los audífonos de compresión lenta han resultado ser bastante exitosos, consolidándose como el esquema de compresión estándar empleado en los audífonos modernos (Dillon, 2012).

\section{El rendimiento}

Los principales logros de los audífonos actuales se reportan en la mayoría de revisiones y textos sobre audífonos (Walker y Dillon, 1982; Levitt, 1987; Plomp, 1994; Kuk, 2002; Souza, 2002; Kates, 2008; Popelka et al., 2016) y se pueden resumir en los siguientes aspectos: (1) optimizan el uso del rango dinámico residual; (2) restauran la percepción normal de la sonoridad; (3) no introducen excesiva distorsión; (4) previenen las molestias asociadas al cambio dinámico de volumen y, por tanto, mantienen la escucha cómoda; (5) maximizan la amplificación sobre el espectro del habla; y (6) pueden reducir algunos efectos adversos del ruido mediante el procesamiento de señales.

Sin embargo, los audífonos también tienen limitaciones. Entre ellas, cabe destacar que: (1) reducen el contraste espectral (Plomp, 1988; Stone y Moore, 2008); (2) distorsionan la envolvente del estímulo acústico (Stone y Moore 1992, 2008; Moore, 2012); (3) no se adaptan totalmente al usuario (Kochkin, 2007; Ng y Loke, 2015); (4) no incluyen un control eferente automático (o reflejo) por atención u otros procesos; (5) distorsionan la audición binaural en aquellas personas que utilizan audífonos en ambos oídos (Byrne y Noble 1998; Wiggins y Seeber 2011, 2012). El principal problema es que no restauran las deficiencias de audición por encima del umbral de audibilidad (Moore, 1996; Oxenham y Bacon, 2003) y, en consecuencia, no resuelven los problemas en inteligibilidad del habla audible en ambientes ruidosos (Festen y Plomp, 1990; Johannesen et al., 2016; Lopez-Poveda et al. 2017). 


\section{Desafíos pendientes}

En 2014 , el $81 \%$ de los usuarios de audífonos estaban satisfechos con sus dispositivos (Abrams y Kihm, 2015). A pesar de ello, los audífonos modernos no pueden reducir eficientemente el ruido porque es el oyente quien define el ruido de fondo en cada situación de escucha y, a menudo, ese ruido no es acústicamente diferente de la señal de interés. Por ejemplo, cuando el usuario de audífono mantiene una conversación con dos o más personas a la vez, sus interlocutores son señal y ruido en diferentes momentos de la conversación. Sin embargo, el audífono procesa sendas señales de la misma manera. Esto hace que la tecnología actual siga sin entregar una inteligibilidad del habla en ruido equivalente a la de personas normoyentes, lo que ofrece un margen para futuras mejoras.

La compresión del rango dinámico en los audífonos es al mismo tiempo problema y solución. Por un lado, restaura parcialmente la audibilidad y reduce el reclutamiento de la sonoridad. Por otro lado, reduce el contraste espectro-temporal de las señales, lo que tiene graves implicaciones en la percepción del habla (Plomp, 1988; Stone y Moore 2008). En los últimos 30 años, numerosos estudios mediante procesamiento digital de las señales han tratado de preservar o restaurar a la salida del audífono las características fundamentales de las señales de habla. Sin embargo, ninguna de las estrategias propuestas se ha consolidado. Por esta razón, actualmente se siguen proponiendo ideas para aumentar la SNR a la salida del audífono.

Por otro lado, tal y como se describe en las siguientes secciones, los esfuerzos actuales están dirigidos a vincular el funcionamiento de los audífonos (los compresores) empleados en ambos oídos a fin de mejorar la inteligibilidad del habla en entornos ruidosos o con múltiples hablantes. Este es, también, el objetivo del presente trabajo.

\subsection{El problema del ruido en los usuarios de audífonos}

Las personas con pérdida auditiva tienen más dificultad de lo normal para entender el habla en ruido, incluso cuando el habla es audible como sucede cuando se presenta a través de un audífono (Plomp, 1978, 1988, 1994; Festen y Plomp, 1986). La pérdida auditiva deteriora la capacidad de reconocer y entender el habla en presencia de otros hablantes, fenómeno 
denominado "cocktail party effect" (Cherry, 1553). Un gran número de estudios han estimado la habilidad de las personas hipoacúsicas para reconocer el habla en ruido en comparación con las personas normoyentes (véase Bronkhorst, 2000, 2015). Esta habilidad se cuantifica midiendo la SNR requerida para lograr un cierto porcentaje (típicamente el 50\%) de identificación de fonemas, sílabas, palabras, o frases. Esta SNR se denomina umbral de recepción verbal (SRT, del inglés Speech Reception Threshold) y se suele expresar en dB SNR. De tal forma, que cuanto más alto sea el SRT, peor es el rendimiento en ruido.

En escenarios acústicos donde la señal se encuentra en distinta posición espacial que la máscara, el sistema auditivo se basa principalmente en dos factores para reconocer la señal: (1) las características acústicas específicas de la señal como, por ejemplo, sus modulaciones en amplitud; y (2) las características (o pistas) relacionadas con la ubicación de las señales. Sendas características pueden deteriorarse cuando se sufre hipoacusia y/o cuando las señales se procesan por dos audífonos funcionalmente independientes. En una hipoacusia, la pérdida o la disfunción de OHCs altera los efectos del mecanismo activo de la cóclea, lo que deteriora las habilidades para entender el habla en ruido (Lopez-Poveda, 2014). Por otro lado, las personas hipoacúsicas a la hora de entender el habla en ruido, en comparación con las normoyentes, se benefician considerablemente menos de (1) la separación espacial señal-máscara (Bronkhorst, y Plomp,1989) y (2) las pausas presentes en las señales enmascarantes (Festen y Plomp, 1990; Bronkhorst, y Plomp,1992). Esto se suma a que la información binaural se distorsiona cuando se procesa a través de dos compresores, uno por oído, funcionalmente independientes (Byrne y Noble 1998; Musa-Shufani et al., 2006; Wiggins y Seeber, 2011, 2012).

Actualmente estos deterioros pueden paliarse parcialmente gracias al procesamiento digital de los sonidos de los audífonos. Existen numerosos estudios que tratan de mejorar la SNR basándose en cualquier diferencia entre la señal 'deseada' y el ruido como, por ejemplo, la tasa de modulación, las características espectrales o el ancho de banda (véanse las revisiones de Sammeth y Ochs, 1991; Levitt, 2001; Kates, 2008). También se puede mejorar la SNR suponiendo que el sonido deseado está frente al usuario del audífono y atenuando las señales 'no deseadas' que proceden de otras direcciones. Este tipo de sistemas (micrófonos direccionales) produce un aumento en la SNR 'efectiva' que conduce a un beneficio en el rendimiento con el audífono correspondiente (Van den Bogaert et al., 2008; McCreery et al., 2012b). Sendos enfoques, haciendo suposiciones sobre las características del ruido y la señal, pueden llegar a mejorar los SRTs en algunas condiciones. Sin embargo, este tipo de 
procesamientos no tiene un mecanismo análogo en el sistema auditivo humano sano. El oído humano no impone preferencias a priori sobre los sonidos que recibe.

En la presente tesis, nuestra filosofía de trabajo es diseñar procesadores binaurales a través de un enfoque bio-inspirado, con el objetivo de mejorar la percepción del habla en ruido de los usuarios de audífonos. En concreto, se pretende restaurar los efectos del reflejo eferente olivococlear medial sobre la compresión y sus posibles efectos desenmascarantes; efectos y beneficios que pueden estar mermados, incluso ausentes, en los usuarios de audífonos al estar deterioradas sus OHCs.

\subsubsection{Procesamiento binaural del sonido}

La (no) difracción de las ondas sonoras alrededor de la cabeza produce una atenuación del sonido en el lado más alejado de la cabeza, efecto denominado 'sombra acústica de la cabeza' (Rayleigh,1907). Los sonidos con frecuencias mayores de $1000 \mathrm{~Hz}$ (equivalente a una longitud de onda de $0.3 \mathrm{~m}$ ) sufrirán esta sombra acústica produciendo una diferencia de intensidad entre los dos oídos, conocida por diferencia interauricular de nivel sonoro. Teniendo en cuenta que los oídos están físicamente separados por la cabeza, las ondas sonoras siempre realizarán un recorrido más largo para el oído que esté más alejado de la fuente sonora. A este retardo temporal entre los oídos se le conoce como diferencia interauricular de tiempo (ITD, del inglés interaural time difference). Las ITDs generan diferencias interauriculares de fase (IPD, del inglés interaural phase difference) diferentes para cada una de las frecuencias componentes del sonido. Las ILDs y las ITDs predominan y son más útiles a altas y bajas frecuencias, respectivamente (Akeroyd, 2006).

La localización de los sonidos en el espacio se consigue con el procesamiento por separado de la información que recibe cada oído, y con la posterior comparación de intensidad y fase entre ambas señales. El procesamiento binaural del sonido proporciona ventajas más allá de la localización, por ejemplo, en la inteligibilidad del habla. La inteligibilidad del habla puede mejorar mediante la atención selectiva al oído con la SNR más favorable (que suele ser el oído más cercano al sonido de interés), fenómeno conocido como 'escucha con el mejor oído'. La inteligibilidad es mejor, no obstante, cuando se escucha con ambos oídos que cuando se escucha solo con el oído que tiene la mejor SNR. El beneficio añadido de escuchar con dos oídos relativo a escuchar con el oído que tiene la mejor SNR se denomina efecto 'squelch' (Koenig, 1950). En otras palabras, el efecto 'squelch' desaparece cuando se escucha solo con el oído con 
mejor SNR, por lo que se ha atribuido este efecto al procesamiento binaural del sonido (Hawley et al., 2004).

Las personas con hipoacusia simétrica emplean las ITDs igual de bien que las personas normoyentes. Sin embargo, perciben las ILDs de forma anómala y diferente de un oyente a otro, dependiendo de la pérdida auditiva en alta frecuencia (Bronkhorst y Plomp, 1989). De hecho, las personas con hipoacusia aprovechan en menor medida la separación espacial entre el hablaruido que las personas normoyentes, lo que deteriora sus SRTs en ruido de 5 a $7 \mathrm{~dB}$ con respecto a las personas normoyentes (Bronkhorst, 2000, 2015).

Existe un consenso general sobre el beneficio de usar dos audífonos en los casos de hipoacusia bilateral en lugar de uno, ya que promueve una escucha bilateral en vez de monoaural. La escucha bilateral proporciona mayor audibilidad en silencio, mejor calidad de sonido (Balfour y Hawkins, 1992) y mejor capacidad de localización (Byrne et al, 1992). Además, mantiene la estimulación auditiva en ambos oídos (Silman et al., 1984). Sin embargo, numerosos estudios no encuentran que la compresión bilateral proporcionada por los audífonos sea ventajosa en ambientes ruidosos frente a la amplificación unilateral, a la ampliación lineal, ni siquiera frente a la "no" amplificación (Nabelek y Mason, 1981; Schreurs y Olsen, 1985; Festen y Plomp, 1986; Peissig y Kollmeier, 1997). Teóricamente, esto se debe a que, cuando se usan audífonos bilateralmente, la compresión de rango dinámico que funciona independientemente en cada oído altera (reduce) potencialmente las ILDs, distorsionando así la percepción binaural y dificultando la segregación de las fuentes de sonido (Byrne y Noble, 1998; Wiggins y Seeber, 2011, 2012). Probablemente, esto dificulta la inteligibilidad del habla en ruido.

Una solución a este problema podría ser vincular el funcionamiento del audífono izquierdo y derecho con el objetivo de controlar la ganancia que se aplica en cada oído con respecto al otro. Este tipo de sistemas, en comparación con dispositivos de operación independiente, pueden mejorar la localización del sonido, el reconocimiento del habla en ruido y la naturalidad del sonido (Hansen, 2008; Sockalingam et al., 2009; Kreisman et al., 2010). Por ejemplo, Wiggins y Seeber (2013) demostraron en simulaciones que el uso de compresores multicanal que aplican la misma ganancia en ambos oídos en cada instante de tiempo mejora los SRTs en el oído con la mejor SNR y en ruido fluctuante. A pesar de esto, los estudios sobre este tipo de compresores son limitados. El beneficio resultante en términos de inteligibilidad del habla se ha mostrado en escasas condiciones e incluso algunos estudios usan audífonos inadecuados como referencia. 
Todos estos resultados sugieren que un procesamiento binaural de los sonidos, es decir un procesamiento que implique algún tipo de coordinación entre audífonos, podría producir una mejora de la inteligibilidad del habla en ruido.

\subsubsection{Función de las OHCs en la escucha en ruido}

La pérdida de sensibilidad a sonidos débiles no es la única deficiencia en la percepción sonora que causa la hipoacusia (Moore, 1996; Oxenham y Bacon, 2003; Moore, 2007). La ausencia o disfunción del mecanismo activo de la cóclea tiene graves implicaciones sobre la selectividad frecuencial (reduce el contraste espectral), la percepción de la sonoridad (produce reclutamiento de la sonoridad), la discriminación de la intensidad (reduce la integración y resolución temporal), la localización de sonidos (altera las ILDs) y algunos mecanismos binaurales como el binaural 'squelch' (Arsenault y Punch, 1999). A continuación, se describe cómo la pérdida o disfunción de OHCs (alteración frecuentemente asociada a la hipoacusia) puede afectar a la inteligibilidad del habla en ruido. Aunque se describen por separado diferentes mecanismos, el deterioro de la percepción de habla se debe probablemente a la combinación de todos ellos. Además, se presentan algunas técnicas de procesamiento de sonidos que tratan de compensar estas deficiencias con el objetivo de mejorar el rendimiento de los usuarios de audífonos.

\section{Reducción de la compresión coclear}

La pérdida o la disfunción de las OHCs reduce la compresión coclear. Teóricamente, la compresión coclear podría facilitar la detección de señales del habla en presencia de sonidos fluctuantes amplificando la señal de interés en las pausas presentes en las señales enmascarantes, fenómeno conocido como 'escucha en los valles'. La disfunción de las OHCs reduce la compresión y 'linealiza' las respuestas cocleares, lo que podría dificultar la escucha en los valles (Gregan et al., 2013).

En teoría, la compresión de acción rápida puede favorecer la escucha en los valles, amplificando el habla, sílaba a sílaba, en los huecos espectro-temporales de la máscara (Moore, 2008). No hay, sin embargo, ningún estudio que lo demuestre. De hecho, los compresores de acción rápida pueden deteriorar la percepción del habla en presencia de otras fuentes sonoras, especialmente cuando están moduladas en amplitud. Esto se debe a que los compresores de acción rápida distorsionan la envolvente de las señales (Plomp, 1988; Stone y Moore 2008; Moore, 2012) lo que produce una fusión perceptiva de las señales que llegan a cada oído y altera la naturalidad de los sonidos (Wiggins y Seeber 2011, 2012). Hohmann y Kollmeier (1995) demostraron, sin 
embargo, que la inteligibilidad del habla se puede preservar cuando se aplica compresión de acción rápida, siempre que no se cambie la SNR instantánea en cada banda de frecuencia

\section{Ensanchamiento de los filtros cocleares}

Los filtros cocleares son más anchos en una cóclea con pérdida o disfunción de las OHCs que en una cóclea sana (Robles y Ruggero, 2001). Esto produce una pérdida de sintonización espectral que dificulta la discriminación de las componentes espectrales del habla en presencia de otras fuentes sonoras (Baer y Moore, 1993). Cuando la pérdida de OHCs va acompañada de una pérdida completa de IHCs, es decir, de zonas cocleares muertas, la percepción de tonos correspondiente a estas regiones cocleares suena como ruido o distorsión (Huss y Moore, 2005a, 2015b) y, por tanto, la percepción del habla, la música y la localización se distorsionan.

Para rehabilitar la audición en zonas cocleares muertas se ha propuesto la compresión espectral (Moore, 2001). Se persigue redistribuir espectralmente la información acústica evitando la estimulación en tales regiones (Kluk y Moore, 2006; Simpson, 2009). Los sistemas de redistribución espectral aún no han mostrado beneficios claros para los oyentes, quizás porque distorsionan el habla (Robinson et al., 2009; McCreery et al., 2012a).

\section{Reducción de la supresión coclear}

La respuesta a sonidos simultáneos en una región de la BM puede suprimir la respuesta de regiones adyacentes (Ruggero et al., 1992). La supresión podría facilitar la inteligibilidad del habla en ruido al mejorar la representación coclear de las características espectrales más destacadas del habla frente a las del ruido (Deng y Geisler, 1987; Young, 2008). La pérdida o la disfunción de OHCs puede reducir la supresión coclear (Lopez-Poveda et al., 2005). Además de reducir el contraste espectral, una menor supresión puede aumentar/reducir de forma anómala la magnitud y número de potenciales de acción en el nervio auditivo, lo que puede degradar la codificación temporal (Sachs y Young, 1980), y, por tanto, la capacidad para usar la información transmitida en los cambios temporales rápidos de los sonidos complejos, como el habla. A estas fluctuaciones rápidas se las conoce como "estructura fina temporal" y son relevantes en tareas de discriminación (Lorenzi et al., 2006). Existe una gran evidencia de que la pérdida auditiva coclear moderada reduce o anula la capacidad de procesar estructura fina temporal (Moore et al., 2006; Hopkins y Moore, 2007).

Existen propuestas para audífonos e implantes que tratan de realzar el contraste espectral del habla en presencia de ruido de fondo. El efecto de estas propuestas es, sin embargo, pequeño 
o incluso negativo (véase, por ejemplo, Baer et al., 1993b; Yang et al., 2003; Oxenham et al., 2007; Chen et al., 2010). Algunas propuestas se inspiran en los efectos de la supresión coclear para aumentar el contraste espectral (Turicchia y Sarpeshkar, 2005; Rasetshwane et al., 2013). Por ejemplo, Rasetshwane et al. (2013) propusieron un sistema que tiene como objetivo compensar el deterioro en la supresión de tonos y el reclutamiento de la sonoridad, demostrando que el algoritmo conserva los contrastes espectrales locales.

\section{Deterioro del control eferente}

Las fibras del haz MOC eferente pueden activarse de manera refleja por sonidos ipsilaterales o contralaterales. EI MOCR es, por tanto, probablemente activado de manera natural durante la escucha binaural, y modula la respuesta coclear mecánica de manera dinámica. Se cree que la activación eferente del MOC desenmascara los sonidos al reducir la adaptación de la respuesta de las fibras nerviosas auditivas al ruido (Winslow y Sash, 1987; Guinan, 2006; Chintanpalli et al., 2012), un efecto que podría facilitar el reconocimiento del habla en ruido (Kim et al., 2006; Brown et al., 2010; Clark et al., 2012). Además, la estimulación contralateral puede mejorar la detección de tonos puros inmersos en ruido (Micheyl y Collet, 1996). Por tanto, cuando hay una ausencia total o una disfunción de OHCs, el sistema eferente pierde control sobre la respuesta de la BM y con ello, su posible beneficio desenmascarante.

Inspirado en el control eferente de la compresión coclear, Kates (2009) diseñó un audífono (compresor) binaural con conexiones cruzadas. Usando el procesamiento básico de la mayoría de los audífonos, Kates propuso simular el sistema eferente auditivo haciendo que la ganancia que aplica el compresor de cada oído se determine a partir de una combinación ponderada de las señales de entrada ipsilateral y contralateral (Figura 2.11). El funcionamiento de este sistema puede considerarse equivalente a tomar el máximo de las señales de entrada (izquierda y derecha) y usar este valor para controlar la ganancia en ambos oídos. Este sistema puede suprimir el ruido para relaciones señal ruido positivas. Sin embargo, los usuarios hipoacúsicos no mostraron una preferencia clara por este sistema cuando se evaluó en una variedad de situaciones cotidianas de escucha (véase el Capítulo 8 de Kates, 2008). 


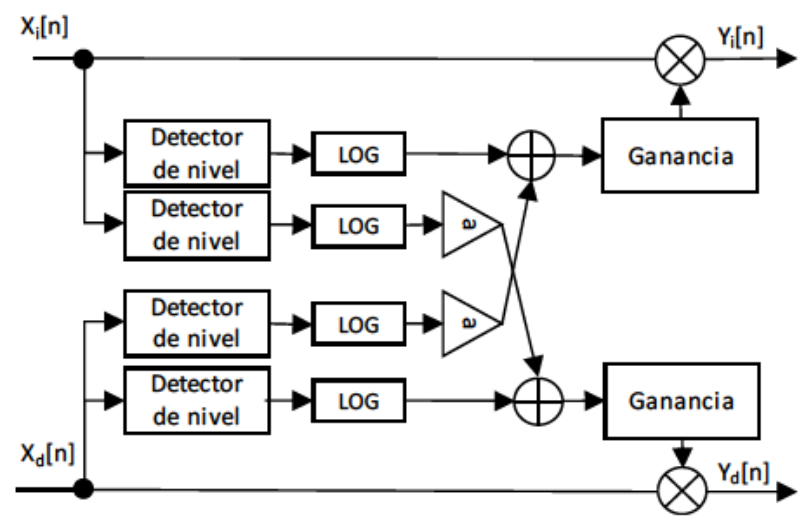

Figura 2.11. Diagrama de bloques de un compresor binaural inspirado en las conexiones neurales eferentes (Kates, 2009). Se muestra un solo canal de frecuencia por cada oído. La señal de entrada de cada oído y canal de frecuencia se procesa por un detector de nivel. La señal de salida del detector de nivel se convierte en escala logarítmica, y se suma con un factor $a$ (en $\mathrm{dB}$ ) que simula el control eferente. La señal resultante se usa para determinar la ganancia ipsilateral. El control eferente (factor a) se calcula con la señal de entrada contralateral, de tal manera que la señal de entrada contralateral se integra con un detector de nivel. La señal de salida del detector se transforma a escala logarítmica y después se escala en $\mathrm{dB}$ dando como resultado $a$.

Algunos estudios han propuesto modelos para estudiar el papel del sistema eferente en la audición. Por ejemplo, Ferry y Meddis (2007) propusieron incluir un atenuador MOC al filtro no lineal de doble resonancia (DRNL) (Meddis et al., 2001; Lopez-Poveda y Meddis, 2001). Este pequeño cambio en la estructura del filtro DRNL fue suficiente para simular los efectos de la activación de los eferentes MOC sobre la respuesta de la BM y del nervio auditivo (Ferry y Meddis, 2007). El modelo ha llegado incluso a mejorar el rendimiento de los reconocedores automáticos del habla en ruido en SNR positivas (Brown et al., 2010; Yasin et al., 2018, 2020). En un estudio de percepción del habla, Ghitza et al. (2007) sugirió una modificación similar al modelo no lineal de paso de banda múltiple de Goldstein (1990) para lograr efectos similares.

BioAid es un algoritmo para audífonos basado en el filtro DRNL con atenuación MOC (Meddis et al., 2013; Clark et al., 2012; Jürgens et al., 2016; Clark et al., 2018). En BioAid (Figura 2.12), los efectos del MOCR ipsilateral se simulan mediante un circuito DFAC (DFAC, por sus siglas en inglés delayed feedback attenuation control) que atenúa con un retardo temporal la señal de entrada al compresor instantáneo del filtro DRNL (Clark et al. 2012). En BioAid, la ganancia se aplica sobre la señal atenuada por el MOCR. Se ha demostrado que BioAid mejora la audibilidad, el procesamiento temporal, y la selectividad frecuencial (Jürgens et al., 2016). Recientemente, se ha presentado una evaluación experimental donde se describe el rendimiento de una versión binaural de BioAid junto a otros sistemas de sincronización binaural de la ganancia. En esta 
versión de BioAid, el procesamiento binaural de los sonidos se consigue promediando las señales de entrada al circuito DFAC de los dos compresores (uno por oído), de modo que la salida DFAC era idéntica en cada dispositivo por cada canal de frecuencia. No se observaron beneficios significativos de ninguno de los sistemas binaurales evaluados frente al procesamiento ofrecido por el uso de un audífono comercial convencional en cada oído (adaptación bilateral) (Ernst et al., 2018).

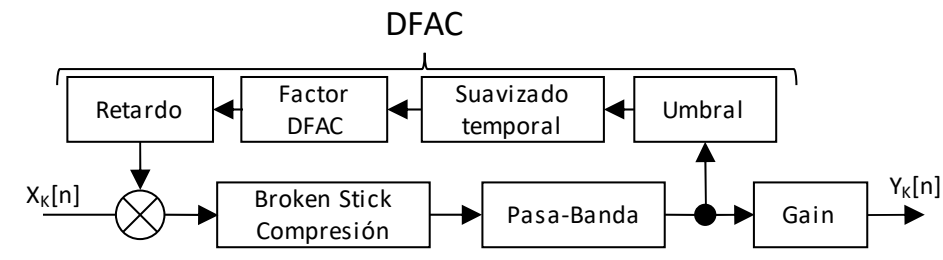

Figura 2.12. Diagrama de bloques de BioAid donde se muestra un solo canal de frecuencia. La señal digital de entrada $\left(\mathrm{x}_{\mathrm{k}}[\mathrm{n}]\right)$ se atenúa antes de someterla a compresión instantánea. La señal resultante del compresor se filtra mediante un filtro pasa-banda para eliminar la posible distorsión introducida por la compresión instantánea. La señal de salida del filtro pasa-banda se divide: una copia se amplifica y constituye la señal de salida $\left(y_{k}[n]\right)$. La otra copia se usa para calcular el factor de atenuación que simula el MOC ipsilateral a través del circuito DFAC. La señal de entrada al DFAC se normaliza, se integra y sirve para calcular un factor de atenuación que se aplica con un retardo sobre la señal de entrada.

Ninguna de estas propuestas ha destacado de una forma contundente. Sin embargo, hay motivos para pensar que este tipo de enfoques pueden llegar a traducirse en un beneficio en la inteligibilidad del habla en ruido (Brown et al., 2010; Yasin et al., 2018, 2020). A continuación, se explica nuestra propuesta de audífono binaural inspirado en el MOCR contralateral.

\subsection{Un nuevo audífono binaural inspirado en el} MOCR contralateral

En el oído humano sano, la sensibilidad y la sintonización frecuencial de la cóclea no son fijas, varían según el estado de activación de las fibras eferentes del haz MOC. Como ya se ha mencionado anteriormente, este haz eferente puede activarse de forma refleja (involuntaria) por sonidos ipsilaterales y contralaterales, dando lugar al MOCR. EI MOCR actúa sobre las OHCs, que modulan la ganancia del amplificador coclear. La hipoacusia neurosensorial frecuentemente está asociada a una disfunción o a un déficit total o parcial de estas células (Lopez-Poveda y 
Johannesen, 2012; Johannesen et al., 2014). Por tanto, las personas hipoacúsicas con una reducción o ausencia de OHCs podrían carecer de los efectos del MOCR sobre la amplificación coclear y de sus posibles beneficios desenmascarantes en entornos ruidosos (Nieder y Nieder, 1970; Winslow and Sachs, 1988; Liberman y Guinan, 1998; Lopez-Poveda, 2018). El objetivo general de esta tesis es reproducir los efectos del MOCR contralateral en la amplificación que proporcionan los audífonos; la propuesta concreta se presenta al final de esta sección. Antes de ello, se describen algunas de las características más importantes del sistema eferente MOC y del MOCR.

\subsubsection{Propiedades del MOCR}

En animales, la activación del sistema eferente puede inducirse mediante pulsos eléctricos en el suelo del cuarto ventrículo. El efecto principal de la activación de las neuronas MOC es inhibir o reducir la amplitud de la vibración mecánica del órgano de Corti en respuesta a sonidos de intensidad baja a moderada y con frecuencias cercanas a la CF de la zona de registro en la cóclea. En humanos, las técnicas de medición del MOCR son indirectas. La respuesta mecánica coclear en humanos puede ser inferida por otoemisiones acústicas (OAEs, del inglés Otoacoustic Emissions), por curvas psicoacústicas de sintonización, o por curvas de E/S inferidas conductualmente (véase Lopez-Poveda, 2018). La estimulación acústica contralateral reduce la magnitud de las OAEs, tanto las evocadas por sonidos (Collet et al., 1994) como las espontáneas (Zhao y Dhar, 2010). La cantidad de inhibición inducida por la estimulación acústica contralateral varía entre 2 y $4 \mathrm{~dB}$ en función de las personas, de la modalidad de OAEs y de las características del sonido contralateral. Al contrario de lo que sucede en animales, en personas no existe una evidencia clara de que el MOCR ipsilateral sea más fuerte que el contralateral (Lilaonitkul y Guinan, 2009a).

Las curvas de E/S cocleares (Figura 2.13) registradas en animales muestran que la inhibición inducida por la activación de las neuronas MOC reduce las respuestas de la BM a los sonidos de baja a moderada intensidad y con frecuencias cercanas a la CF del sitio de registro en la cóclea. Este efecto 'linealiza' la respuesta de la BM (reduce la compresión). La activación de las neuronas MOC puede aumentar la respuesta de la BM en intensidades altas y frecuencias por encima de la CF (Dolan et al., 1997). En humanos, las curvas de E/S inferidas por métodos conductuales sugieren que la presencia de un activador del reflejo MOC reduce la magnitud de 
la respuesta coclear de 2 a 20 dB (Aguilar, 2013; Yasin et al., 2014). Dado un sonido contralateral fijo, la inhibición es mayor para tonos sonda de baja intensidad que de alta (Hood et al., 1996).
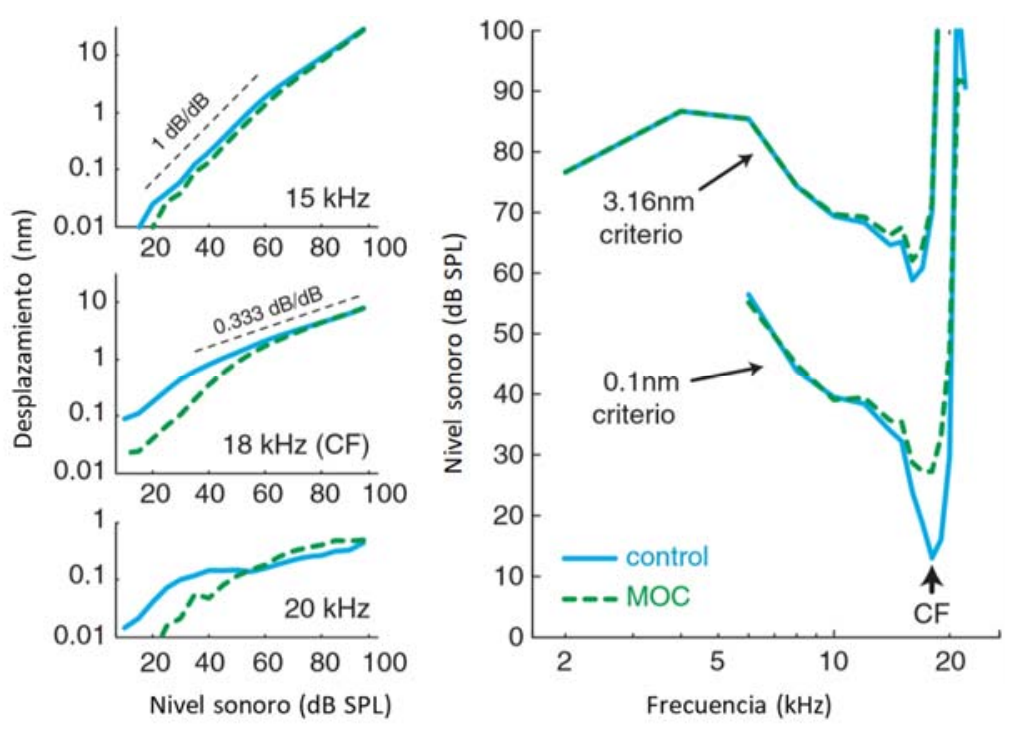

Figura 2.13. Efectos de la activación eléctrica de los eferentes olivococleares sobre el desplazamiento de la BM (CF 18 kHz). Izda. Curvas de entrada/salida frente a estímulos de distintas frecuencias. Dcha. Curvas de sintonización (o curvas de isorespuesta). Imagen de Cooper y Guinan (2006).

La activación del haz eferente MOC ensancha las curvas de sintonización coclear desplazando hacia arriba las puntas de las curvas (Figura 2.13). La activación de los eferentes MOC exige más energía para que los sonidos de baja intensidad produzcan una misma oscilación coclear. La inhibición del MOC es mayor para tonos de baja intensidad que para sonidos de alta intensidad (Figura 2.13). Este efecto, sin embargo, se restringe a estímulos con frecuencias cercanas a la CF; es decir, la activación de los eferentes MOC apenas altera la respuesta mecánica de la cóclea a frecuencias alejadas de la CF. En humanos, también se pueden ver algunos de estos efectos. La actividad MOC evocada por sonido contralateral reduce el retraso temporal necesario para que las OAEs transitorias alcancen su nivel máximo. Esto indica que la activación del MOCR amplía las frecuencias de estímulo a las que responde cada región coclear; es decir, que ensancha los filtros cocleares (Francis y Guinan, 2010). Este mismo efecto de la estimulación acústica contralateral también se ha observado sobre las curvas psicoacústicas de sintonización (Aguilar et al., 2013).

Tanto en humanos como en animales, la inhibición de la ganancia coclear inducida por la activación del MOC mediante sonido no es instantánea (e.g., Mott et al., 1989; Kim et al., 2001). De hecho, tanto la activación como la desactivación ocurren gradualmente en el tiempo (Figura 2.14) (Backus y Guinan, 2006). La activación puede describirse como una función exponencial con varias constantes de tiempo. El tiempo necesario para activar totalmente el MOCR es de al 
menos $300 \mathrm{~ms}$. La desactivación ocurre también de forma exponencial con una constante de tiempo de aproximadamente 160 ms. Tanto la activación como la desactivación ocurren con retrasos de aproximadamente 25-60 ms. Por otro lado, la evolución temporal muestra que la inhibición aumenta al incrementar la intensidad del sonido evocador del MOCR (Figura 2.14 B). También se ha demostrado que la inhibición es mayor cuanto mayor es el ancho de banda del sonido evocador (Lilaonitkul y Guinan, 2009a). Para un sonido contralateral de banda ancha, la inhibición MOC inducida por estimulación acústica bilateral, es decir, por sonido ipsilateral y contralateral, es aproximadamente igual a la suma de sendos reflejos por separado (condición bilateral en el panel izquierdo de la Figura 2.14)
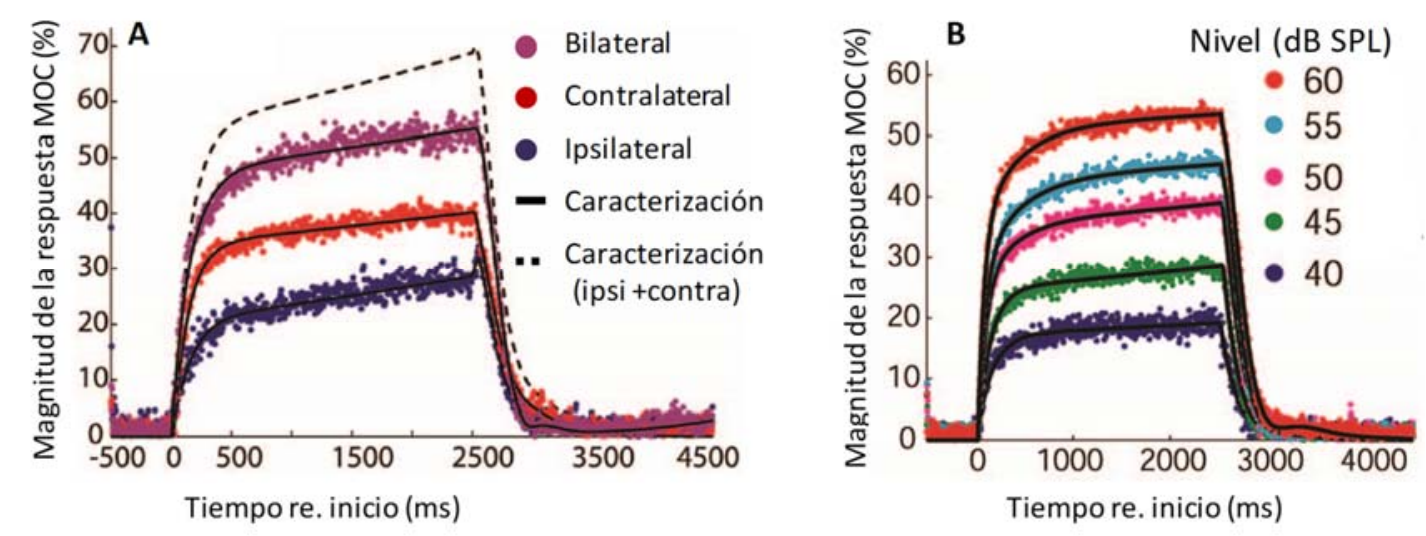

Figura 2.14. Curso temporal del reflejo olivococlear medial en humanos medido mediante la supresión de las otoemisiones acústicas. A: Las respuestas fueron evocadas con un ruido contralateral de banda-ancha, con un ruido ipsilateral con un hueco espectral, y con ambos ruidos (evocador bilateral). B: Respuestas evocadas por un ruido contralateral de banda ancha de diferente intensidad. Figuras tomadas de Backus y Guinan (2006).

La activación de los eferentes MOC reduce la respuesta del nervio auditivo frente a tonos puros en silencio, como consecuencia de inhibir la respuesta coclear mecánica. Sin embargo, realza la respuesta del nervio auditivo frente a tonos puros en ruido (Nieder y Nieder, 1970; Winslow y Sachs, 1988; Kawase et al., 1993; Liberman y Guinan, 1998; Lopez-Poveda, 2018). Este efecto 'desenmascarante' se ha demostrado indiscutiblemente en animales, pero permanece controvertido en humanos. La activación eléctrica del sistema eferente desplaza horizontalmente las curvas de descarga-intensidad del nervio auditivo hacia los niveles de sonidos más altos, como consecuencia del efecto inhibitorio del MOC (Figura 2.15). Este efecto descomprime la respuesta del nervio a tonos puros en presencia de ruido de fondo, restaurando así el rango dinámico de las fibras a los valores observados en silencio (Winslow y Sachs, 1988). En otras palabras, aunque la activación de los eferentes MOC reduce la sensibilidad del nervio auditivo, 
en ruido restaura su rango dinámico a valores próximos a los observados en silencio. Este mecanismo puede facilitar la codificación y la detección de cambios de intensidad, así como la codificación y la inteligibilidad del habla en entornos ruidosos, dando lugar a la noción de que los eferentes MOC facilitan la audición en el ruido (véase la revisión de Lopez-Poveda, 2018).

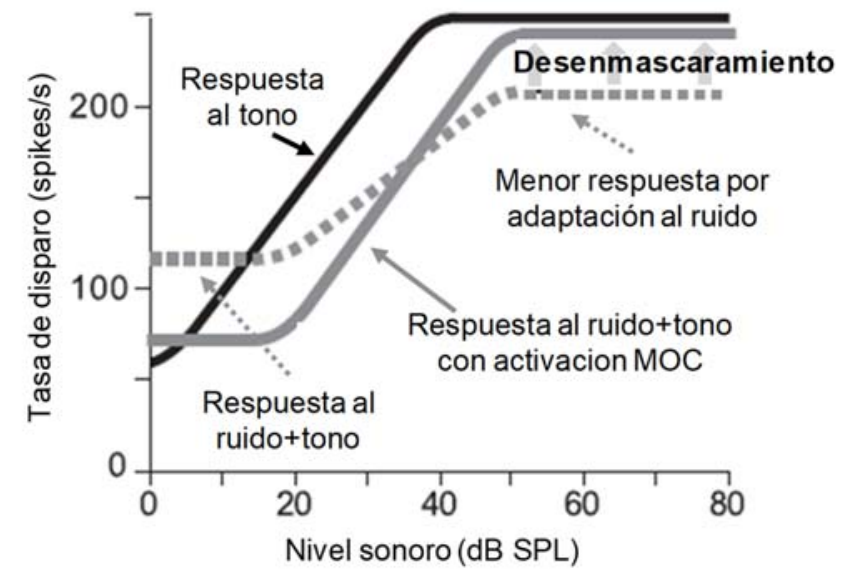

Figura 2.15. Tasa de descarga de una única fibra del nervio auditivo frente a tonos puros de diferentes intensidades en silencio (curva sólida negra), en presencia de ruido simultaneo ipsilateral (curva gris punteada), y en presencia de ruido ipsilateral con activación de los eferentes MOC (curva sólida gris). Figura adaptada de Guinan (2006).

Se han sugerido varias funciones para el sistema eferente MOC: facilitar el desarrollo de la cóclea, ajustar el rango dinámico de la cóclea, reducir el efecto de enmascaramiento, posibilitar un control de la cóclea mediante la atención, o proteger la cóclea frente a sonidos de alta intensidad. Sin embargo, las evidencias que avalan las diferentes propuestas son todavía escasas y, a veces, contradictorias (véase Lopez-Poveda, 2018).

\subsubsection{La estrategia MOC para implantes cocleares}

La estimulación eléctrica que proporciona un implante coclear (IC) es independiente del haz eferente MOC (Wilson et al., 2005), lo que impide a los usuarios de IC beneficiarse de los posibles efectos desenmascarantes del MOCR (Lopez-Poveda et al., 2016a). Lopez-Poveda et al. (2016b) sugieren que este hecho puede contribuir a que los usuarios de ICs tengan más dificultad de lo normal para comprender el habla en entornos ruidosos. Lopez-Poveda et al. (2016a, 2016b, 2017a) han desarrollado una estrategia de procesamiento binaural para ICs (denominada estrategia MOC) dirigida a simular los efectos del MOCR contralateral con ICs, con el objetivo de restituir los posibles beneficios desenmascarantes del MOCR contralateral a los usuarios de IC. 


\section{Fundamentos}

La estrategia MOC propone acoplar dinámicamente la compresión entre los oídos inspirándose en el papel modulador del sistema eferente sobre la mecánica coclear (Lopez-Poveda, 2015, 2017). La estrategia MOC es un sistema de procesamiento binaural de sonidos propuesta, en su origen, para ICs. En esta tesis, se propone una versión de esta estrategia para audífonos.

En su versión para ICs, la estrategia comprende un par de micrófonos que recogen el sonido que llega a cada oído y un par de procesadores de sonidos que reciben y codifican la información captada por los micrófonos. Cada uno de dichos procesadores de sonidos están adaptados para generar un patrón de estimulación eléctrica que es enviado a través de unos electrodos hasta las cócleas de los oídos internos del usuario. Este sistema se caracteriza por tener un control contralateral de la compresión que acopla entre sí el funcionamiento de los dos procesadores de sonidos (Figura 2.16). El control contralateral de la compresión genera señales dinámicas de control que son enviadas al procesador opuesto para modular su respuesta. Como resultado, cada uno de los dos procesadores de sonidos entrega un patrón de estimulación eléctrica final en la cóclea del usuario que se ajusta a los estímulos acústicos detectados por los micrófonos pero que está modulado por señales procedentes del procesador contralateral.

\section{Funcionamiento}

La estrategia MOC para ICs propone imitar el control eferente MOCR contralateral mediante el uso de un procesador bilateral, donde la cantidad de compresión en un canal de frecuencia dado en un procesador varía dinámicamente dependiendo del nivel sonoro de salida ponderado en el tiempo de un canal (o canales) de frecuencia apropiado en el procesador contralateral. Un ejemplo particular de implementación de este tipo de control se muestra en la Figura 2.16, donde la compresión en el k-ésimo canal del procesador derecho depende del nivel de salida ponderado en el tiempo del canal de frecuencia j-ésimo en el procesador izquierdo. El diagrama también ilustra cómo las señales de habla y ruido se filtraron con la función de transferencia relacionada con la cabeza (HRTF) para simular estímulos en 'campo libre' en los oídos izquierdo y derecho y cómo se procesó el estímulo en cada oído.

La estrategia MOC disminuye la cantidad de compresión en cada canal de frecuencia; es decir, 'linealiza' la respuesta del procesador. En comparación con dos procesadores de sonido independientes, el procesador inspirado en el MOCR reduce el ruido dentro de cada canal y a través de los canales, realza las ILDs y el contraste espectral y mejora las modulaciones de amplitud dentro de cada canal (Lopez-Poveda, 2015, 2017; Lopez-Poveda et al., 2016a, 2016b, 
2020). En conjunto, mejora objetivamente la SNR a la salida de los procesadores con respecto al uso de dos procesadores independientes (Lopez-Poveda y Eustaquio-Martín, 2018).

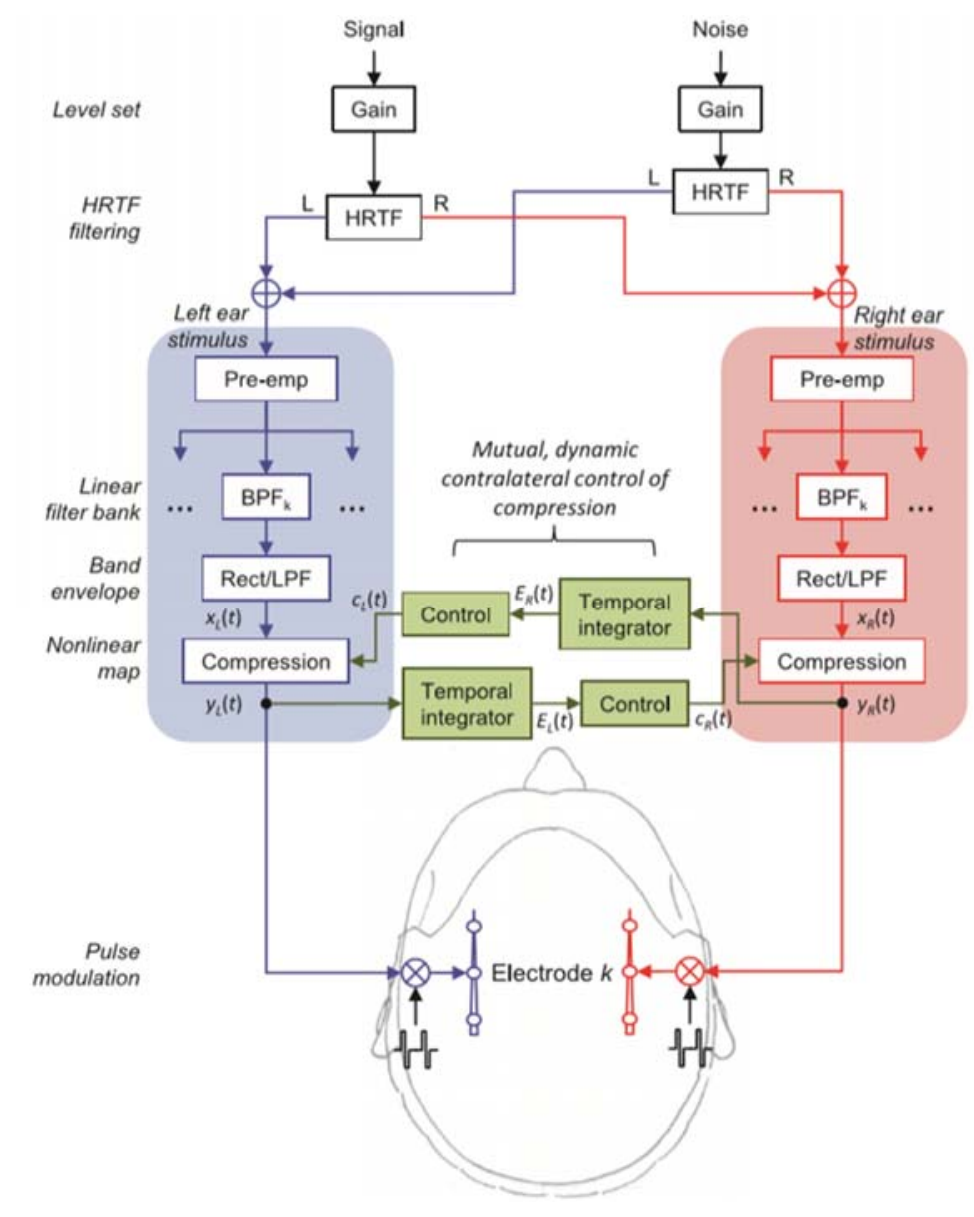

Figura 2.16. Diagrama de bloques de procesamiento de señal en las estrategias STD y MOC para implantes cocleares (tomado con permiso de Lopez-Poveda et al., 2016b). Obsérvese que los procesadores STD y MOC son idénticos, excepto que los procesadores MOC incluyen un control contralateral de la compresión (destacado en color verde). El diagrama también ilustra cómo las señales de habla y el ruido se filtraron con función de transferencia relacionada con la cabeza (HRTF) para simular estímulos en campo libre en los oídos izquierdo y derecho y cómo se procesa el estímulo en cada oído a través de los procesadores STD y MOC correspondientes (el procesamiento solo se muestra para el canal $k$ ).

\section{Resultados}

En comparación con el uso de dos procesadores de sonido funcionalmente independientes y con compresión fija (estrategia estándar o STD), la estrategia MOC puede proporcionar amplios beneficios sobre la inteligibilidad (Lopez-Poveda et al., 2016b, 2017, 2020) y la localización (Lopez-Poveda et al., 2019). Por ejemplo, la estrategia MOC mejora objetivamente la información del habla en el oído con la mejor SNR acústica, es decir, en el oído más cercano a la fuente de sonido de interés. Las pruebas de percepción realizadas con los usuarios de IC han demostrado que, en comparación con la STD, la estrategia MOC facilita el reconocimiento del habla en ruido, tanto cuando el ruido es estacionario (Lopez-Poveda et al., 2016b, 2020) como cuando es otra persona hablando (Lopez-Poveda et al., 2017a). La mejora se produce tanto en condiciones de escucha bilateral (con dos ICs) como unilateral (con un solo IC), siempre que la fuente de sonido de interés y de sonido enmascarador estén separadas espacialmente. 
El uso de compresión acoplada binauralmente también puede mejorar las ILDs en cada canal de frecuencia, y por lo tanto la ILD global (Figura 2.17), en comparación con las ILDs proporcionadas por dos procesadores que funcionan independientemente (Lopez-Poveda et al., 2019). En comparación con una estrategia STD, la estrategia MOC con un control rápido de la compresión y una mayor inhibición en los canales de frecuencia más altos, mejoró ligeramente la localización de ruidos de banda ancha $(125-6000 \mathrm{~Hz})$ en el plano horizontal virtual.

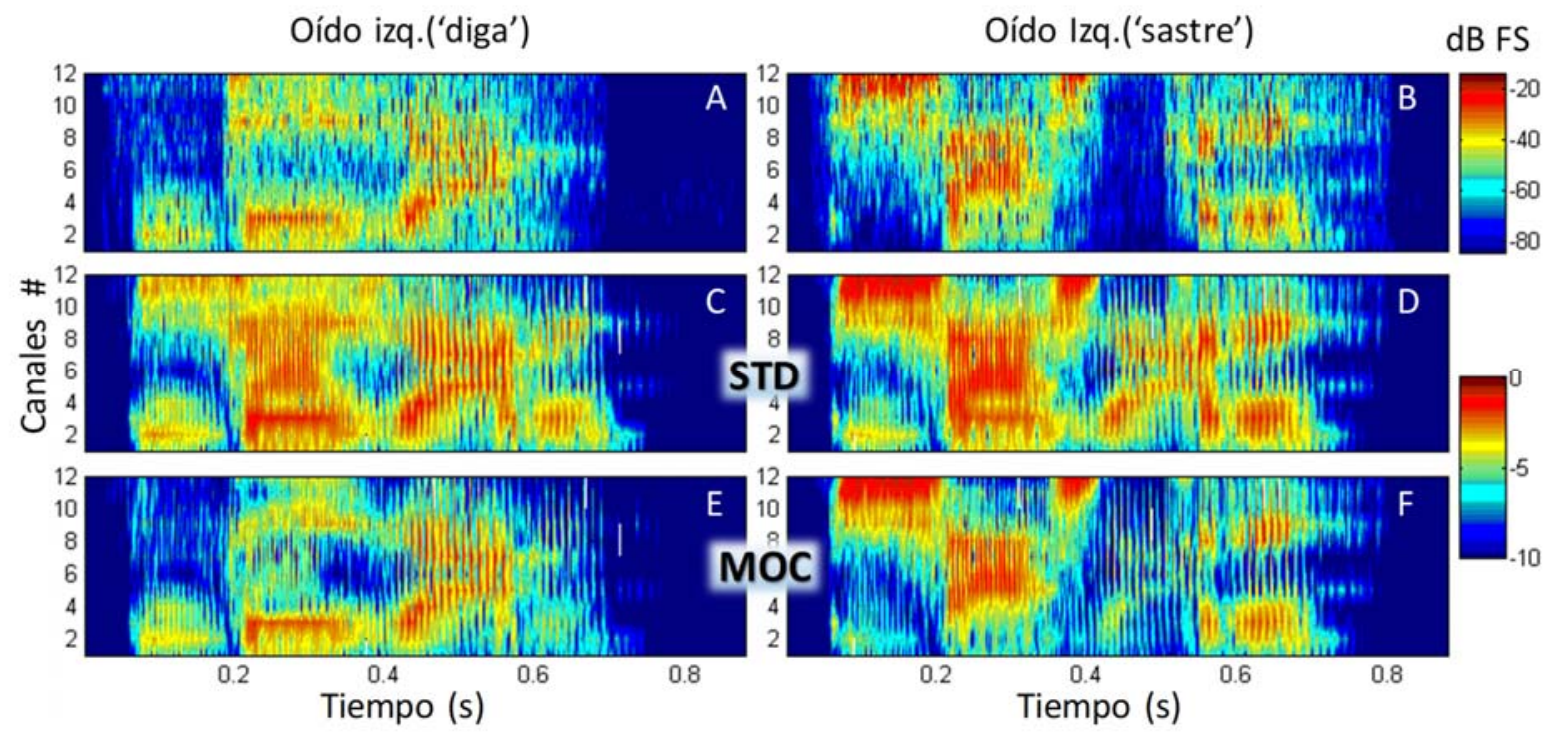

Figura 2.17. Electrodogramas ${ }^{3}$ bilaterales generados con las estrategias STD y MOC cuando la señal y el 'ruido' son las palabras 'diga' y 'sastre' generadas por fuentes ubicadas en posiciones azimutales de $270^{\circ}$ y $90^{\circ}$, respectivamente (figura tomada de Lopez-Poveda et al., 2016a). Ambas palabras se presentaron con un nivel sonoro de -20 dB FS (es decir, $0 \mathrm{~dB}$ SNR). Magnitudes en la salida del banco de filtros lineales del oído: izquierdo solo para el habla (panel A) y derecho solo para el ruido (palabra 'sastre') (panel B). C-D. Electrodogramas para los procesadores STD del oído izquierdo y derecho, respectivamente. E-F. Electrodogramas correspondientes para los procesadores MOC del oído izquierdo y derecho, respectivamente. Los electrodogramas muestran los beneficios potenciales de la estrategia MOC sobre la SNR y las ILDs. Observe que la señal de salida del procesador MOC (en cada oído) se parece más al estímulo 'limpio' (paneles A y B) que las señales de salida del procesador STD. FS: de inglés full scale.

Sin embargo, la estrategia MOC puede tener algunas desventajas con respecto al uso de procesadores funcionalmente independientes (Lopez-Poveda et al., 2016b). Por ejemplo, puede reducir la información del habla en el oído con la peor SNR acústica, lo que podría dificultar la inteligibilidad en la escucha unilateral cuando el oído del implante tiene la peor SNR acústica.

\footnotetext{
${ }^{3}$ Electrodograma: representación gráfica de las amplitudes de salida de los procesadores en función del tiempo y el número de canal de frecuencia.
} 
Esta(s) página(s) se han omitido porque contienen información confidencial de interés industrial 


\section{III - HIPÓTESIS Y OBJETIVOS}


III - Hipótesis y objetivos 


\section{III - Hipótesis y objetivos}

\subsection{Hipótesis}

La hipótesis general del presente trabajo es que, comparado con el uso de dos audífonos convencionales funcionalmente independientes, el audífono MOC aquí propuesto (Figura 4.1; véase el Apartado IV) mejorará la inteligibilidad del habla en ruido de las personas con hipoacusia neurosensorial.

Esta hipótesis general puede desglosarse en las siguientes hipótesis específicas:

(1)

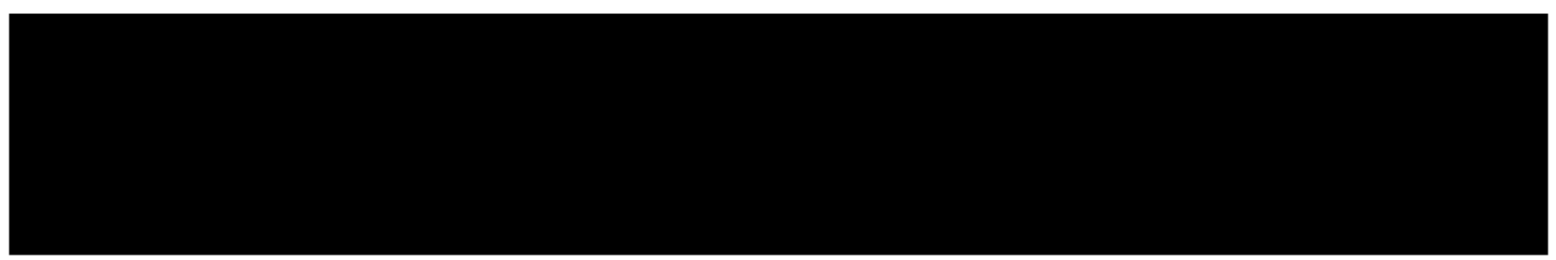

(2) El audífono MOC reproduce cualitativamente el efecto de la activación del MOCR natural sobre la respuesta mecánica coclear. Es decir, el sonido ipsilateral, contralateral o bilateral ejerce sobre las curvas de E/S y de sintonización frecuencial del audífono MOC un efecto cualitativamente parecido al que esos mismos sonidos ejercen sobre la compresión y la sintonización de la BM por activación del MOCR.

(3) El audífono MOC reproduce los beneficios técnicos de la estrategia MOC para ICs ilustrados a través de los espectrogramas (o electrodogramas) de las señales de salida. En otras palabras, el audífono MOC realza las ILDs y/o restaura, al menos parcialmente, el efecto sombra de la cabeza.

(4) El audífono MOC restaura el rango dinámico de audición aplicando compresión no instantánea multicanal.

(5) El beneficio proporcionado por el audífono MOC en tareas de la inteligibilidad del habla en ruido depende de:

a. La programación del audífono.

b. La separación espacial de la máscara y la señal.

c. Las características físicas del ruido. 


\subsection{Objetivos}

El objetivo principal de esta tesis es reducir las deficiencias que sufren los usuarios de audífonos cuando tratan de entender el habla en presencia de otras fuentes sonoras mediante el procesamiento del audífono MOC.

Para la consecución de este objetivo general, es necesario alcanzar los siguientes objetivos específicos:

1. Diseñar e implementar en formato software un audífono binaural que incorpore los principios de la estrategia MOC para implantes cocleares utilizando un compresor no instantáneo.

2. Analizar y describir el funcionamiento del audífono MOC y compararlo, en la medida de lo posible, con:

a. El procesamiento de un audífono convencional.

b. Los efectos del MOCR natural.

3. Diseñar una regla de prescripción de ganancia específica para el audífono MOC en función de los umbrales audiométricos del usuario para restaurar el rango dinámico auditivo.

4. Evaluar objetivamente la SNR a la salida del audífono MOC, así como la inteligibilidad del habla en ruido en personas con hipoacusia cuando escuchan con el audífono MOC y cuando lo hacen con un par de audífonos funcionalmente independientes. 
IV - EL AUDÍFONO MOC 
IV - El audífono MOC 
Esta(s) página(s) se han omitido porque contienen información confidencial de interés industrial 


\section{V - EVALUACIÓN EXPERIMENTAL}


V - Evaluación experimental 


\section{V - Evaluación experimental}

\subsection{Introducción}

La hipótesis general del presente trabajo es que el audífono binaural MOC proporcionará mejor inteligibilidad en ambientes ruidosos que dos audífonos funcionalmente independientes (denominado procesamiento estándar o STD). Este apartado describe una serie de experimentos dirigidos a comprobar esta hipótesis.

La confirmación experimental

de esta predicción teórica es importante por dos razones. Primero, las personas hipoacúsicas, a la hora de entender el habla en ruido se benefician menos de la separación espacial señalmáscara que las personas normoyentes (Bronkhorst y Plomp,1989; véase la revisión de Bronkhorst, 2000). En la medida que este beneficio está ligado a las ILDs generadas por el efecto sombra de la cabeza en alta frecuencia y que la mayoría de la pérdida auditiva neurosensorial es mayor a alta frecuencia, cabe esperar que el uso de dos compresores independientes entre sí, que distorsiona y/o reduce las ILDs, deteriore aún más el desenmascaramiento espacial (Byrne y Noble 1998; Musa-Shufani et al. 2006; Wiggins y Seeber, 2011, 2012). Segundo, Kim et al. (2006) encontraron que para personas normoyentes, la mejora de la inteligibilidad que se obtiene al separar espacialmente las fuentes de habla y de ruido está correlacionada con la fuerza del MOCR contralateral. Esto sugiere que los efectos desenmascarantes del MOCR podrían ser mayores cuando las fuentes de sonido están separadas espacialmente. En la medida en la que los usuarios de audífonos reciben señales con ILDs distorsionadas y carecen de los efectos desenmascarantes del MOCR, parece posible que el audífono MOC mejore la comprensión de habla, especialmente cuando el habla y el ruido están en diferentes ubicaciones espaciales. En este apartado se exploran los beneficios potenciales del audífono MOC sobre la inteligibilidad del habla para diferentes configuraciones espaciales de la máscara y la señal. 


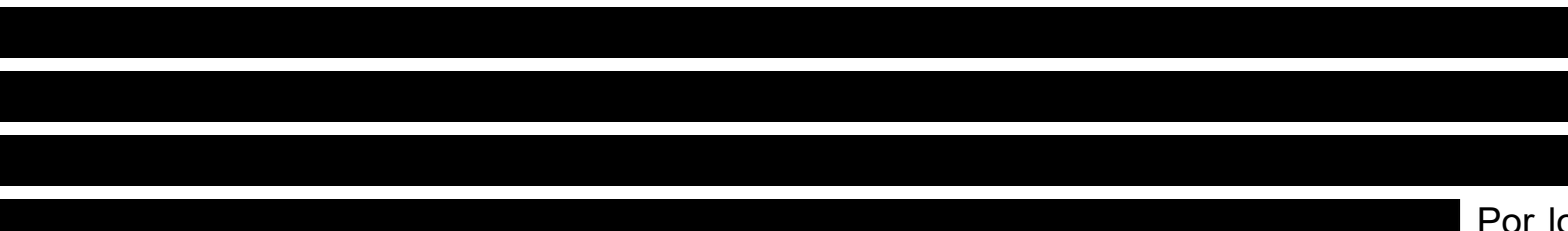

tanto, el audífono MOC podría mejorar la inteligibilidad de diferente forma con máscaras tipo habla o con ruido estacionario. Además, las personas con hipoacusia tienen mayores dificultades para entender el habla, en comparación con las personas normoyentes, cuando el sonido enmascarante es fluctuante, como el habla, que cuando es un ruido estacionario (Festen y Plomp, 1990). Por lo tanto, cualquier beneficio del audífono MOC para reconocer el habla enmascarada por habla sería más representativo del beneficio potencial de este audífono en la escucha natural y tendría un mayor impacto. En este apartado, se investigan los potenciales beneficios del audífono MOC sobre el reconocimiento del habla enmascarado por sonidos fluctuantes (en concreto, por un hablante) y estacionarios.

Los principales objetivos de la evaluación experimental son los siguientes:

(1) Comprobar si la implementación software de los audífonos STD y MOC, así como el software de evaluación están implementados correctamente.

(2) Proponer y evaluar un método de prescripción de ganancia para el audífono MOC.

(3) Investigar si los audífonos implementados y el método de prescripción de ganancia diseñados son adecuados para restaurar la audibilidad.

(4) Investigar si el audífono MOC proporciona mejor inteligibilidad en ruido estacionario que el audífono STD. Este objetivo incluye dos objetivos específicos.

a. Explorar diferentes parámetros temporales del audífono MOC.

b. Explorar los beneficios potenciales del audífono MOC en diferentes configuraciones espaciales.

(5) Investigar si el audífono MOC mejora la inteligibilidad en ruido fluctuante (otro hablante) con diferentes parámetros del audífono MOC.

Para alcanzar estos objetivos se han llevado a cabo dos estudios en los que se comparan los umbrales de recepción verbal medidos con los audífonos STD y MOC. En el Estudio 1, se evaluó el rendimiento del audífono MOC en personas con pérdida conductiva simulada mediante tapones de espuma colocados en el canal auditivo del oyente. Este estudio se considera un estudio piloto, ya que el objetivo principal de la tesis es investigar el posible beneficio del audífono MOC en personas con hipoacusia neurosensorial que, presuntamente, no tienen MOCR o lo 
tienen dañado por ausencia o disfunción de OHCs. En el Estudio 2, se evaluó el rendimiento del audífono MOC en personas con hipoacusia neurosensorial. Se exploró el posible beneficio del audífono MOC con diferentes parámetros de programación, para diferentes ubicaciones de la máscara y la señal, y para diferentes tipos de máscaras. El audífono MOC se programó con diferentes parámetros en cada uno de los dos estudios, tal y como se explica más adelante. A continuación, se describen los métodos experimentales comunes a los dos estudios. Después, se describe cada uno de los dos estudios. Al final del apartado, se presentan las principales conclusiones de los dos estudios.

\subsection{Métodos generales}

Esta sección describe los métodos generales aplicables a ambos estudios. Los métodos particulares de cada estudio se describen más adelante.

\subsubsection{Procedimiento}

Ambos estudios incluyeron tres fases: (1) selección de los participantes atendiendo a criterios audiológicos (anamnesis, otoscopia y audiometría tonal); (2) adaptación de la ganancia del audífono acorde a la pérdida audiométrica de cada participante; (3) medición de los SRTs en las diferentes condiciones experimentales. Todos los sonidos se procesaron a través de implementaciones software de los audífonos STD y MOC, y se presentaron al oyente mediante auriculares.

\subsubsection{Umbrales de recepción verbal}

Los SRTs se midieron usando un procedimiento adaptativo tipo "uno-arriba, uno-abajo" (Levitt, 1971). Para medir cada SRT, se presentaron 30 oraciones. Las primeras 10 oraciones siempre fueron las mismas y se presentaron en orden aleatorio para dar al oyente la oportunidad de familiarizarse con la tarea. La SNR disminuyó cada vez que el oyente reconoció una frase completa, y aumentó cada vez que falló al menos una palabra de la frase. La disminución o el aumento de la SNR fue de $4 \mathrm{~dB}$ de las oraciones 1 y 14 y de $2 \mathrm{~dB}$ de las oraciones 14 y 30 . El SRT se calculó como la media de las SNRs a las que se presentaron las 17 últimas oraciones. En las condiciones con un sonido enmascarante (ruido estacionario u otro hablante), la 
intensidad del habla se mantuvo constante a $-55 \mathrm{~dB}$ FS y la intensidad de la máscara se varió de forma adaptativa partiendo de una SNR de $20 \mathrm{~dB}$. En las condiciones sin máscara (referidas como condiciones "en silencio"), la intensidad del habla osciló adaptativamente partiendo de -55 dB FS. Como referencia, con los auriculares empleados (descritos más adelante) el nivel de la señal de $-55 \mathrm{~dB}$ FS corresponde, aproximadamente, a $65 \mathrm{~dB}$ SPL.

Se instruyó a los participantes para que repitieran cada oración presentada durante la prueba. Se consideró que la oración se reconoció correctamente solo cuando el oyente reconoció todas las palabras de la oración. No se informó a los participantes de los aciertos ni de los fallos en el reconocimiento de las palabras o las oraciones.

\subsubsection{Orden de presentación de las condiciones}

Las condiciones experimentales, definidas como la combinación de audífono y configuración espacial, se pasaron en orden aleatorio. Ni el experimentador ni el participante fueron informados del audífono que se estaba probando en ningún momento (enfoque doble ciego). Por cada condición experimental, en la mayoría de los casos se midieron al menos tres SRTs y el promedio de las tres medidas se consideró el SRT final.

\subsubsection{Configuraciones espaciales}

La mayoría de las evaluaciones se realizaron simulando escucha en campo libre mediante auriculares. Para ello, se filtraron grabaciones monofónicas de cada oración con las respuestas impulso de la cabeza (HRIR, del inglés head-related impulse response) de campo difuso para un maniquí de KEMAR (Knowles Inc, USA) medidas a $1.2 \mathrm{~m}$ de distancia del centro de la cabeza del maniquí (Gardner y Martin, 1995). En todos los casos, el ángulo de elevación fue de $0^{\circ}$; es decir, las fuentes de sonido del habla y la máscara estaban al nivel de los ojos.

En la medida de lo posible, el Estudio 2 también incluyó medidas del rendimiento de los participantes con sus propios audífonos, con el objetivo de obtener un valor referencia de rendimiento con el audífono comercial. Estas medidas se realizaron en 'campo libre' reproduciendo los sonidos a través de un altavoz colocado a la altura del ojo a $1 \mathrm{~m}$ de distancia frente al oyente. Los estímulos se filtraron para minimizar los efectos de la acústica de la sala en el espectro del estímulo. El filtro era tal que un ruido con un espectro igual al espectro de habla a largo plazo, emitido por el altavoz, tendría el espectro promedio de habla a largo plazo cuando 
se registra con un micrófono colocado en la posición de la cabeza del oyente (Lopez-Poveda et al., 2017b).

\subsubsection{Participantes}

En total participaron 17 personas (véase la Tabla 5.1). En el Estudio 1 participaron cinco personas normoyentes. En el Estudio 2, participaron 12 personas hipoacúsicas, aunque no todas ellas realizaron todas las pruebas. Para cada oído de los participantes, se midieron los umbrales audiométricos por vía aérea y vía ósea en las frecuencias de $0.25,0.5,1.0,2.0,4.0$ y $8 \mathrm{kHz}$ utilizando un audiómetro clínico (Interacoustics AD229e). En el Estudio 2, se consideró que un participante con hipoacusia era candidato para utilizar audífono cuando su pérdida de audición superó los $35 \mathrm{~dB} \mathrm{HL}$ al promediar los umbrales audiométricos en 0,5, 1 y $2 \mathrm{kHz}$, o $45 \mathrm{~dB} \mathrm{HL}$ al promediar los umbrales en 3, 4 y $6 \mathrm{kHz}$, en cualquier oído.

Todos los participantes eran hablantes nativos de castellano y dieron su consentimiento por escrito antes de ser admitidos en el estudio.

Tabla 5.1. Datos de los participantes. PTA: umbral audiométrico tonal promedio (dB HL) en las frecuencias de $0.5,1$ y $2 \mathrm{kHz}$. I: izquierdo. D: derecho. ${ }^{\circ} \mathrm{HA}$ : número de audífonos que utilizaba el participante al ser admitido en el estudio [en el caso de usar solo un audífono, se indica el oído (I o D) en el que lo usaba].

\begin{tabular}{lcccrrr}
\hline \multicolumn{1}{c}{ ID } & Sexo & Estudio & Oído test & I-PTA & D-PTA & $\mathrm{n}^{\circ} \mathrm{HA}$ \\
\hline $\mathrm{NH}-310$ & $\mathrm{~F}$ & 1 & $\mathrm{I}$ & 41.7 & 40.6 & - \\
$\mathrm{NH}-314$ & $\mathrm{~F}$ & 1 & $\mathrm{D}$ & 36.7 & 38.3 & - \\
$\mathrm{NH}-451$ & $\mathrm{M}$ & 1 & $\mathrm{I}$ & 33.3 & 34.4 & - \\
$\mathrm{NH}-358$ & $\mathrm{M}$ & 1 & $\mathrm{D}$ & 38.9 & 45.6 & - \\
$\mathrm{NH}-459$ & $\mathrm{M}$ & 1 & $\mathrm{I}$ & 35.0 & 35.0 & - \\
$\mathrm{IH}-057$ & $\mathrm{~F}$ & 2 & $\mathrm{I}$ & 38.3 & 45.0 & 2 \\
$\mathrm{IH}-094$ & $\mathrm{~F}$ & 2 & $\mathrm{D}$ & 41.7 & 38.3 & 0 \\
$\mathrm{IH}-134$ & $\mathrm{~F}$ & 2 & $\mathrm{I}$ & 40.0 & 41.7 & $\mathrm{D}$ \\
$\mathrm{IH}-097$ & $\mathrm{M}$ & 2 & $\mathrm{D}$ & 61.7 & 58.3 & $\mathrm{I}$ \\
$\mathrm{IH}-173$ & $\mathrm{M}$ & 2 & $\mathrm{D}$ & 41.7 & 36.7 & 2 \\
$\mathrm{IH}-116$ & $\mathrm{M}$ & 2 & $\mathrm{D}$ & 63.3 & 56.7 & 2 \\
$\mathrm{IH}-084$ & $\mathrm{M}$ & 2 & $\mathrm{I}$ & 43.3 & 46.7 & 0 \\
$\mathrm{IH}-152$ & $\mathrm{~F}$ & 2 & $\mathrm{I}$ & 53.3 & 63.3 & 2 \\
$\mathrm{IH}-142$ & $\mathrm{M}$ & 2 & $\mathrm{D}$ & 66.6 & 61.6 & $\mathrm{D}$ \\
$\mathrm{IH}-180$ & $\mathrm{M}$ & 2 & $\mathrm{D}$ & 35.0 & 25.0 & 2 \\
$\mathrm{IH}-511$ & $\mathrm{~F}$ & 2 & $\mathrm{I}$ & 46.6 & 46.6 & 0 \\
$\mathrm{IH}-045$ & $\mathrm{M}$ & 2 & $\mathrm{I}$ & 56.6 & 71.6 & 2 \\
\hline
\end{tabular}

\subsubsection{Programación de los audífonos STD y MOC}

A la hora de programar un audífono no lineal, hay evidencias que sugieren que un procedimiento lineal bien validado constituye un buen punto de partida para decidir la ganancia a aportar para 
Esta(s) página(s) se han omitido porque contienen información confidencial de interés industrial 
los valores positivos de SRT benefit indican que el SRT fue mejor (más bajo) con el audífono MOC que con el STD. Por el contrario, los valores negativos indican que el SRT fue peor (más alto) con el audífono MOC que con el STD.

El error estándar del beneficio ( $\left.\mathrm{SE}_{\text {benefit }}\right)$ se calculó de la siguiente forma:

$$
S E_{\text {Benefit }}=\sqrt{\frac{S D_{S T D}^{2}+S D_{M O C}^{2}}{N}}
$$

donde $\mathrm{SD}_{\text {STD }}$ y $\mathrm{SD}_{\text {MOC }}$ denotan la desviación estándar de los SRTs medidos con los audífonos STD y MOC, respectivamente, y $\mathrm{N}$ el número total de SRTs obtenidos con cada audífono en cada condición (típicamente $\mathrm{N}=3$ ).

Se utilizaron análisis de medidas repetidas para evaluar el efecto del audífono, de la configuración espacial máscara-señal, y su interacción sobre los SRTs. Cuando los datos se ajustaron a una distribución Gaussiana, se emplearon pruebas estadísticas paramétricas, como el análisis de la varianza de medidas repetidas (RMANOVA). En caso contrario, se emplearon pruebas no paramétricas (test de Friedman por rangos). Las pruebas concretas se describen en cada estudio. En todos los casos, se consideró que un efecto fue estadísticamente significativo cuando la probabilidad de observarlo por casualidad era menor del $5 \%$ ( $p \leq 0.05)$. Las comparaciones post hoc por parejas se realizaron empleando ANOVA o test de Wilcoxon con signos, y el nivel de significación se determinó después de aplicar la corrección de Bonferroni para comparaciones múltiples. Todos los análisis estadísticos se realizaron utilizando IBM SPSS para Windows v. 23.

\subsection{Estudio 1}

En este estudio piloto, se evaluó el rendimiento del audífono MOC programado con un compresor relativamente lento (al que denominaremos MOC1) en comparación con el audífono STD. Por conveniencia, y al tratarse de un estudio piloto, la evaluación se realizó en personas normoyentes con pérdida auditiva conductiva simulada mediante tapones para los oídos.

Se realizaron dos bloques de experimentos. En primer lugar, para comprobar que los audífonos y el software de evaluación estaban implementados correctamente, se midieron los SRTs en silencio con estimulación diótica (idéntica señal en ambos oídos) en tres condiciones: 
(1) Condición NH. Sin tapones para los oídos y usando un audífono STD programado linealmente con ganancia cero (STD-LinG0). Esta condición se incluyó como referencia.

(2) Condición HI. Igual que (1) pero con tapones para los oídos. Esta condición se incluyó para comprobar el efecto de la pérdida auditiva simulada sobre la inteligibilidad en ausencia de amplificación. Es decir, si la simulación de pérdida de audición era exitosa, los SRTs serían peores (más altos) en esta condición que en la condición $\mathrm{NH}$.

(3) Condición HI-HA. Con tapones para los oídos y usando el audífono STD programado para compensar la pérdida de audibilidad ocasionada por los tapones. Si el audífono STD fuese adecuado, los SRTs deberían ser mejores en esta condición que en la Condición HI y comparables a los obtenidos en la Condición $\mathrm{NH}$.

En segundo lugar, para investigar si el audífono MOC proporciona mejor inteligibilidad en ruido estacionario que el audífono STD, se midieron los SRTs de los participantes con señales dicóticas.

Los participantes (con pérdida conductiva simulada y amplificación) realizaron las pruebas con el audífono STD y con dos programaciones diferentes del audífono MOC1 (descritas más adelante en la Sección 5.3.1) en diferentes configuraciones espaciales de la señal y la máscara:

(1) Condición SLNF. La señal se encontraba a la izquierda del oyente y la máscara en frente (ángulos azimutales de $270^{\circ}$ y $0^{\circ}$, respectivamente). En esta condición espacial el procesamiento binaural MOC hace que la máscara, al ser idéntica en ambos oídos, se inhiba por igual en los dos oídos, reduciendo así su intensidad. La señal, por el contrario, se inhibe en mayor medida en el oído derecho que en el izquierdo.

(2) Condición SFNR. La señal se encontraba en frente y la máscara a la derecha del oyente (ángulos azimutales de $0^{\circ}$ y $90^{\circ}$, respectivamente). Esta condición se propuso para explorar los beneficios del procesamiento binaural MOC en comparación con la condición SLNF.

(3) Condición SLNR. La señal se encontraba a la izquierda y el ruido a la derecha del oyente (azimuts de $270^{\circ}$ y $90^{\circ}$, respectivamente). La señal predomina en el oído izquierdo y la máscara en el derecho y como consecuencia de la inhibición MOC mutua entre oídos se espera una señal más clara en el oído izquierdo y un ruido 'más claro' en el oído derecho.

A continuación, se dan más detalles. 


\subsubsection{Material y métodos}

A menos que se indique lo contrario, los procedimientos y el equipo fueron idénticos a los descritos en la Sección 5.2 (Métodos Generales).

\section{Participantes}

En este estudio participaron cinco adultos normoyentes con edades entre 23 y 27 años (Tabla 5.1).

Para simular una pérdida auditiva conductiva, se probaron diferentes tipos de tapones para los oídos (para más detalles, véase el Apéndice B). Las principales diferencias entre los tapones fueron el material, la forma y el método para introducirlos en el canal auditivo. Se evaluaron todos los tipos de tapones para los oídos comparando la pérdida audiométrica causada por los tapones. Finalmente, se eligieron los tapones 3M E-A-R Classic pues produjeron la máxima pérdida auditiva. La Tabla 5.2 muestra los umbrales audiométricos promedio (de tres medidas) de cada participante con estos tapones.

Tabla 5.2. Umbrales audiométricos medios (dB HL) de los participantes normoyentes del Estudio 1 con los tapones seleccionados 3M E-A-R Classic.

\begin{tabular}{c|cccccc|cccccc|}
\cline { 2 - 12 } & \multicolumn{4}{|c|}{ Oído izquierdo } & \multicolumn{5}{c|}{ Oído derecho } \\
\cline { 2 - 13 } & \multicolumn{4}{c|}{ Frecuencia (Hz) } & \multicolumn{5}{c|}{ Frecuencia (Hz) } \\
\hline Participante & 250 & 500 & 1000 & 2000 & 4000 & 8000 & 250 & 500 & 1000 & 2000 & 4000 & 8000 \\
\hline NH-310 & 32 & 42 & 45 & 45 & 47 & 58 & 30 & 40 & 47 & 35 & 43 & 52 \\
NH-314 & 23 & 33 & 38 & 38 & 55 & 53 & 30 & 35 & 38 & 42 & 53 & 60 \\
NH-451 & 32 & 32 & 37 & 32 & 35 & 53 & 33 & 32 & 38 & 33 & 37 & 57 \\
NH-358 & 28 & 37 & 38 & 42 & 55 & 65 & 37 & 52 & 45 & 40 & 60 & 75 \\
NH-459 & 32 & 32 & 35 & 38 & 47 & 58 & 33 & 30 & 33 & 42 & 50 & 53 \\
\hline
\end{tabular}

\section{Los audífonos MOC}

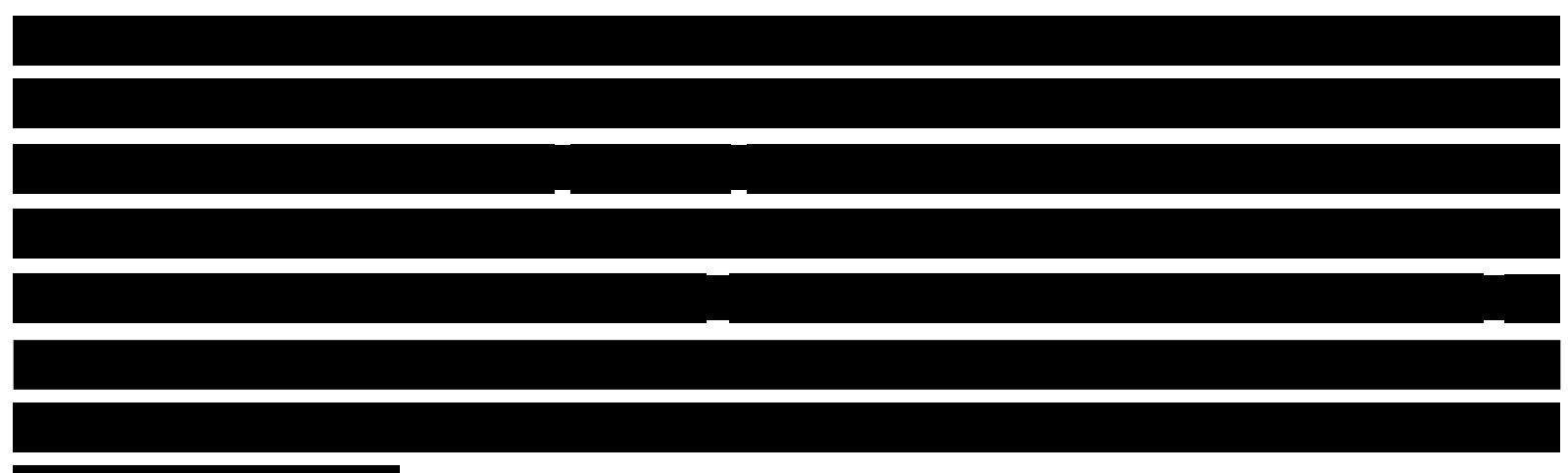




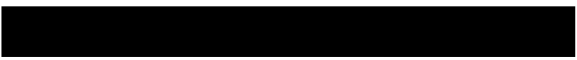

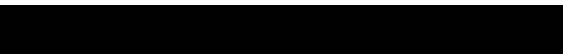

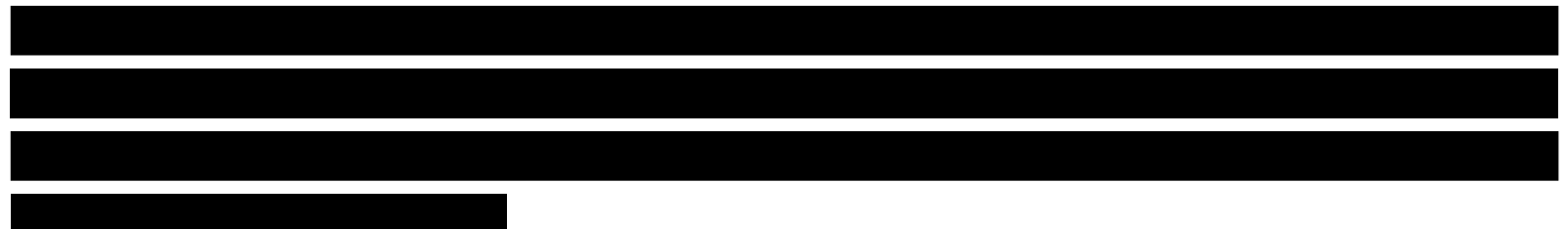

\section{Estímulos}

Los SRTs se midieron empleando las oraciones de la prueba matricial en español (Hochmuth et al., 2012). Estas oraciones tienen una estructura gramatical fija que incluye un nombre, un verbo, un número, un objeto y un adjetivo. Debido a que la declinación del adjetivo en español depende del género, solo contienen objetos masculinos, lo que permite una combinación aleatoria de todas las palabras de la matriz de palabras. Cada oración se presentó precedida de $500 \mathrm{~ms}$ silencio, con el fin de asegurar que el control contralateral de la compresión estaba totalmente activo al momento de presentarse la oración. En las condiciones con ruido, se empleó un ruido Gaussiano (estacionario) filtrado para tener el espectro del habla (SSN, del inglés Speech Shaped Noise) que comenzó también 500 ms antes de la oración.

\subsubsection{Resultados}

\section{Restauración de la audibilidad en silencio}

La Figura 5.3 ilustra los SRTs en silencio en las tres condiciones de escucha evaluadas: $\mathrm{NH}, \mathrm{HI}$ y HI-HA. Recuerde que, al tratarse de medidas en silencio, cuanto más negativo sea el SRT, mejor es la inteligibilidad del habla y, por tanto, mayor es la audibilidad.

Los SRTs fueron mejores (más bajos) en la condición NH (es decir, con audición normal, sin tapones ni amplificación) que en cualquier otra condición. El uso de tapones redujo la audibilidad e incrementó el SRT medio en $38 \mathrm{~dB}$. El audífono STD, programado de acuerdo a la pérdida conductiva simulada de cada participante, restauró la audibilidad, y disminuyó (mejoró) el SRT medio hasta -95 dB FS, un valor prácticamente normal (-100 dB FS). 
La prueba de Friedman por rangos confirmó un efecto significativo de la condición experimental $\left[\chi^{2}(2)=8.4, p=0.015\right]$. El análisis post hoc con la prueba de rangos Wilcoxon demostró que los SRTs fueron significativamente mejores en la condición $\mathrm{NH}$ que en la $\mathrm{HI}(p=0.043)$, en la condición HA-HI que en la $\mathrm{HI}(p=0.043)$. Por el contrario, la comparación de los SRTs entre la condición HI-HA y la condición $\mathrm{NH}$ mostró un efecto no significativo $(\mathrm{p}=0.08)$.

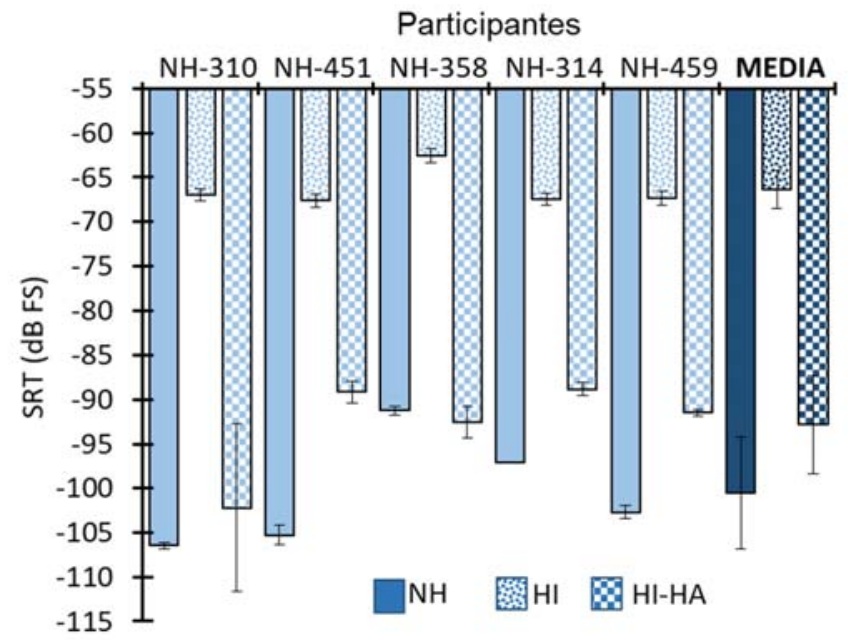

Figura 5.3. Umbrales de recepción verbal en silencio en las condiciones $\mathrm{NH}$ (sin tapones), $\mathrm{HI}$ (con tapones) y HI-HA (con tapones y amplificación). Se ilustran datos individuales para cinco participantes. Cada barra ilustra el promedio de tres medidas. Las barras de error ilustran un error estándar de la media. También se ilustra el promedio de los cinco participantes y su erro estándar.

\section{El efecto del procesamiento MOC sobre los SRTs en silencio}

La Figura 5.4 ilustra los SRTs de los cinco participantes con los audífonos STD, MOC1a y MOC1b en silencio y para una señal ubicada frente al oyente $\left(0^{\circ}\right.$ de azimut). Como puede observarse, los SRTs fueron similares con los tres audífonos. EI RMANOVA demostró que el tipo de audífono no tuvo un efecto significativo sobre los SRTs $[F(2,8)=1,743, p=0,235]$. 


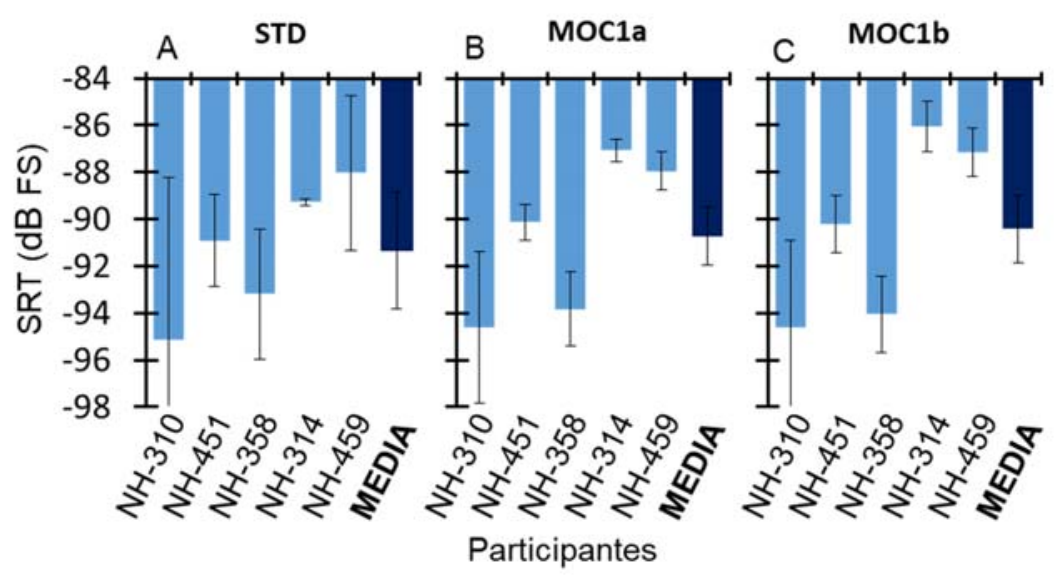

Figura 5.4. Umbrales de recepción verbal (individuales y promedio) con los tres audífonos (STD, MOC1a y MOC1b) en silencio y para una señal ubicada a $0^{\circ}$ de azimut. Cada barra ilustra el promedio de tres medidas; las barras de error ilustran \pm un error estándar de la media.

\section{El efecto del procesamiento MOC sobre los SRTs en ruido estacionario}

La Figura 5.5 ilustra los SRTs de los cinco participantes en ruido SSN con los tres audífonos (STD, MOC1a y MOC1b) y para tres configuraciones espaciales de la señal y el ruido (SRNL, SLNF y SFNR). Cada fila ilustra resultados para un audífono diferente y cada columna para una configuración espacial diferente.

La prueba de Friedman por rangos confirmó un efecto significativo de la condición experimental $\left[\chi^{2}(8)=26.5, p=0.001\right]$. El análisis post hoc con la prueba de rangos Wilcoxon demostró que los SRTs fueron significativamente mejores para algunas condiciones espaciales y con un mismo audífono. En concreto, los SRTs fueron significativamente mejores en la condición espacial: SLNR que en SFNR para el STD ( $p=0.043)$; SLNR que en SLNF para el STD $(p=0.043)$, SLNR que en SFNR para el MOC1a $(p=0.043)$ y SLNR que en SLNF para el MOC1b $(p=0.043)$. Es decir, en algunos casos, los SRTs mejoraron al aumentar la separación espacial entre la señal y la máscara, pero no se observaron diferencias significativas entre los audífonos. Nótese que los valores de $p$ coinciden en las cuatro comparaciones destacadas. Probablemente esto se debe a que la muestra es pequeña $(\mathrm{N}=5)$ y que la significancia se determina en los cuatro casos mediante rangos positivos. 


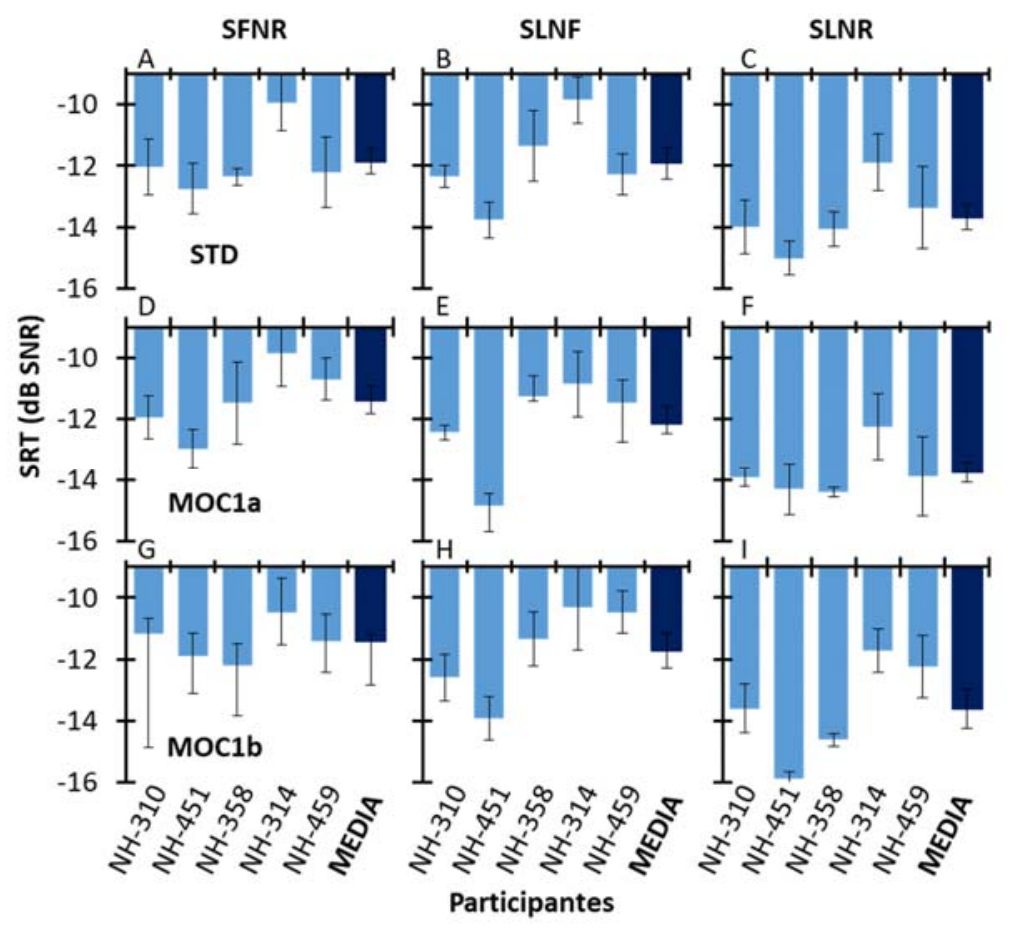

Figura 5.5. Umbrales de recepción verbal en ruido estacionario obtenidos con los audífonos STD (fila superior), MOC1a (fila del medio), y MOC1b (fila inferior). Cada columna ilustra resultados para una configuración espacial diferente de las fuentes de habla $y$ ruido, tal y como se indica en los títulos de la columna. Se ilustran datos individuales para cinco participantes. Cada barra ilustra la media de tres medidas y las barras de error un error estándar. También se ilustra la media y error estándar de los cinco participantes.

\subsubsection{Discusión}

En este estudio piloto, se ha evaluado el rendimiento del audífono STD y de dos audífonos MOC, diferentes entre sí en los tiempos de relajación de sus compresores, midiendo SRTs en personas normoyentes con pérdida auditiva conductiva simulada mediante tapones para los oídos. Se ha demostrado que los tres audífonos evaluados entregan ganancia suficiente para restaurar una audibilidad 'normal'. Sin embargo, ninguno de los dos audífonos MOC evaluados mejoran la inteligibilidad en ruido estacionario con respecto al audífono STD en ninguna de las tres configuraciones espaciales simuladas.

Al igual que otros autores (Irving y Moore, 2011; Lupo et al., 2011), aquí también se ha supuesto que la atenuación inducida por tapones para los oídos simula una pérdida conductiva. En este estudio, los participantes sufrieron una pérdida audiométrica media de $38 \mathrm{~dB}$, lo que parece suficiente para valorar si la compresión entregada por los audífonos es beneficiosa (Plomp, 1978). Para comprobar que la pérdida conductiva simulada es equivalente a una pérdida auditiva real, se ha calculado la pérdida auditiva del habla (SHL, del inglés Speech Hearing Loss) y comparado con la PTA. En personas con pérdida auditiva real, la PTA es una buena aproximación de SHL (Plomp, 1978). La SHL se define como la diferencia entre el SRT de un individuo o grupo con pérdida auditiva y el SRT de sujetos jóvenes, normoyentes en la misma 
situación (Plomp, 1978). Aquí, la SHL se puede calcular como la diferencia entre el SRT para cada sujeto cuando no usa tapones para los oídos y cuando los usa. La Tabla 5.3 muestra que, en promedio para el grupo de participantes, la PTA y la SHL fueron similares (diferencia de 3 $\mathrm{dB}$ ). En conjunto, los resultados sugieren que el empleo de tapones para los oídos en personas con audición normal es un modelo razonable para estudiar los efectos de la amplificación sobre la inteligibilidad en silencio. Sin embargo, hay que tener en cuenta que, dado que los participantes tienen audición normal, y por tanto un MOCR sano, el modelo empleado podría no ser adecuado para evaluar los beneficios de un audífono que imita los efectos del MOCR natural.

El hecho de que los SRTs en silencio con tapones y amplificación fueran comparables a los obtenidos con audición normal demuestra que la regla de prescripción de ganancia diseñada es adecuada para compensar la pérdida auditiva, tanto con el audífono STD como con los audífonos MOC. Típicamente las reglas de prescripción recomiendan ganancias entre $1 / 2$ y $2 / 3$ de la PTA (véase Pascoe, 1988; Byrne et al., 2001). Probablemente nuestra regla de ganancia recomienda valores similares al estar basada en NAL-RP. Esto se puede comprobar. Teniendo en cuenta que el SRT en silencio es proporcional al nivel de los sonidos recibidos en el oído (Plomp, 1978), el incremento de SRT entre la condición $\mathrm{HI}$ y la condición HI-HA debe ser proporcionar a la ganancia que aplica el audífono. En la Tabla 5.3 denotamos a esta diferencia AMP. Considerando un PTA promedio de $38 \mathrm{~dB}$, tenemos que 2/3×PTA es igual a $25.3 \mathrm{~dB}$, que se asemeja al valor AMP promedio $(26.1 \mathrm{~dB})$. En resumen, la ganancia que aportan los audífonos STD y MOC es similar a la dada por otras reglas y suficiente para restaurar una audibilidad 'normal'.

Tabla 5.3. Datos de los participantes para las condiciones en silencio con el audífono STD. PTA: promedio de los umbrales audiométricos a 500,1000 y $2000 \mathrm{~Hz}$ de cada oído (I-PTA, oído izquierdo y D-PTA oído derecho). SHL: Diferencias de SRTs entre la condición NH y HI. AMP: diferencia de SRTs entre las condiciones HI y HI-HA. La columna de la derecha muestra el promedio de las medidas y su desviación estándar (SD).

\begin{tabular}{ccccccc} 
& \multicolumn{5}{c}{ Participante } \\
\hline I-PTA (dB) & 41.7 & 36.6 & 33.3 & 38.9 & 35.0 & $37.1 \pm 3.3$ \\
D-PTA (dB) & 40.6 & 38.3 & 34.4 & 45.6 & 35.0 & $38.8 \pm 4.7$ \\
SHL (dB) & 39.9 & 37.6 & 28.7 & 29.6 & 35.4 & $34.2 \pm 4.9$ \\
AMP (dB) & 35.5 & 21.5 & 30.0 & 20.5 & 22.8 & $26.1 \pm 6.5$ \\
\hline
\end{tabular}


puede no ser adecuado para evaluar los beneficios de un audífono que imita los efectos del MOCR natural. A pesar de esto, probablemente esta no es la principal razón de la ausencia de beneficio con los audífonos MOC. La principal razón probablemente sea que el control contralateral de la compresión es poco efectivo en los audífonos MOC evaluados, y por tanto dominan los efectos de la compresión no instantánea. La ausencia de beneficio en ruido estacionario con los audífonos MOC evaluados en este estudio puede deberse a una o varias de las siguientes razones.

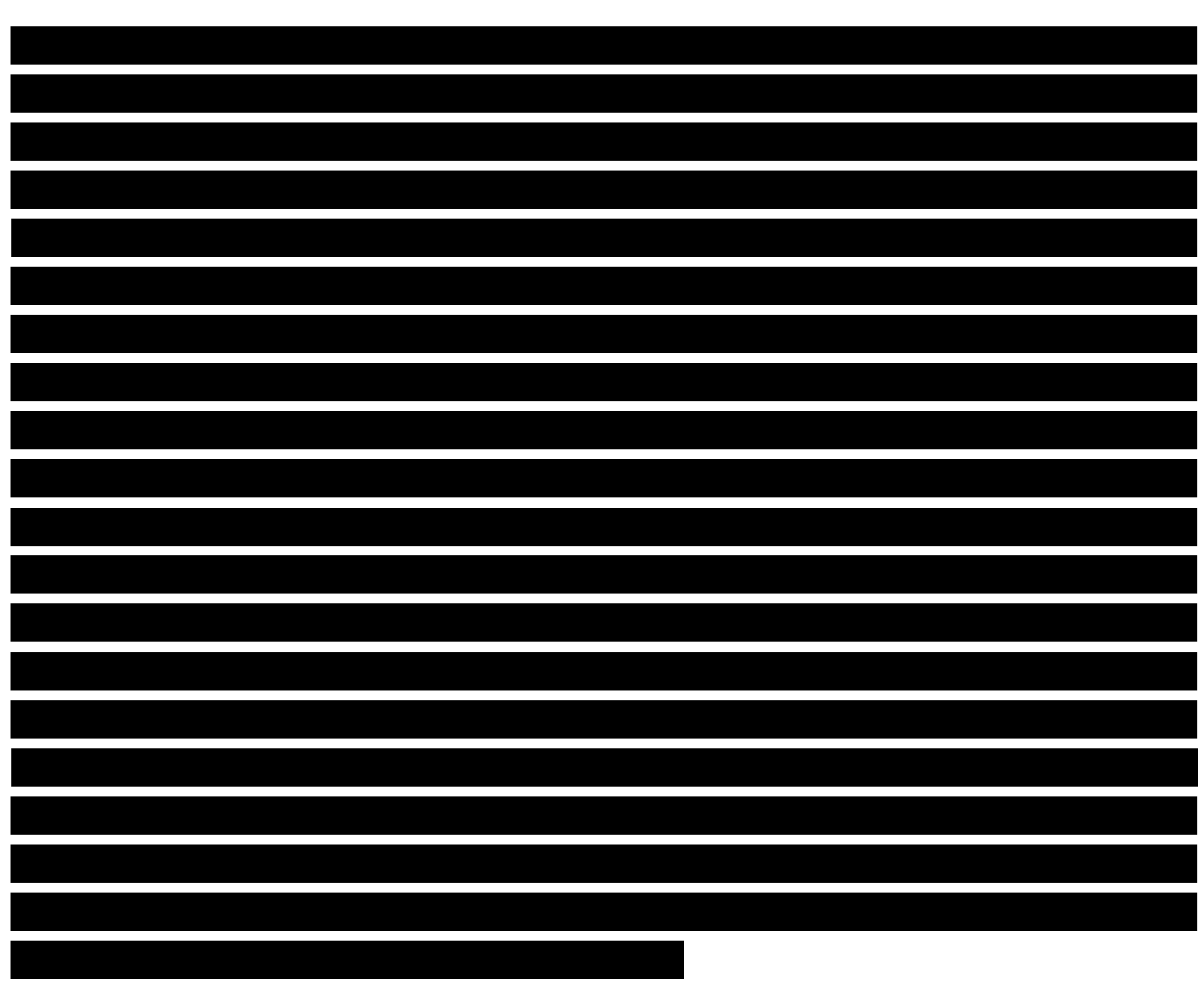




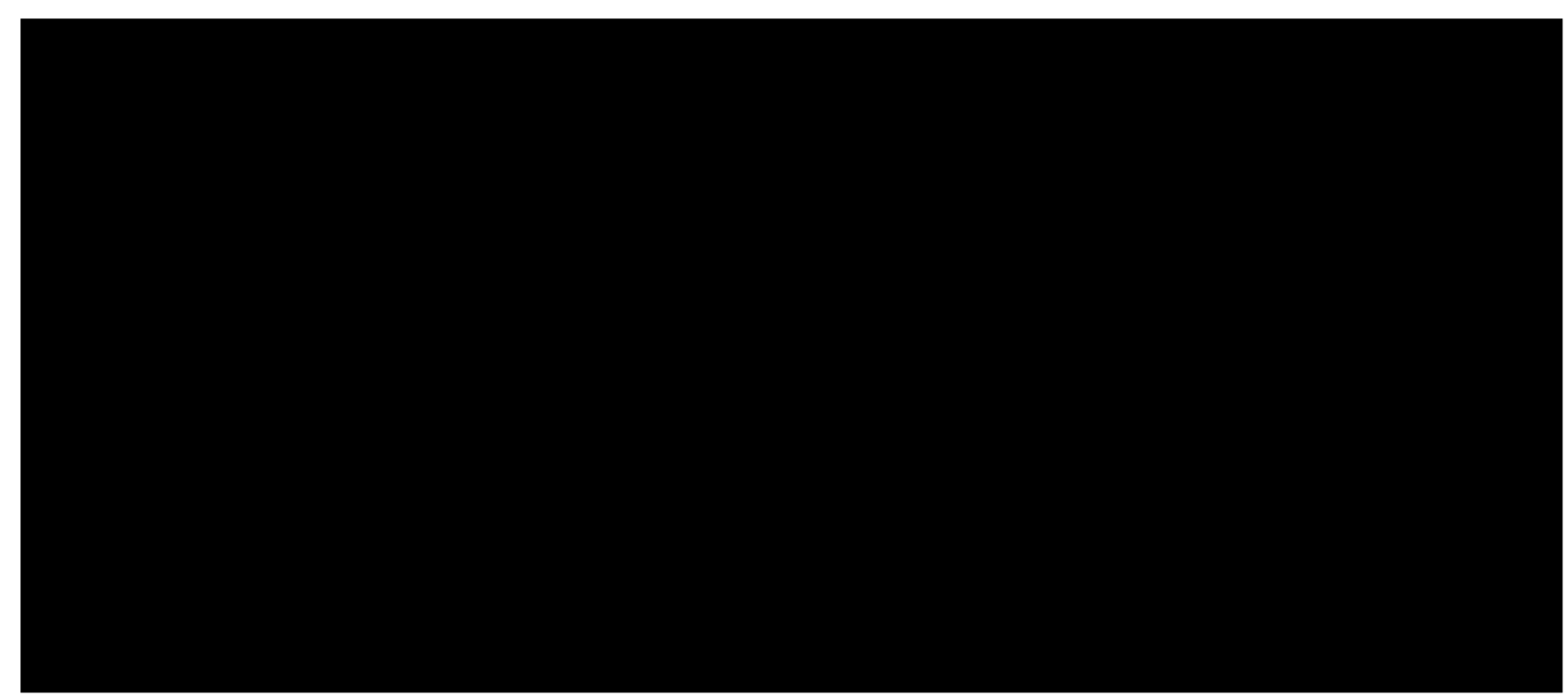

En resumen, hasta donde el modelo de pérdida auditiva empleado es fiable, este estudio piloto ha servido para demostrar que los audífonos (STD y MOC) y el software de evaluación están correctamente implementados (Objetivo 1). Además, ha demostrado que el audífono MOC programado con compresores de acción lenta restaura la audibilidad en silencio (Objetivo 2) pero no mejora la inteligibilidad en ruido estacionario (Objetivo 3). El Estudio 2 que se describe a continuación tuvo como objetivo explorar el beneficio del audífono MOC en personas con 
hipoacusia neurosensorial simétrica con una programación que corrige algunas de las limitaciones del audífono MOC con compresores de acción lenta. Estas correcciones van desde una prescripción de la ganancia igual para los dos oídos, una función de control centrada en el rango típico del habla, y dinámica (tiempo relajación del compresor y constante lenta de la ventana de integración contralateral) más rápida con el objetivo de preservar el curso temporal de la inhibición natural (Sección 4.3.2) y explorar los beneficios encontrados en los espectrogramas (Sección 4.3.5).

\subsection{Estudio 2}

El objetivo principal de este estudio fue evaluar los posibles beneficios del audífono MOC para mejorar la inteligibilidad de las personas hipoacúsicas en ambientes ruidosos. Difiere del Estudio 1 en tres aspectos fundamentales. El primero, y más importante, es que la evaluación se realizó en usuarios de audífonos o candidatos a usarlos. La segunda diferencia es que al contrario del Estudio 1 , en el que el audífono MOC se programó con compresores lentos, en este estudio el audífono MOC se programó con un compresor de acción muy rápida,

En adelante, nos referiremos a este audífono como MOC2 (Tabla 4.4).

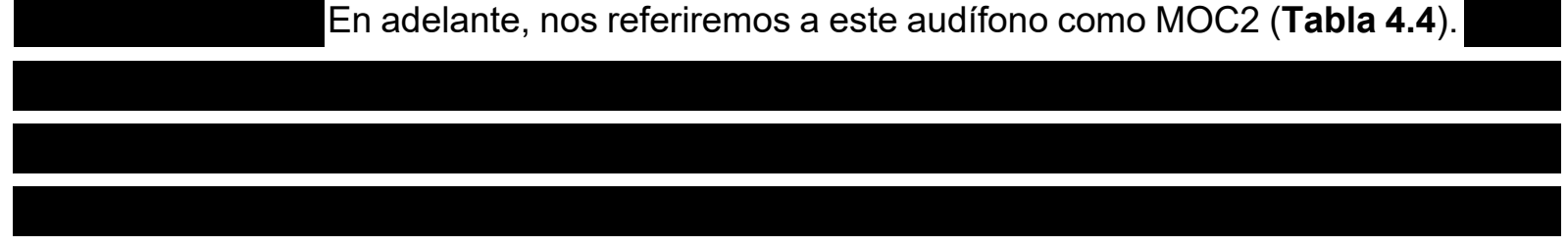
La tercera diferencia con respecto al Estudio 1 es que, en este estudio, se evalúa el efecto del audífono MOC sobre el reconocimiento del habla enmascarado tanto por ruido estacionario (tipo SSN) como por máscaras fluctuantes (un solo hablante).

Se realizaron dos bloques de experimentos en diferentes periodos de tiempo y sobre muestras distintas de participantes. En el primer bloque, se midieron SRTs para oraciones enmascaradas por ruido tipo SSN procesadas con el audífono MOC2a (reproduce con mayor fidelidad el curso temporal de la inhibición del MOCR natural) y con un audífono STD en diez personas con hipoacusia neurosensorial $(\mathrm{HI})$ usuarios de audífonos o candidatos a usarlos. Las comparaciones se realizaron para tres configuraciones espaciales de las fuentes de habla y ruido:

- Condición SFNF: con las fuentes de habla y ruido frente al oyente (a $0^{\circ}$ azimut). En este caso, el audífono MOC inhibe por igual los dos oídos reduciendo el nivel sonoro total, lo que quizás 
podría reducir la audibilidad y, por tanto, obtener un peor rendimiento con el audífono MOC2a que con el STD.

- Condición SFNR: con la fuente de habla frente al oyente y la de ruido a la derecha del oyente (azimuts de $0^{\circ}$ y $90^{\circ}$, respectivamente). El procesamiento binaural MOC implica que el habla se inhiba por igual en los dos oídos. El ruido, en cambio, se inhibe más en el oído izquierdo que en el derecho. Como resultado se espera que el audífono MOC entregue una mejor SNR que el audífono STD, sobre todo en el oído izquierdo.

- Condición SLNR: con la fuente de habla a la izquierda y la de ruido a la derecha del oyente (azimuts de $270^{\circ}$ y $90^{\circ}$, respectivamente). En esta configuración, cabe esperar el máximo beneficio de las tres, ya que el habla sería más clara en el oído izquierdo y el ruido en el derecho.

Además, se incluyó una condición en silencio para condiciones de escucha unilaterales y bilaterales con el objetivo de investigar si los audífonos implementados y el método de prescripción de ganancia diseñados son adecuados para restaurar la audibilidad en personas hipoacúsicas. Esta condición es útil para saber si la ganancia MOC deteriora la audibilidad.

En el segundo bloque, se evaluaron los posibles beneficios del audífono MOC2 sobre la inteligibilidad del habla enmascarado por otro hablante (ruido fluctuante) y con la fuente de habla y ruido ubicadas a $345^{\circ}$ y $15^{\circ}$ de azimut, respectivamente, es decir, con un sonido enmascarante y una configuración espacial más representativa de la escucha natural (Grange y Culling, 2016). Se midieron SRTs en ocho personas con hipoacusia neurosensorial (usuarios de audífonos o candidatos a usarlos) con el audífono STD y con audífonos MOC2 programados de tres formas diferentes:

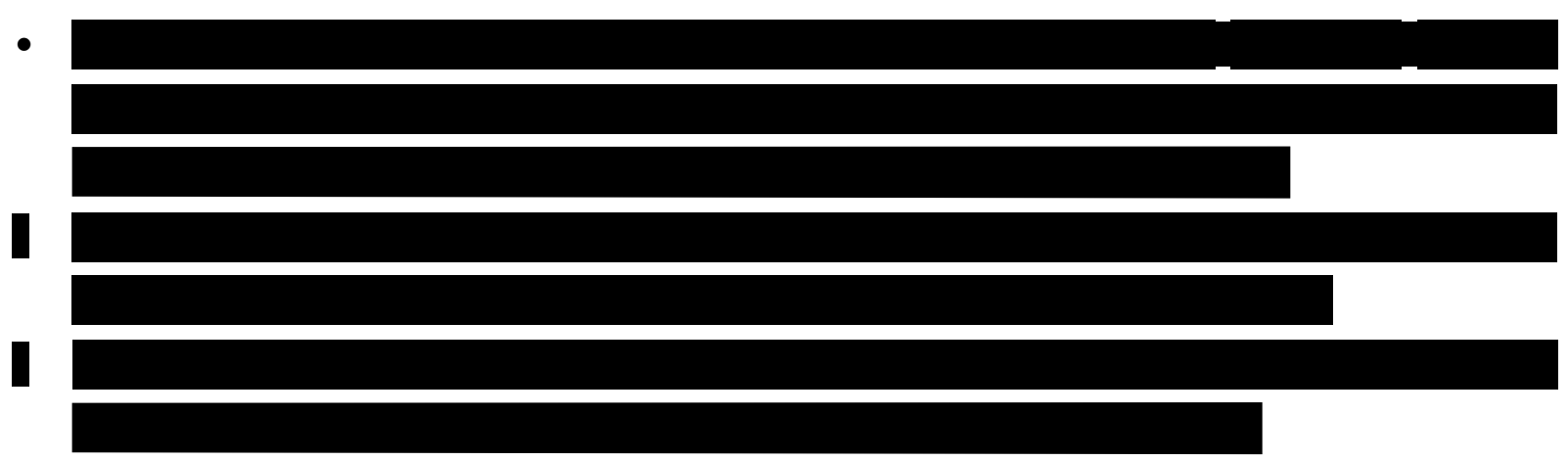

A continuación, se dan más detalles. 


\subsubsection{Material y métodos}

A menos que se indique lo contrario, los procedimientos y el equipo fueron idénticos a los descritos en la Sección 5.2 (Métodos Generales).

\section{Participantes}

En el Estudio 2 participaron 12 personas hipoacúsicas (5 mujeres) (Tabla 5.1), aunque no todas ellas realizaron todas las pruebas. Una pérdida auditiva se consideró neurosensorial cuando los umbrales audiométricos por vía aérea y vía ósea diferían menos de $10 \mathrm{~dB}$ en todas y cada una las frecuencias audiométricas excepto una de ellas (como máximo), en la que se permitió que la diferencia fuese $<15 \mathrm{~dB}$. Una pérdida de audición se consideró simétrica cuando los umbrales audiométricos por vía aérea diferían entre los dos oídos menos de $15 \mathrm{~dB}$ en promedio a $0,5,1$ y $2 \mathrm{kHz}$, y menos de $30 \mathrm{~dB}$ en promedio a 3, 4 y $6 \mathrm{kHz}$ (AAOHNS, 1993). La Tabla 5.4 muestra los umbrales audiométricos de los participantes.

Tabla 5.4. Umbrales audiométricos ( $\mathrm{dB} \mathrm{HL})$ de los participantes del Estudio 2.

\begin{tabular}{|c|c|c|c|c|c|c|c|c|c|c|c|c|}
\hline \multirow[b]{3}{*}{ Participante } & \multicolumn{6}{|c|}{ Oído izquierdo } & \multicolumn{6}{|c|}{ Oído derecho } \\
\hline & \multicolumn{6}{|c|}{ Frecuencia $(\mathrm{Hz})$} & \multicolumn{6}{|c|}{ Frecuencia $(\mathrm{Hz})$} \\
\hline & 250 & 500 & 1000 & 2000 & 4000 & 8000 & 250 & 500 & 1000 & 2000 & 4000 & 8000 \\
\hline $\mathrm{IH}-057$ & 30 & 30 & 30 & 55 & 70 & 90 & 30 & 35 & 45 & 55 & 75 & 85 \\
\hline $\mathrm{IH}-094$ & 30 & 35 & 45 & 45 & 45 & 75 & 15 & 30 & 40 & 45 & 50 & 75 \\
\hline $\mathrm{IH}-134$ & 20 & 25 & 40 & 55 & 65 & 70 & 20 & 25 & 40 & 60 & 65 & 65 \\
\hline $\mathrm{IH}-097$ & 35 & 55 & 60 & 70 & 95 & 90 & 25 & 45 & 55 & 75 & 80 & 90 \\
\hline $\mathrm{IH}-173$ & 40 & 50 & 40 & 35 & 65 & 90 & 20 & 45 & 35 & 30 & 95 & 90 \\
\hline $\mathrm{IH}-116$ & 40 & 60 & 70 & 60 & 70 & 70 & 30 & 50 & 60 & 60 & 75 & 70 \\
\hline $\mathrm{IH}-084$ & 5 & 15 & 45 & 70 & 60 & 65 & 5 & 20 & 50 & 70 & 65 & 70 \\
\hline $\mathrm{IH}-152$ & 35 & 40 & 45 & 75 & 95 & 100 & 45 & 55 & 60 & 75 & 95 & 100 \\
\hline $\mathrm{IH}-142$ & 65 & 65 & 75 & 60 & 55 & 85 & 45 & 55 & 65 & 65 & 65 & 80 \\
\hline $\mathrm{IH}-180$ & 15 & 20 & 30 & 55 & 75 & 100 & 5 & 15 & 15 & 45 & 55 & 70 \\
\hline $\mathrm{IH}-511$ & 20 & 40 & 55 & 45 & 60 & 80 & 20 & 45 & 50 & 45 & 60 & 70 \\
\hline $\mathrm{IH}-045$ & 30 & 40 & 55 & 75 & 75 & 85 & 45 & 65 & 80 & 70 & 70 & 75 \\
\hline
\end{tabular}

\section{Los audífonos MOC}

Tanto los audífonos MOC como el audífono STD se programaron de forma idéntica en ambos oídos. El ajuste de las curvas de ganancia-intensidad para los dos oídos se estableció en función del oído con los mejores umbrales audiométricos (medido como el promedio de la pérdida en 500, 1000 y $2000 \mathrm{~Hz}$ ). Wiggins y Seeber (2013) utilizaron el mismo criterio. Debe recordarse, no obstante que, aunque la compresión fue idéntica en el ajuste inicial, la ganancia 'real' aplicada 
en cada oído varió de forma dinámica en el tiempo en función de las características de los sonidos ipsilaterales y contralaterales. La Tabla 5.5 muestra los valores del control de volumen de cada participante.

Tabla 5.5. Control de volumen (\%) de los participantes. L-VC: control de volumen del oído izquierdo; R-VC: control de volumen del oído derecho. Una ganancia escalar de valor 1 equivale a un valor del $100 \%$ del control de volumen.

\begin{tabular}{ccc}
\hline $\mathrm{ID}$ & L- VC & R-VC \\
\hline $\mathrm{IH}-057$ & 75 & 75 \\
$\mathrm{I}-094$ & 50 & 50 \\
$\mathrm{IH}-134$ & 50 & 50 \\
$\mathrm{IH}-097$ & 50 & 50 \\
$\mathrm{IH}-173$ & 60 & 60 \\
$\mathrm{IH}-116$ & 100 & 100 \\
$\mathrm{IH}-084$ & 100 & 100 \\
$\mathrm{IH}-152$ & 75 & 75 \\
$\mathrm{IH}-142$ & 100 & 100 \\
$\mathrm{IH}-180$ & 50 & 50 \\
$\mathrm{IH}-511$ & 100 & 100 \\
$\mathrm{IH}-045$ & 75 & 75 \\
\hline
\end{tabular}

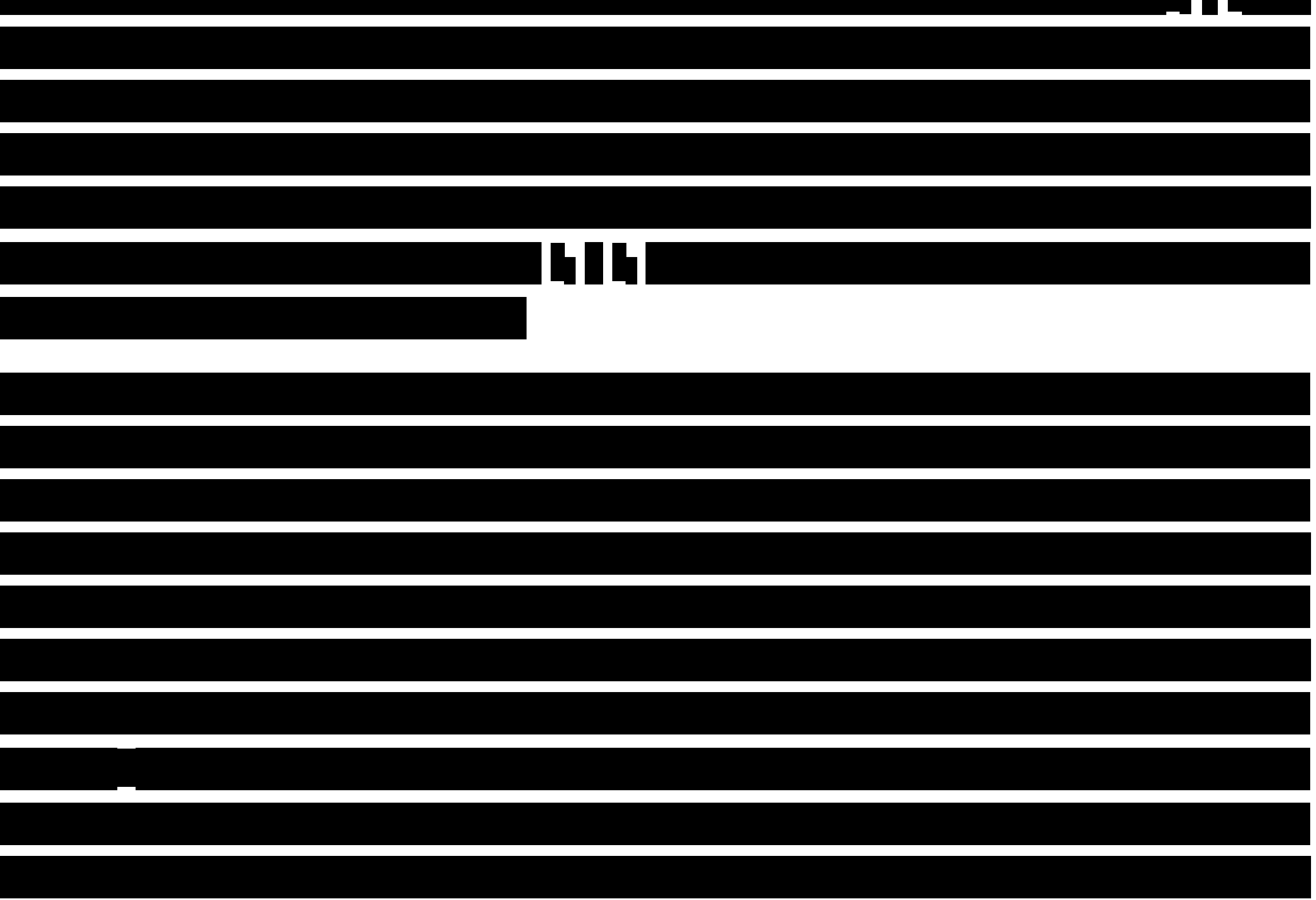




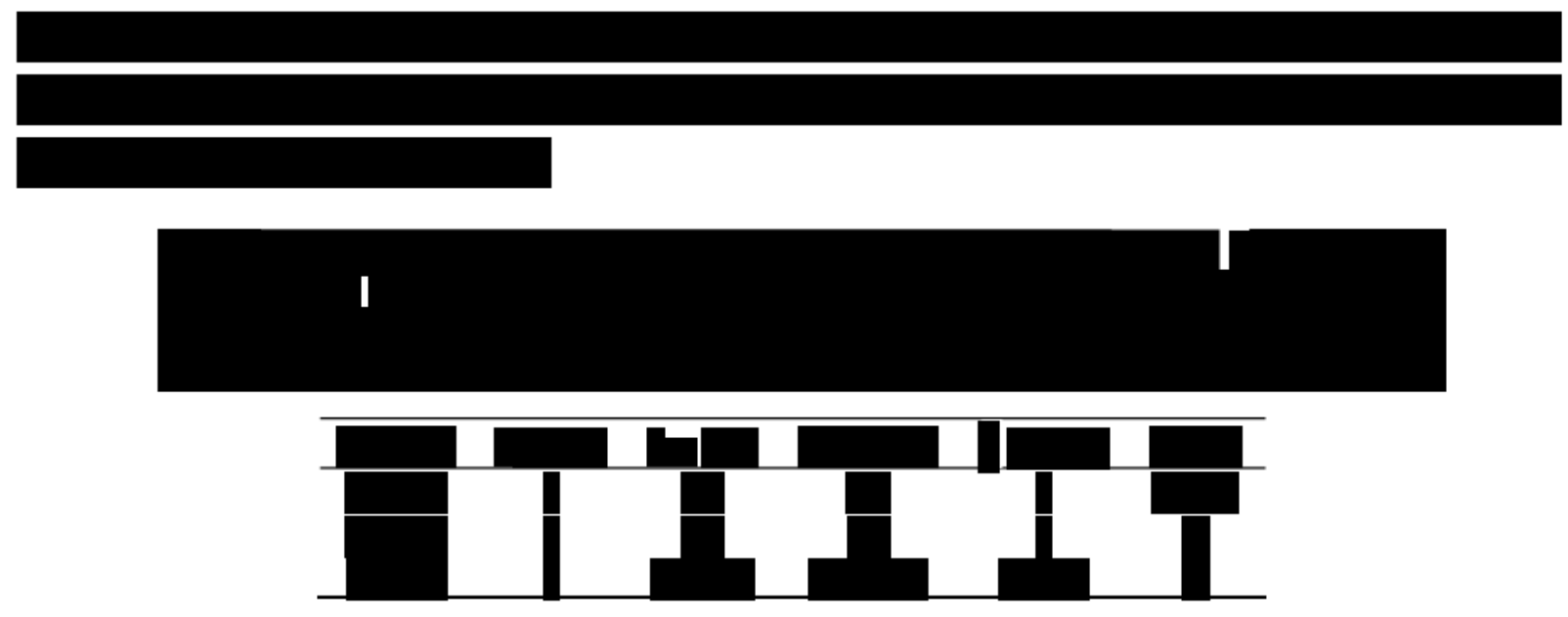

\section{Estímulos}

En el primer conjunto de pruebas, se utilizaron las oraciones del corpus HINT en españolcastellano, que están pronunciadas por un hombre (HINT, Huarte, 2008). Todas las oraciones se presentaron con un silencio previo y posterior de $500 \mathrm{~ms}$ y $50 \mathrm{~ms}$, respectivamente. El silencio previo tenía el objetivo de asegurar que el control contralateral de la compresión estaba totalmente activo en el momento de presentar la oración al participante.

En el segundo conjunto de pruebas, los participantes recibieron la instrucción de repetir la oración pronunciada por una mujer (la 'señal') mientras se presentaba otra oración pronunciada por un hombre (la 'máscara'). Las oraciones pronunciadas por la mujer y el hombre se tomaron del corpus de oraciones matriciales en español (Hochmuth et al., 2013) y del corpus Sharvard (Aubanel et al., 2014), respectivamente. Ambas oraciones, señal y máscara, se presentaron siempre centradas en el tiempo. Cuando su duración era diferente, la oración más corta se completó con silencio; es decir, con muestras de amplitud cero. Es improbable que estos ceros hayan afectado a los resultados, ya que las oraciones enmascaradoras eran generalmente más largas que las oraciones 'señal'. Además, la respuesta se calificó como correcta solo cuando el participante reconoció todas y cada una de las palabras de la oración 'señal'. En todo caso, cualquier posible efecto del relleno con ceros sobre el reconocimiento de oraciones habría afectado por igual a los SRTs obtenidos con los audífonos STD y MOC. 


\subsubsection{Resultados}

\section{El efecto del procesamiento MOC sobre los SRTs en silencio}

La Figura 5.7 muestra los SRTs de diez participantes con pérdida auditiva neurosensorial en condiciones de escucha unilateral oído izquierdo (OI), unilateral oído derecho (OD) y bilateral, para estímulos en silencio procesados por los audífonos STD y MOC2a. La señal estaba ubicada frente al oyente, es decir, a $0^{\circ}$ de azimut (condición SF). Para todos y cada uno de los participantes, los SRTs fueron más bajos (mejores) en escucha unilateral con el oído derecho que con el oído izquierdo. Además, los SRTs siempre fueron más altos (peores) en escucha unilateral que bilateral. Por otro lado, la mayoría de los participantes mostraron mejores SRTs con el audífono MOC2c que con el audífono STD (paneles inferiores en la Figura 5.7).

EI RMANOVA indicó un efecto significativo del audífono $[F(1,9)=12,648, p=0,006]$, pero no de la condición de escucha (unilateral OD, unilateral OI y Bilateral) $[F(2,18)=3.302, p=0.06]$, aunque se observa que la escucha bilateral tiende a ser mejor que la escucha unilateral OI. La interacción entre los dos factores (tipo de audífono y condición de escucha) no fue estadísticamente significativa $[F(2,18)=0.311, p=0.737]$. El análisis post hoc usando colecciones de Bonferroni confirmó que los SRTs fueron significativamente mejores con el audífono MOC que con el STD $(p=0.006)$. Las comparaciones por pares para cada condición de escucha mostró los siguientes valores: STD vs MOC para el OI $(p=0,04)$, STD vs MOC para el OD $(p=0,028)$ y STD vs MOC para bilateral $(p=0,099)$. Note que el audífono MOC no fue significativamente mejor que el STD en la condición de escucha bilateral.

Cabe destacar que los SRTs del participante $\mathrm{HI}-084$ fueron muy negativos, cercanos a los de las personas normoyentes. Esto probablemente se debe a que sus umbrales audiométricos a frecuencias bajas eran casi normales (véase Tabla 5.3). 

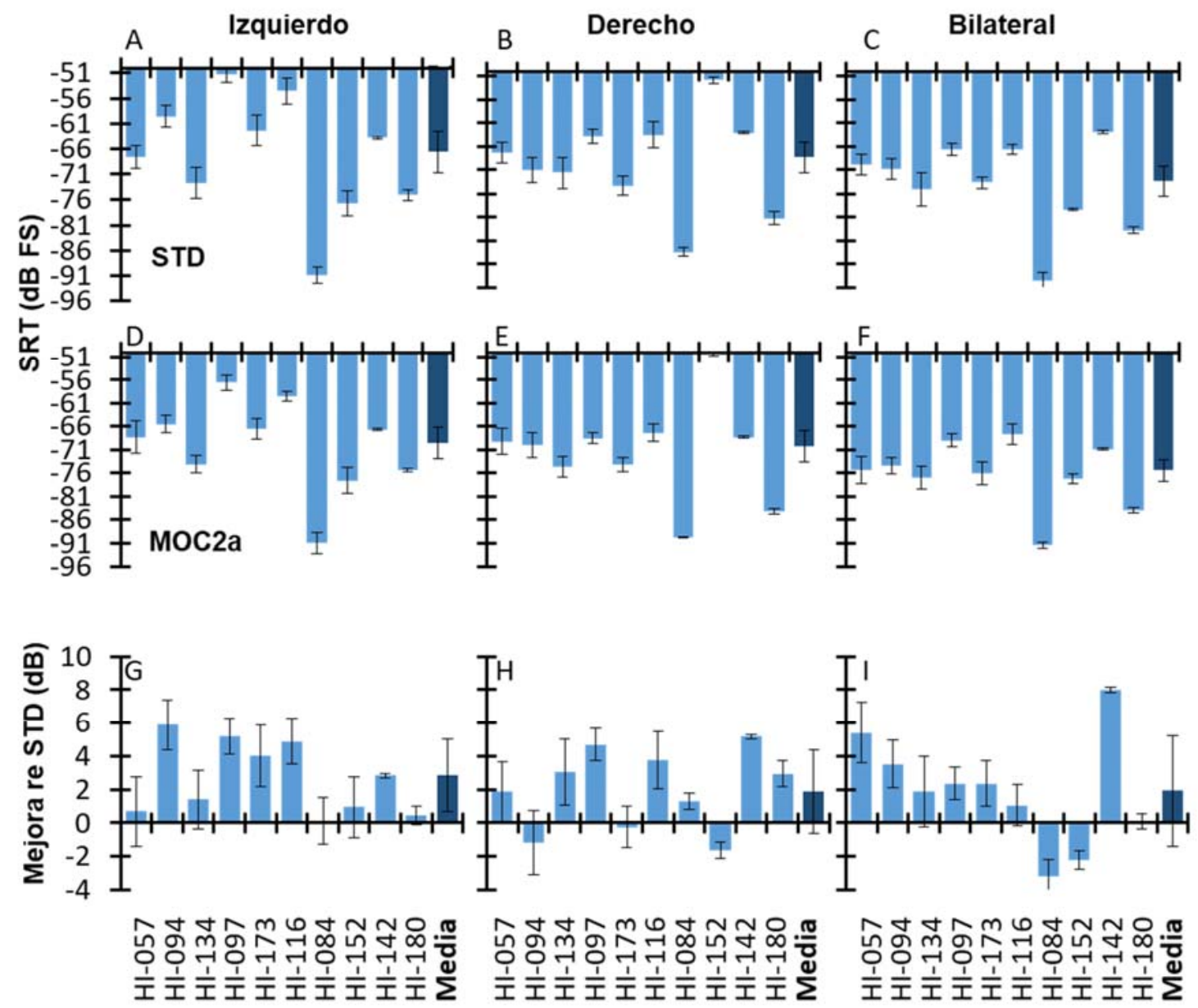

Participantes

Figura 5.7. Umbrales de recepción verbal en silencio obtenidos con los audífonos STD (fila superior) y MOC2a (fila media). Los paneles inferiores muestran la mejora del SRT en ruido proporcionada por el audífono MOC respecto al STD. Cada columna ilustra resultados para una condición de escucha diferente (unilateral con el oído izquierdo, unilateral con el oído derecho, o bilateral), tal y como se indica en los títulos de la columna. Cada panel ilustra datos individuales para diez participantes. Cada barra ilustra la media de tres medidas; las barras del error ilustran el error estándar. También se ilustra la media y el error estándar de los diez participantes.

\section{El efecto del procesamiento MOC sobre los SRTs en ruido estacionario}

La Figura 5.8 muestra los SRTs en ruido SSN con dos audífonos (STD, MOC2a) y para tres ubicaciones espaciales para la señal y el ruido (SFNF, SFNR y SLNR). Todas las medidas se realizaron en condiciones de escucha bilateral. Cada fila ilustra los resultados para un audífono diferente y cada columna para una configuración espacial diferente.

El RMANOVA mostró que el tipo de audífono no influyó significativamente sobre los SRTs $[F(1,9)=0,308 p=0,592]$. Sin embargo, el efecto de la configuración espacial sí fue significativo 
$[F(2,18)=49,988, p<0.001]$. La interacción entre el tipo de audífono y la configuración espacial no fue significativa $[F(2,18)=0.485, p=0.623]$. La comparación por pares post hoc, utilizando el método de corrección Bonferroni, mostró los siguientes valores de $p$ entre las configuraciones espaciales: SFNF vs SFNR, $p=0.005$; SFNF vs SLNR, $p<0.001$ y SFNR vs SLNR, $p=0.001$. En definitiva, los SRTs mejoraron significativamente al aumentar la separación espacial entre la señal y la máscara, pero no se observaron diferencias significativas entre ambos audífonos.

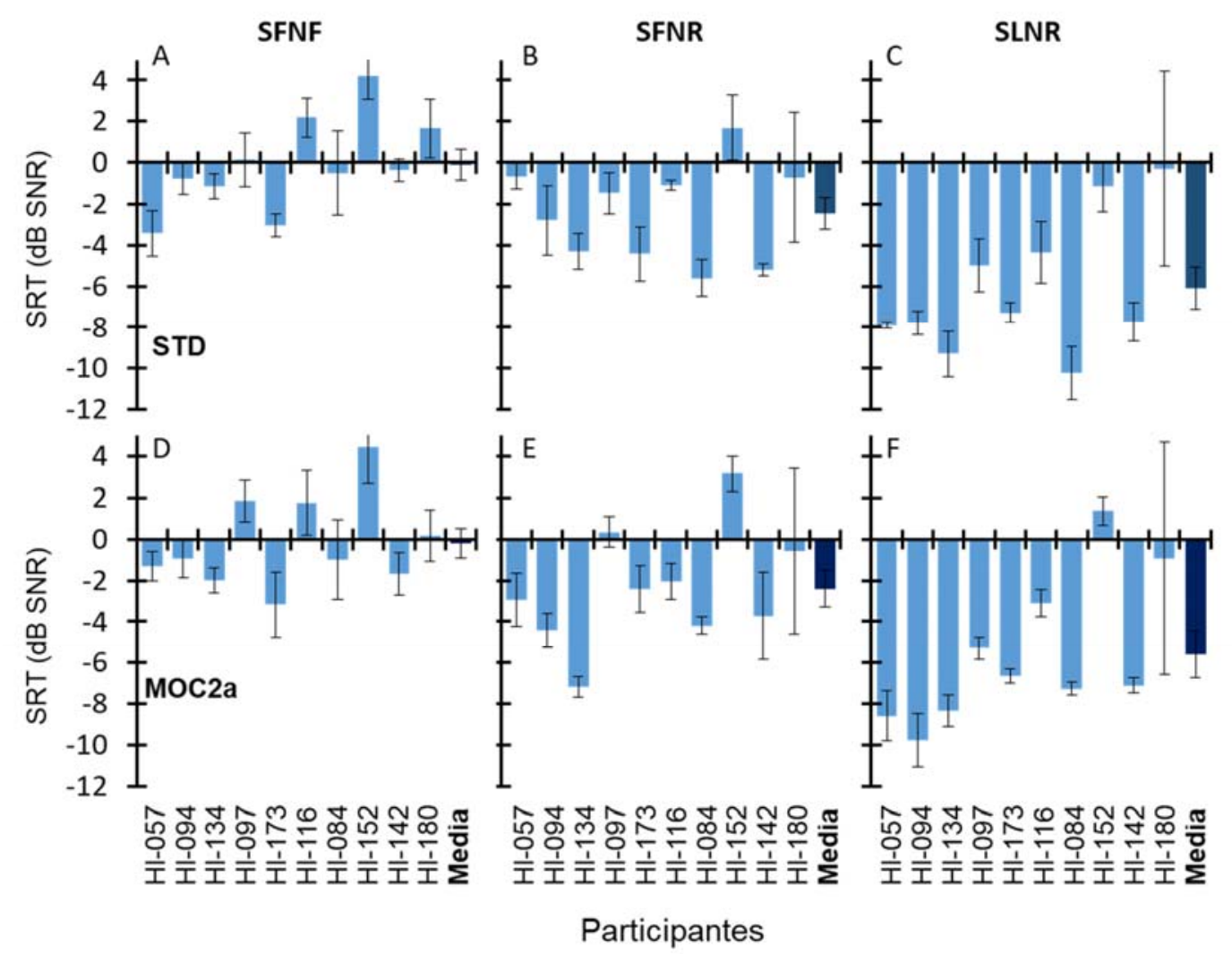

Figura 5.8 Umbrales de recepción verbal en ruido estacionario (SSN) obtenidos con los audífonos STD (fila superior) y MOC2a (fila inferior). Cada columna ilustra resultados para una configuración espacial diferentes de las fuentes de habla y ruido, tal y como se indica en los títulos de la columna. Se ilustran datos individuales para diez participantes. Cada barra ilustra la media de tres medidas (excepto para HI180 que solo se tomaron dos medidas) y las barras de error el error estándar. También se ilustra la media y error estándar de los diez participantes. Nótese que los SRTs del sujeto HI-152 son atípicos (anormalmente altos).

\section{El efecto del procesamiento MOC sobre los SRTs en ruido fluctuante}

La Figura 5.9 muestra los SRTs de los ocho participantes con los cuatro audífonos (STD, MOC2a, MOC2b, MOC2c) cuando la señal y el ruido (otro hablante) estaban ubicados en ángulos 
azimutales de $345^{\circ} \mathrm{y}+15^{\circ}$, respectivamente. La Figura 5.10 muestra los SRTs obtenidos con los audífonos MOC2 relativos a los obtenidos con el audífono STD.

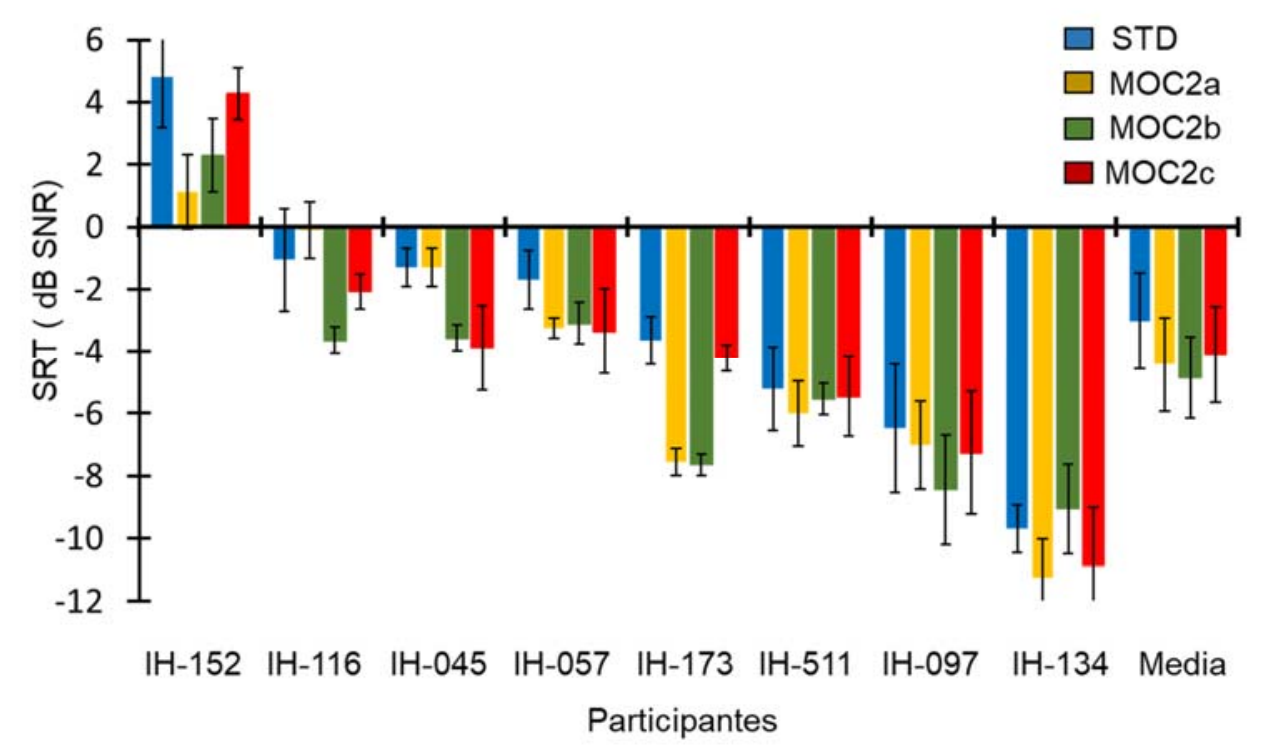

Figura 5.9. Umbrales de recepción verbal en ruido fluctuante (otro hablante) en la condición S345N15 para audífonos STD, MOC2a, MOC2b y MOC2c en oyentes con pérdida auditiva neurosensorial. Se ilustran datos individuales para ocho participantes. Cada barra ilustra la media de tres medidas y las barras de error el error estándar. También se ilustra la media y el error estándar de los ocho participantes. Los datos están ordenados de izquierda a derecha por SRT decreciente con el audífono STD.

Los SRTs promedios tendieron a ser más bajos (mejores) con los tres audífonos MOC que con el audífono STD (Figura 5.9 y Figura 5.10). EI RMANOVA reveló un efecto significativo del audífono $[F(3,21)=3,52, p=0,033]$. Las comparaciones por pares post hoc utilizando la corrección de Bonferroni para múltiples comparaciones revelaron que los SRTs fueron significativamente mejores (más bajos) con el audífono MOC2c que con el STD ( $p=0.03)$. Las diferencias entre los SRTs medios para otros pares de estrategias no fueron estadísticamente significativas (STD vs MOC2a, $p=0.323$; STD vs MOC2b, $p=0.057$; MOC2a vs MOC2b, $p=1.0$; MOC2a vs MOC2c, $p=1.0 ;$ MOC2b vs MOC2c, $p=1.0)$. 


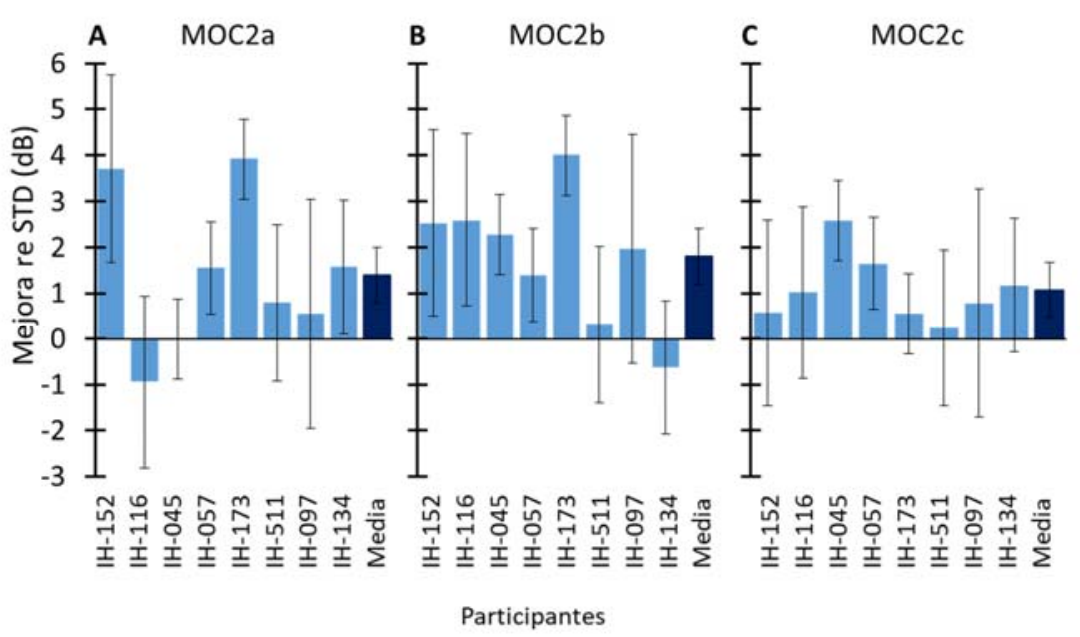

Figura 5.10. Mejora de los SRTs proporcionada por los audífonos MOC2a, MOC2b y MOC2c (Figura 5.9) con respecto al audífono STD [Ecs. (21) y (22)].

Aunque los SRTs fueron más bajos para el audífono MOC2b (Figura 5.9 y Figura 5.10), solo los SRTs para el audífono MOC2c fueron significativamente más bajos (mejores) que aquellos para el STD. Esto sugiere que el audífono MOC2c proporcionó un mayor beneficio que los otros MOC2 ya que el beneficio fue consistente (menos variable) entre los participantes individuales. Esto posiblemente se debió al uso de parámetros de atenuación contralateral individualizados destinados a preservar la audibilidad y un rango dinámico optimizado. Sin embargo, ha de tenerse en cuenta que el beneficio proporcionado por audífono MOC2b con respecto al STD fue casi significativo $(p=0.057)$.

\section{Rendimiento con los audífonos comerciales}

En la medida que fue posible, se determinó el rendimiento de los participantes con sus audífonos comerciales en condiciones de campo libre con el fin de comparar el rendimiento de los audífonos STD y MOC2a con respecto a un audífono estándar clínico actual. Los resultados se muestran en la Tabla 5.7. La prueba de Friedman por rangos confirmó un efecto significativo del tipo de audífono en silencio $\left[X^{2}(5)=21,114 p=0,010\right]$. El análisis post hoc con la prueba de rangos Wilcoxon demostró que los SRTs fueron significativamente mejores con el audífono MOC2a que con el comercial $(p=0.043)$. Por otro lado, para comprobar el efecto del audífono en ruido se realizó un RMANOVA que reveló un efecto no significativo del tipo de audífono $[F(1,4)=3,330$, $p=0,142]$. 
Tabla 5.7. Umbrales de recepción verbal en silencio y en ruido estacionario (tipo SSN) obtenidos con los audífonos experimentales STD y MOC2a, y con un audífono clínico (Comercial). Todas las medidas son en escucha bilateral. En todos los casos, el habla y el ruido se situaron frente al oyente ( $0^{\circ}$ azimut). Los SRTs con audífonos experimentales STD y MOC2a se obtuvieron en condiciones de campo libre simulado presentando estímulos filtrados HRTF mediante auriculares de inserción ER2. Los valores con el audífono comercial se obtuvieron en condiciones de campo libre real, presentando los estímulos a través de un altavoz ubicado a $1 \mathrm{~m}$ de distancia frente al oyente en una cabina sonoamortiguada y semianecoica.

\begin{tabular}{cccc|ccc} 
& \multicolumn{3}{c|}{ SRTs en silencio (dB FS) } & \multicolumn{3}{c}{ SRTs en ruido (dB SNR) } \\
\cline { 2 - 6 } ID & Comercial & STD & MOC2a & Comercial & STD & MOC2a \\
\hline HI-057 & -75.3 & -69.9 & -75.4 & -0.4 & -3.4 & -1.3 \\
HI-173 & -74.2 & -73.7 & -76.1 & -2.3 & -3.0 & -3.2 \\
HI-116 & -53.2 & -66.6 & -67.7 & 5.2 & 2.2 & 1.8 \\
HI-152 & -74.7 & -79.4 & -77.1 & -0.9 & 4.1 & 2.7 \\
HI-180 & -79.5 & -83.8 & -83.9 & -3.1 & -0.1 & -2.0 \\
Media & $-69,2$ & $-73,3$ & $-75,4$ & 0,5 & $-0,8$ & $-0,7$ \\
\hline
\end{tabular}

\subsubsection{Discusión}

En este estudio se ha determinado el rendimiento de personas con hipoacusia neurosensorial en tareas de reconocimiento del habla con un audífono STD y con diversos audífonos MOC2

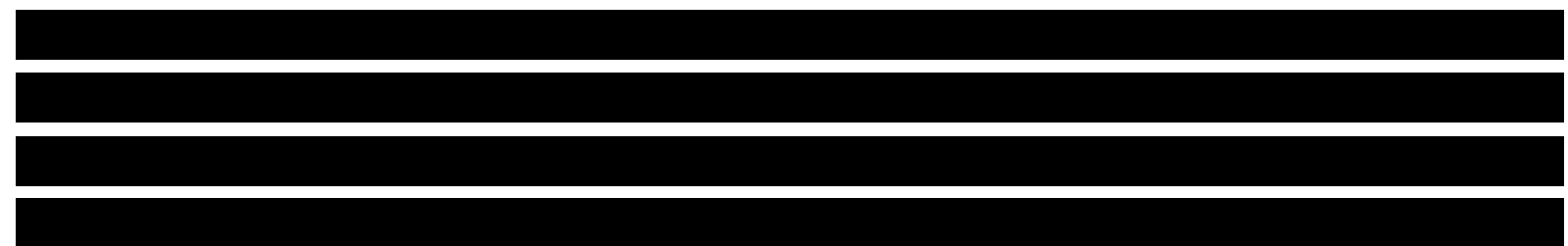

lugar, se ha demostrado que las ganancias entregadas por los audífonos implementados restauran la audibilidad de los niveles más bajos. En segundo lugar, se ha demostrado que los audífonos MOC2 no mejoran el rendimiento respecto al audífono STD en ruido estacionario (SSN) en ninguna de las tres configuraciones espaciales de la máscara y la señal evaluadas. En tercer lugar, los audífonos MOC2 mejoraron 1-2 dB los SRTs cuando el habla se presentó competencia con otro hablante para la localización de la señal y el ruido de $345^{\circ}$ y $15^{\circ}$, respectivamente.

Los participantes en el presente estudio fueron heterogéneos en sexo, edad, grado de hipoacusia y experiencia en el uso de audífonos (Tabla 5.1). Esta heterogeneidad puede haber contribuido a la variabilidad observada en los SRTs (véase, por ejemplo, la Figura 5.9). En cualquier caso, es razonable suponer que la heterogeneidad en cuestión debería haber afectado a los SRTs obtenidos con las estrategias STD y MOC por igual, y su efecto potencial en el aumento de la variabilidad de los SRTs se habría explicado mediante el uso de una prueba estadística de 
medidas repetidas. Por lo tanto, es poco probable que la heterogeneidad de la muestra afecte a nuestras conclusiones respecto al beneficio del audífono MOC en relación con el STD.

\section{EI audífono STD como referencia}

La ganancia prescrita a intensidades medias es similar a la dada por otras reglas como NAL-RP o NAL-NL1 (para más detalles, véase la Sección 5.2.6 y el Apéndice A). Las modificaciones introducidas a bajas y altas intensidades pueden tener sus limitaciones. Por ejemplo, la relación de compresión debería haber sido mayor que la prescrita, ya que el máximo nivel de salida se igualó a $0 \mathrm{~dB}$ FS para todos y cada uno de los canales, en vez de ajustarlo en cada canal a un valor tal que la suma de todos ellos tenga como resultado un nivel total de $0 \mathrm{~dB} F S$. Siempre se buscó que el punto de partida fuera similar a la utilizada en los audífonos comerciales actuales. Es decir, en ningún caso se partió de una mala programación o diseño en el audífono control (STD) para facilitar la mejora con el audífono MOC. Este hecho es importante a la hora de reportar un beneficio/perjuicio relativo a los estándares actuales.

Para la mayoría de los participantes, la inteligibilidad en silencio fue mejor y estadísticamente significativa con el audífono MOC2a que con el STD o el audífono comercial. La compresión de acción rápida del audífono MOC aumenta la ganancia a bajas intensidades y, por tanto, la audibilidad con respecto al compresor de acción lenta del audífono STD y probablemente también del audífono MOC. Además, los resultados en silencio muestran si existe una inhibición MOC a bajas intensidades reflejando un deterioro en la audibilidad en los SRTs. Los resultados obtenidos indican que no existe inhibición a bajos niveles sonoros o bien que la posible inhibición es menor que el efecto inducido por el compresor de acción rápida. Estos resultados son tranquilizadores ya que podría pensarse que el uso de inhibición en audífonos tuviera un efecto perjudicial a la hora de restaurar el rango dinámico residual de los usuarios.

Los resultados con los audífonos comerciales y su comparación con el rendimiento de los audífonos implementados sugieren que el audífono STD es una referencia razonable del procesamiento típico en los audífonos comerciales. Esto es importante porque un beneficio del audífono MOC relativo al STD es indicativo de un beneficio real con los audífonos comerciales.

\section{Beneficio del audífono MOC en ruido estacionario}

En ruido estacionario, todos los participantes hipoacúsicos mostraron mejores SRTs (es decir, SNRs más negativas) a medida que se incrementó la separación espacial entre el habla y el ruido. El beneficio medio obtenido al mover la fuente de ruido interferente desde la posición 
frontal a la lateral (es decir, desde SFNF a SFNR fue de aproximadamente $3 \mathrm{~dB}$ (Figura 5.8). Este beneficio es equivalente al reportado por otros estudios (por ejemplo, Festen y Plomp, 1986). Esto indica que el desenmascaramiento espacial con los audífonos STD y MOC es comparable con el proporcionado por audífonos de otros estudios.

En ruido estacionario, el audífono MOC2a no entrega una mejora con respecto al procesamiento ofrecido por el audífono STD, al menos, en las condiciones evaluadas. Las causas de la ausencia de beneficio son inciertas y solo podemos conjeturar. Uno de los posibles motivos de la ausencia de beneficio puede ser que el número de canales es insuficiente para conseguir una inhibición adecuada, es decir, que la inhibición MOC es poco especifica en frecuencia. Sin embargo, creemos que la causa más probable sea que la inhibición MOC está mal adaptada al usuario en alguna región de frecuencia provocando un exceso de inhibición que podría haber comprometido audibilidad en algún oído o región de frecuencia y por tanto la inteligibilidad del habla en ruido. La posibilidad de que se haya producido este efecto se puede explorar a partir de algunos de los datos obtenidos para cada participante, por ejemplo, los SRTs en silencio y/o los umbrales audiométricos, tal y como tratamos de hacer a continuación.

En promedio, los SRTs en silencio fueron mejores (más bajos) con el audífono MOC2a que con el STD, reflejando la mayor audibilidad entregada por el compresor de acción rápida del audífono MOC que por el de acción lenta empleado en el audífono STD. Sin embargo, los resultados de algunos de los participantes no mostraron esta diferencia, lo que sugiere que a niveles más altos la posible mejora entregada por el audífono MOC podría no ser efectiva. Los participantes HI152 y HI-084 no se benefician del audífono MOC en la condición bilateral en silencio (Figura 5.7). Casualmente, estos participantes representan casos extremos. $\mathrm{HI}-084$ obtuvo los mejores SRTs en escucha bilateral (-94 dB FS). A intensidades tan bajas se puede asegurar que no existe inhibición contralateral en el audífono MOC. Por tanto, la falta de beneficio reflejaría una incapacidad para entender con un compresor de acción rápida o bien un efecto techo, es decir, el rendimiento de este participante es tan bueno con cualquiera de los audífonos que es difícil mejorarlo. El participante $\mathrm{HI}-152$, en cambio, obtuvo la diferencia más grande entre los SRTs medidos con el STD en escucha unilateral con los oídos derecho e izquierdo ( $24.8 \mathrm{~dB}$ ); es decir, la mayor asimetría de SRTs entre condiciones unilaterales. Si a esta asimetría de partida se le suma la inhibición contralateral MOC, puede provocar que la escucha bilateral en ruido con el audífono MOC sea, en realidad, una escucha unilateral frente a una escucha bilateral (o unilateral pero menos asimétrica) con el STD. Por tanto, aunque el audífono MOC estuviese entregando un beneficio unilateral, este beneficio no es mayor que escuchar con dos oídos. 
Por otra parte, aunque no se observaron grandes diferencias en las PTAs de los participantes (Tabla 5.1), algunos participantes sufrían gran pérdida de audición a alta frecuencia (Tabla 5.3). Esto implicaría una ganancia compensatoria alta y, por tanto, un posible exceso en la inhibición MOC y, por ende, una mayor reducción de la audibilidad en esta región espectral. Un análisis de la correlación entre la pérdida audiométrica ponderada 4 (incluyendo frecuencias medias y altas) frente a la mejora entregada por el audífono MOC (datos de la Figura 5.8 expresados como se indica en la Ec. 21) mostró una tendencia casi significativa (no se muestra aquí). Esta tendencia sugiere que el beneficio MOC es menor en pacientes con gran pérdida auditiva debido a una pérdida de audibilidad por exceso de inhibición MOC en alta frecuencia. De hecho, en la evaluación con máscaras fluctuantes se propuso el audífono MOC2c que minimizara este efecto, lo que resultó en un beneficio (relativo al STD) estadísticamente significativo.

\section{Beneficio del audífono MOC en ruido fluctuante}

Cuando la interferencia es un único hablante, los audífonos MOC2c mejora los SRTs 1-2 dB SNR respecto al STD. Además de incluir inhibición contralateral, los audífonos MOC2 diferían del audífono STD también en la velocidad de compresión. Los tres audífonos MOC2 (MOC2a, MOC2b y MOC2c) utilizaron una compresión de acción muy rápida

mientras que el compresor en el audífono STD fue de acción lenta

- Al no haber incluido un audífono STD con compresión de acción rápida, no es posible aclarar en qué medida las diferencias de SRTs entre los audífonos STD y MOC2 se debieron a la diferencia en la velocidad del compresor, al uso de inhibición contralateral, o a la posible interacción entre ambos factores.

Algunos autores afirman que la compresión de acción rápida puede facilitar la audibilidad de los tramos de los sonidos de bajo nivel, lo que puede usarse para extraer la información del habla derivada de estructura temporal fina durante las caídas del sonido de fondo (Moore et al., 1999). Varios estudios, sin embargo, han concluido que la inteligibilidad del habla con máscaras fluctuantes es peor con compresores de acción rápida que de acción lenta al menos con señales vocodizadas (Stone y Moore, 2003, 2008). Además, se observa una mejor SNR en los espectrogramas de cada oído con los audífonos MOC2 que con un STD rápido (Figura 4.13).

\footnotetext{
${ }^{4}$ La pérdida audiométrica ponderada se calculó en el oído test como el promedio de los umbrales audiométricos en $0,5,1$ y $2 \mathrm{kHz}$ por un factor 0.7 más el promedio los umbrales audiométricos en 4 y 6 $\mathrm{kHz}$ por un factor 0.3 , estas ponderaciones se establecieron en base a la función de importancia (Pavlovic, 1987; Eisenberg et al., 1998)
} 
Por lo tanto, es probable que la mejora en los SRT con los audífonos MOC se deba a la inhibición contralateral.

El efecto perjudicial sobre la inteligibilidad de las máscaras fluctuantes frente a las estacionarias es mayor para los oyentes hipoacúsicos que para los normoyentes (Festen y Plomp, 1990). Es decir, en comparación con las personas normoyentes, las personas hipoacúsicas tienen más dificultades al comprender el habla en competencia con máscaras fluctuantes que estacionarias. Esto indica que pequeñas mejoras en inteligibilidad con máscaras fluctuantes pueden tener un mayor impacto para los usuarios de audífonos que mejorar la inteligibilidad en el ruido estacionario. Aquí, se ha descubierto que los audífonos MOC2 proporcionan mayores beneficios sobre la inteligibilidad del habla cuando la máscara es otro hablante que cuando es un ruido estacionario. Este hallazgo sugiere que las implementaciones aquí propuestas, u otras implementaciones alternativas, del audífono MOC2 podrían mejorar los resultados de los audífonos actuales.

\subsection{Conclusiones}

En resumen, cuando el habla está enmascarada por otro hablante separado espacialmente (azimuts de $345^{\circ}$ y $15^{\circ}$, respectivamente) y en condiciones de escucha bilateral, el audífono MOC (con compresión de acción rápida y parámetros apropiados) proporciona mejor inteligibilidad a las personas con hipoacusia neurosensorial que un audífono STD (con compresión de acción lenta). En general, los beneficios del procesamiento MOC son mayores cuando la interferencia es único hablante que cuando es ruido estacionario (SSN).

En la medida en que el habla es un tipo de interferencia acústica más natural que el ruido estacionario, los resultados actuales son prometedores para los audífonos MOC. El uso del control dinámico de compresión contralateral específico de frecuencia (inspirado en el reflejo MOC contralateral) podría ser beneficioso para preservar una percepción binaural natural del entorno acústico y evitar el efecto nocivo inducido por la compresión de acción rápida. En todo caso, los resultados obtenidos justifican realizar evaluaciones adicionales del presente audífono MOC, así como explorar otras implementaciones alternativas. 
V - Evaluación experimental 


\section{VI - DISCUSIÓN GENERAL}


VI - Discusión general 


\section{VI - Discusión general}

\subsection{Resumen de los resultados}

El principal objetivo de esta tesis fue diseñar un audífono binaural con control contralateral de la compresión inspirado en el MOCR contralateral (Figura 4.1). Para conseguirlo, se ha diseñado un algoritmo con ganancia tipo broken stick (Meddis et al., 2001; Lopez-Poveda y Meddis, 2001), en el que la señal de entrada a cada canal de frecuencia se atenúa o se inhibe en función del nivel sonoro de salida del canal contralateral correspondiente (Lopez-Poveda, 2015). El abordaje se basa en el modelo computacional del efecto del MOCR contralateral de Ferry y Meddis (2007). Se ha demostrado que este algoritmo reproduce cualitativamente algunos aspectos del MOCR contralateral (Cooper y Guinan, 2006; Backus y Guinan, 2006),

Un segundo objetivo fue evaluar el audífono MOC comparando el reconocimiento del habla en ruido con el obtenido con dos audífonos funcionalmente independientes entre sí, es decir, comparado con dos audífonos sin control contralateral de la compresión. Se ha demostrado que el audífono MOC programado adecuadamente mejora los SRTs en ruido fluctuante en personas con hipoacusia neurosensorial simétrica (Figura 5.10). Sin embargo, no mejora inteligibilidad en ruido estacionario en ninguna de las configuraciones espaciales de la señal y el ruido evaluadas (Figura 5.8). Estos resultados verifican que la mejora de inteligibilidad proporcionada por el audífono MOC depende del tipo de ruido y de los parámetros del audífono. Sin embargo, las condiciones evaluadas experimentalmente son insuficientes para establecer conclusiones sobre la dependencia del beneficio en función de la separación espacial entre la máscara y la señal.

Los hallazgos apoyan parcialmente la hipótesis principal de la tesis, lo que indica que la compresión binaural tipo MOC es una prometedora alternativa al procesamiento actual en 
audífonos bilaterales, gracias a que realza las ILDs y/o restaura (al menos parcialmente) el efecto sombra de la cabeza. Además, creemos que el audífono MOC reduce los efectos nocivos de la compresión de acción rápida aplicada a través de dos audífonos (Stone y Moore, 2007; Wiggings y Seeber, 2012, 2012)

No obstante, la generalización de estos resultados está sujeta a ciertas limitaciones.

\subsection{Limitaciones}

\subsubsection{Un único diseño de audífono MOC}

Se ha propuesto y evaluado un diseño particular del audífono MOC con atenuación contralateral basada en el modelo de Ferry y Meddis (2007).
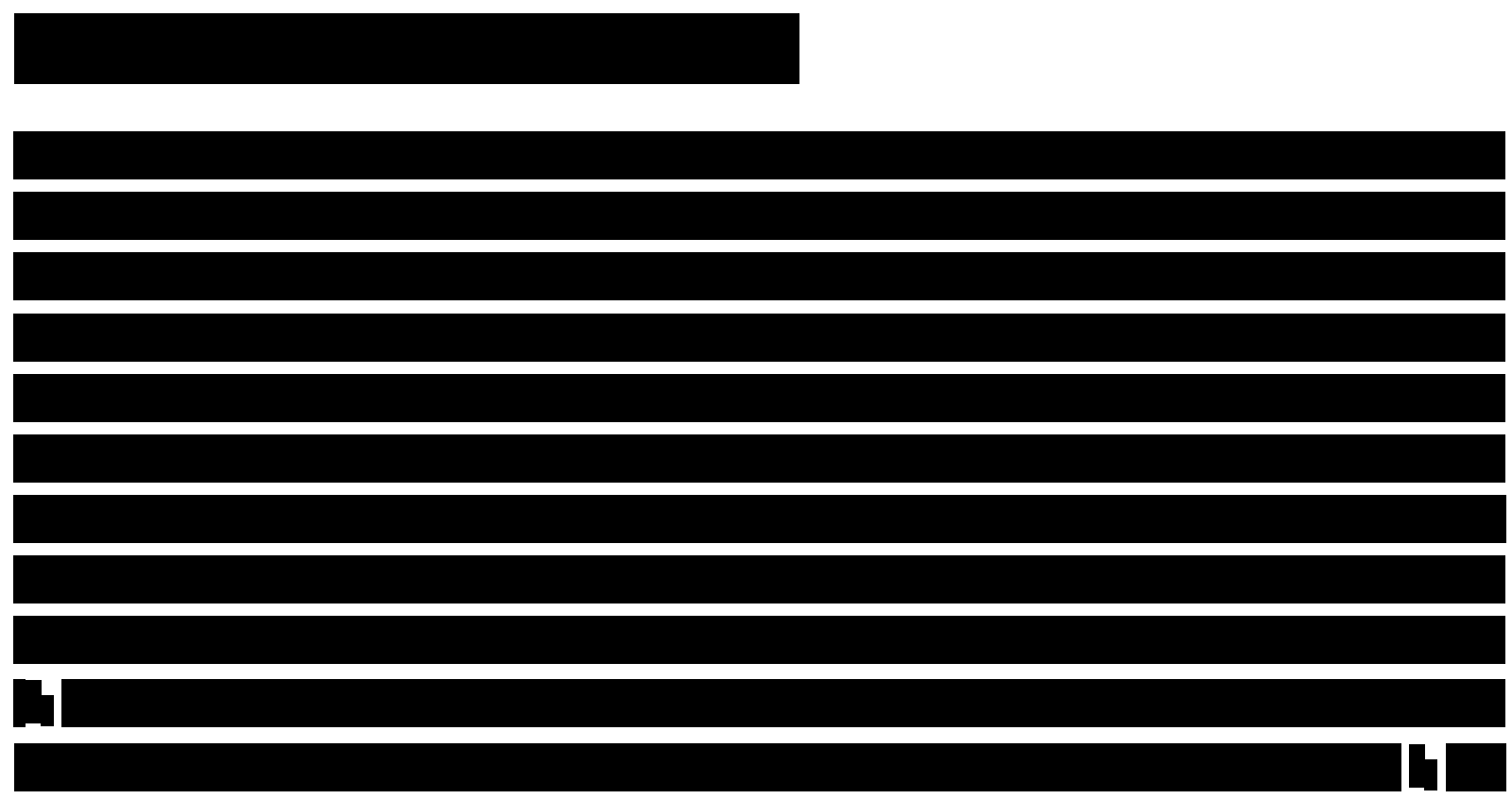


\subsubsection{Dependencia de la inhibición de la pérdida auditiva}

En la implementación propuesta, la cantidad de inhibición contralateral depende de la ganancia aplicada y, por ende, de la pérdida auditiva. A mayor pérdida auditiva, mayor ganancia en el compresor, mayor nivel de salida del audífono y, por tanto, mayor inhibición contralateral. Esto hace que la inhibición sea diferente de unos sujetos a otros, lo que puede deteriorar la audibilidad en alguno de los oídos y/o regiones frecuenciales. Este aspecto podría explicar la ausencia beneficio del procesamiento MOC en algunas condiciones. De hecho, el beneficio significativo del MOC2c y no de otras programaciones como la MOC2b (que es idéntica a MOC2c, pero con una función de control de la inhibición contralateral fija), confirma que una programación óptima de la inhibición contralateral en el diseño actual del audífono MOC debería ser individualizada

\subsubsection{Condiciones experimentales}

Los resultados obtenidos deben interpretarse con prudencia puesto que las condiciones experimentales y los métodos aplicados en esta investigación han sido limitados. En primer lugar, el tamaño de la muestra es pequeño, lo que limita la generalización de los resultados. En segundo lugar, el audífono se ha evaluado solo en personas con hipoacusia conductiva (simulada mediante tapones) y con hipoacusia neurosensorial simétrica, por lo que es posible que los hallazgos no sean generalizables a otro tipo de pérdida. En tercer lugar, solo fue posible evaluar una implementación particular del audífono MOC en un número limitado de condiciones experimentales: a un nivel sonoro de la señal (-55 dB FS), en cinco configuraciones espaciales máscara-señal (SFNF, SFNR, SLNF, SLNR Y S345N15) y con dos tipos de máscaras (ruido estacionario y un hablante). Además, hay que tener en cuenta que las condiciones de laboratorio, aunque útiles para explorar los posibles beneficios, son condiciones idealizadas. Por lo tanto, se debe ser cauto al interpretar los resultados y generalizarlos a otras condiciones y situaciones de escucha. 


\subsubsection{Un audífono control}

El rendimiento del audífono MOC se ha comparado con un solo audífono de referencia; a saber, el audífono STD consistente en dos audífonos funcionalmente independientes con tiempos de ataque y relajación convencionales de 5 y 2000 ms, respectivamente. Aunque esta referencia se considera el estándar actual, también se podría haber comparado el rendimiento del audífono MOC con otros audífonos, tales como compresores de acción rápida o procesadores lineales sin acoplamiento binaural. El empleo de un único audífono de referencia limita la generalización del posible beneficio obtenido con el audífono MOC y sugiere que sería interesante en futuros estudios incluir otros procesamientos como control.

\subsection{Idoneidad de la implementación MOC}

Se debe tener en cuenta las siguientes puntualizaciones ya que estas pueden dar soporte a nuestras conclusiones y resultados.

\subsubsection{La implementación de los audífonos}

Como se ha descrito en la Introducción, un audífono comercial es básicamente un compresor no instantáneo multicanal (Levitt, 1987; Kates, 2008; Popelka et al., 2016). Por tanto, el diseño de los audífonos implementados es conceptualmente idéntico al de un audífono comercial actual. Por otro lado, el rango de frecuencias elegido, el número de canales y el ancho de banda de cada canal han sido elegidos de forma razonable y similar a la usada en audífonos comerciales o en otros estudios (Salorio-Corbetto et al., 2020). La prescripción de la ganancia está basada en una regla de ganancia NAL-RP ampliamente validada (Byrne y Dillon, 1986; Byrne, 1991). De hecho, los SRTs en silencio demuestran que la ganancia prescrita aquí es adecuada para restaurar el rango dinámico (Figura 5.3, Figura 5.4 y Figura 5.7). También se ha demostrado que audífonos con compresores de acción rápida proporcionan mayor audibilidad en silencio en comparación con la proporcionada por la compresión de acción lenta (Figura 5.7), al igual que se reporta en otros estudios (por ejemplo, Kowalewski et al., 2018). Además de esto, los SRTs obtenidos con los audífonos implementados parecen ser consistentes con los que se obtienen con los audífonos comerciales de los participantes (Tabla 5.4.). Todo esto evidencia que el audífono STD funciona como un audífono comercial, por tanto, cualquier beneficio medido a 
través de los SRTs con el audífono MOC, y expresado en términos relativos a los SRTs obtenidos con el STD, puede considerarse representativo de una mejora real de la inteligibilidad en ruido.

\subsubsection{El efecto de la inhibición sobre la inteligibilidad}

Nuestros hallazgos muestran que un 'pequeño' deterioro de la audibilidad/sonoridad por medio de una inhibición contralateral puede conducir a una mejora en la inteligibilidad de habla. La inhibición a priori puede ser contraproducente, ya que la función principal de un audífono es amplificar los sonidos para restaurar la audibilidad. De hecho, como ya hemos comentado antes, en alguna de las condiciones evaluadas, un exceso de inhibición podría haber comprometido la audibilidad y, por lo tanto, la inteligibilidad. A pesar de ello, no se intentó compensar la reducción de la sonoridad utilizando un volumen más alto en el audífono MOC que en el STD porque un objetivo implícito del presente estudio fue probar la idea de que el MOCR natural mejora la inteligibilidad, aunque reduce la sensibilidad auditiva (Chintanpalli et al. 2012). Ya que hemos obtenido un beneficio con el audífono MOC2c, podríamos decir que esta idea se cumple siempre y cuando se proporcione audibilidad suficiente.

\subsubsection{El efecto del tipo de ruido}

Hemos demostrado que el audífono MOC mejora los SRTs en ruido fluctuante (un solo hablante) pero no en ruido estacionario. Esto indica que el audífono MOC podría resultar más o menos ventajoso con respecto a un audífono STD según las características físicas del ruido. Nuestros resultados coinciden con los de Lopez-Poveda et al. (2017a). Sin embargo, contrastan con los de Lopez-Poveda et. (2016b). Sendos estudios reportan un beneficio de la estrategia MOC para ICs sobre la inteligibilidad tanto en máscaras estacionarias como fluctuantes. La causa de la ausencia de beneficio con el audífono MOC con máscaras estacionarias es incierta y solo podemos conjeturar.

El ruido tipo SSN es un ruido artificial, inusual en la vida real pero útil en condiciones de laboratorio. Este tiene el espectro del habla, pero sin sus modulaciones en amplitud típicas. Esto 
hace que el ruido tienda a inhibir la señal (o a el propio ruido contralateral) de forma constante en el tiempo, a pesar de que la distribución espectro-temporal de la energía de la palabra este más concentrada que la del ruido. Quizás para obtener un beneficio en la inteligibilidad del habla tanto el habla como el ruido deben inhibir. Esto se puede conseguir aumentando el número de canales y/o adaptando la función de control contralateral de forma similar a como se hizo en el audífono MOC2c (Apéndice $\mathbf{C}$ ). Sendas medidas conducirían a una inhibición contralateral más específica en frecuencia y, por tanto, a equilibrar la inhibición que ejerce cada señal sobre la señal contralateral y viceversa. En la Sección 6.5 se proponen nuevas líneas de investigación con el objetivo de encontrar un beneficio en la inteligibilidad del habla en ruido estacionario con el audífono MOC donde se tienen en cuenta estas consideraciones.

\subsubsection{Predicciones del audífono MOC sobre el MOCR}

Los resultados obtenidos contribuyen a la controversia existente acerca del papel desenmascarante del MOCR (revisado por Lopez-Poveda, 2018). Muchos estudios reportan resultados contradictorios basándose en la suposición de que un MOC más fuerte (es decir, mayor efecto inhibitorio), implica una mejor inteligibilidad del habla en ruido (Micheyl y Collet, 1996; Kumar y Vanaja, 2004; Wagner et al., 2008; Bhagat y Carter, 2010; de Boer et al., 2012). Sin embargo, el presente trabajo sugiere que esta suposición no tiene por qué cumplirse, como también proponen Otsuka et al. (2019). En nuestro caso, una mayor inhibición contralateral no implica una mejora en la inteligibilidad del habla en ruido. De hecho, para obtener una mejora, los parámetros MOC deben ser cuidadosamente seleccionados, ya que un exceso de inhibición puede conducir a un deterioro en la audibilidad, algo que también podría suceder en algunos estudios que tratan de correlacionar la fuerza del MOC con la inteligibilidad del habla en ruido (Michelyl et al., 1995; Garinis et al., 2011; Wagner et al., 2008; Boer et al., 2012).

\subsection{Comparaciones con estudios relacionados}

Este trabajo no es el primero ni el único que propone un audífono inspirado en el MOCR, un audífono binaural, o un procesamiento de señales que realce la ILDs o mejore la SNRs. 


\subsubsection{Audífonos inspirados en el MOCR}

En nuestra implementación del audífono MOC nos basamos en la atenuación según Ferry y Meddis (2007), como también ocurre en BioAid (Meddis et al., 2013; Clark et al., 2012; Jürgens et al., 2016; Clark et al., 2018). No obstante, existen diferencias entre nuestro audífono MOC y BioAid, tanto en el diseño como en el funcionamiento. Una de las principales diferencias es que en el audífono MOC aquí propuesto, la ganancia de cada uno de los audífonos depende dinámicamente del nivel de salida del audífono contralateral (Figura 4.1). Por tanto, la compresión en el audífono MOC es binaural y dinámica. Otra diferencia fundamental es que la compresión en el audífono MOC no es instantánea, esto reduce la distorsión y acerca el funcionamiento al convencional en audífonos. Por otro lado, aunque BioAid mejora la audibilidad, el procesamiento temporal, y la selectividad frecuencial (Jürgens et al., 2016), no se han observado beneficios significativos en inteligibilidad frente al procesamiento ofrecido por un audífono bilateral comercial (Ernst et al., 2018). Por tanto, aunque el audífono MOC y BioAid parten de ideas similares; su diseño, funcionamiento y rendimiento en ruido es distinto.

Existen otros trabajos que se inspiran en el MOC contralateral para diseñar un audífono binaural. Kates (2009) se inspira en el control eferente de la compresión coclear para proponer un audífono binaural. Sin embargo, no reporta ninguna mejora en la inteligibilidad del habla en una variedad de situaciones cotidianas de escucha (véase el Capítulo 8 de Kates, 2008). Kates no muestra que el funcionamiento de su algoritmo sea similar al MOC natural, como sí hacemos aquí. El audífono MOC y el audífono binaural de Kates usan la señal contralateral para modular una ganancia binaural, sin embargo, Kates usa la señal de entrada para calcular el factor MOC, y en nuestra propuesta se usa la señal de salida contralateral. El sistema de Kates es equivalente a tomar el máximo de las dos señales de entrada y usar este valor para controlar la ganancia en ambos oídos. Como resultado, la ganancia que aplica cada audífono es resultado de la mezcla de las dos señales de entrada (una por oído). Esto puede introducir modulación cruzada y ocasionar una fusión perceptiva de señales. En cambio, en nuestro audífono MOC, la ganancia en cada oído se calcula con las señales que predominan en cada lado de la cabeza, obteniendo así, una señal más limpia en un oído y un ruido más claro en el otro (siempre que no tengan la misma ubicación espacial). Por tanto, aunque ambos diseños tengan similitudes, su funcionamiento y efecto sobre la inteligibilidad son diferentes. 


\subsubsection{Otros audífonos binaurales}

A pesar de que nuestro diseño difiere del utilizado en audífonos sincronizadores de ganancia, los resultados son consistentes con la mejora que ellos reportan. Wiggings y Seeber (2013) hicieron una evaluación de inteligibilidad donde la señal del habla estaba localizada en frente del oyente y el ruido tenía un azimut de $60^{\circ} \circ 300^{\circ}$. La compresión fue de acción rápida y la relación de compresión de $3: 1$. Los oyentes reconocieron entre un $8 \%$ y $14 \%$ más de frases con el audífono con compresión vinculada que con la compresión no vinculada. Esto apoya la idea (presente en el audífono MOC) de que vincular o coordinar el funcionamiento de dos audífonos puede mejorar la inteligibilidad si consigue realzar las ILDs y/o restaurar total o parcialmente el efecto sombra de cabeza.

\subsubsection{La estrategia MOC para ICs}

Los resultados observados en este estudio son parcialmente consistentes con los encontrados en estudios previos de la estrategia MOC para ICs (Lopez-Poveda et al., 2016b, 2017 y 2020) No obstante, con ICs si se observaron beneficios en ruido estacionario, una mejora que no se observa en audífonos. Una de las posibles causas de esta diferencia puede ser que los principios de estrategia MOC se introducen de forma distinta en la implementación para audífonos. En la implementación de ICs se vincula directamente el control contralateral a la función de compresión instantánea (Figura 2.16). En los audífonos, el control de la compresión contralateral se aplica a través de una etapa de atenuación previa al compresor no instantáneo (Figura 4.1). Esto hace que el funcionamiento del audífono MOC tenga una respuesta particular y diferente a la de ICs, sin embargo, en ambos casos se produce una linealización de la respuesta que presumiblemente realza las ILDs. Por tanto, el audífono MOC reproduce los beneficios técnicos de la estrategia MOC para ICs ilustrados a través de los espectrogramas de las señales de salida (o electrodogramas en el caso de ICs) a pesar de las diferencias que existen entre sendos procesamientos.

\subsection{Trabajo futuro}

Entre las posibles futuras líneas de investigación que pueden abrirse a partir de los resultados obtenidos en esta investigación se encuentran las siguientes. 


\subsubsection{Evaluación experimental}

Hay abundante espacio para seguir avanzando en la generalización del beneficio obtenido con diseño actual del audífono MOC. Tendrán que llevarse a cabo otros estudios que tomen en cuenta las siguientes consideraciones.

El beneficio significativo encontrado en los SRTs con máscaras fluctuantes en las configuraciones S345N15 con el audífono MOC2c,

, nos lleva a plantearnos

varias preguntas. ¿Se mantiene el beneficio encontrado con el audífono MOC2c en otras localizaciones y/o con otro tipo de ruido?

¿Cómo afecta la compresión binaural tipo MOC a otras áreas de la percepción auditiva como la localización de fuentes sonoras? Con el objetivo de resolver estas cuestiones proponemos hacer una evaluación experimental similar a la realizada en este trabajo donde se exploren estas configuraciones de parámetros, configuraciones espaciales y tipo de máscara. También, se puede añadir una evaluación para explorar el impacto sobre la localización de las fuentes sonoras (véase Lopez-Poveda et al., 2019).

En este trabajo se ha investigado la inteligibilidad del habla en campo libre simulado con funciones de transferencia (HRTF). Sin embargo, estas configuraciones no son representativas de los ambientes en los que se utilizan audífonos. Sería interesante realizar un conjunto de pruebas con una versión hardware del audífono (véase Grimm et al., 2006) en condiciones de campo libre real que pueden extender la evidencia de la posible mejora. En estos experimentos, además, se pueden abordar las preguntas planteadas en el párrafo anterior.

Con el objetivo de explorar el impacto de la compresión binaural MOC sobre los efectos de la compresión de acción rápida, en las evaluaciones propuestas se podría considerar otros audífonos de referencia, como, por ejemplo, un audífono STD con compresores de acción rápida.

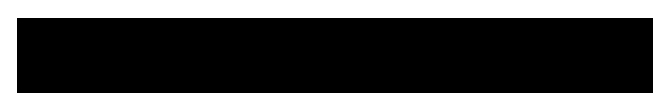


Esta(s) página(s) se han omitido porque contienen información confidencial de interés industrial 


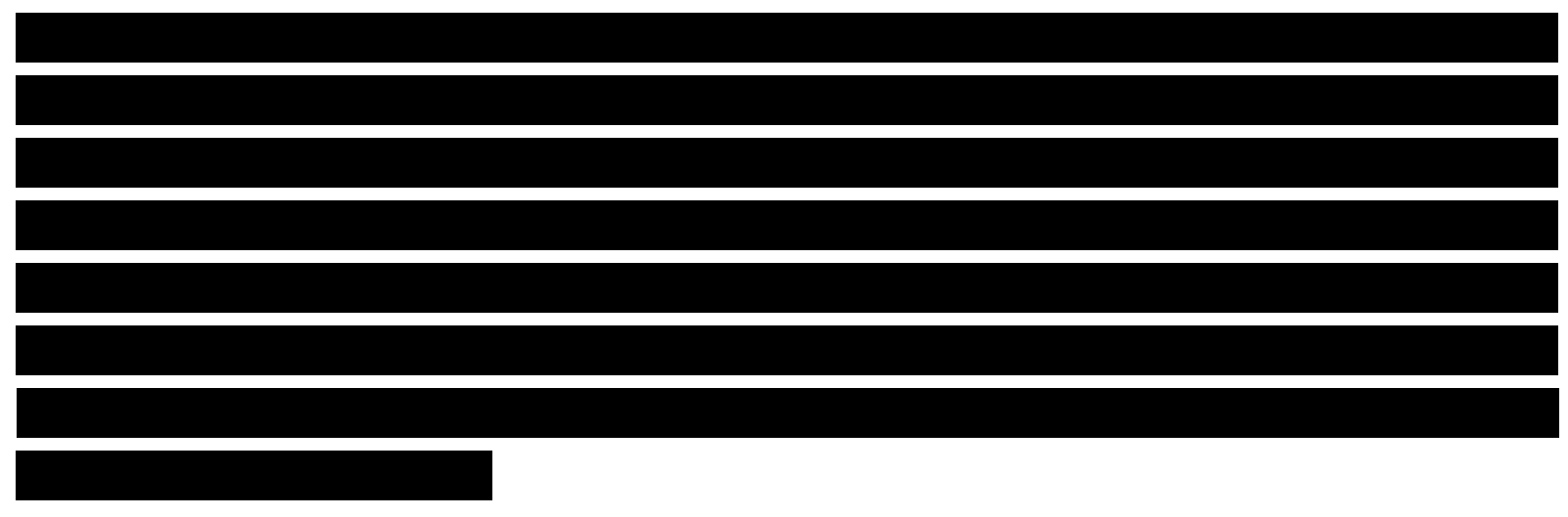

\subsubsection{Evaluaciones técnicas}

Nuestros resultados sugieren que el procesamiento binaural MOC puede reducir algunos de los efectos nocivos de la compresión de acción rápida (Plomp, 1988; Stone y Moore, 1992, 2007,2008 Wiggins y Seeber, 2011, 2012). Para demostrar esto, se propone realizar una evaluación técnica con señales moduladas en amplitud (o habla 'vocodizada'), donde se calcule sobre las señales de salida del audífono MOC y una referencia STD con compresores de acción rápida la SNR, la profundidad de modulación, correlaciones de envolventes entre canales y/o oídos (como por ejemplo se hace en Stone y Moore, 2008). De esta manera se podría evaluar técnicamente el impacto de la compresión binaural tipo MOC sobre la compresión de acción rápida convencional.

\subsection{Implicaciones}

Los resultados obtenidos en esta investigación tienen implicaciones en diferentes áreas.

\subsubsection{Implicaciones clínicas}

Se estima que, en los países en desarrollo, alrededor del $20 \%$ de las personas con pérdida auditiva requieren el uso de audífonos (Organización Mundial de la Salud, 2013). En comparación con un audífono bilateral STD, el audífono MOC mejora 1-2 dB la inteligibilidad del habla en presencia de otro hablante. Esto equivale a que 72 millones de potenciales usuarios de audífonos podrían a mejorar entre un $20 \%$ y un $40 \%$ el reconocimiento de frases en escenarios 
acústicos tales como reuniones, fiestas o lugares de trabajo, donde las señales enmascaradoras son otras personas hablando.

Hemos demostrado que una compresión binaural y dinámica tipo MOC mejora la inteligibilidad del habla en ruido fluctuante. Por tanto, podemos concluir que el enfoque bio-inspirado es un planteamiento prometedor para el diseño de procesadores de sonidos. Este enfoque bioinspirado podría, quizás, facilitar también la comodidad de escucha y reducir el esfuerzo auditivo, lo que fomentaría el uso y aceptación de audífonos entre las personas hipoacúsicas.

\subsubsection{Implicaciones científicas}

El papel del MOCR en la audición humana es todavía controvertido (véase Lopez-Poveda, 2018). Aunque estudios de simulación computacional sugieren que contribuye a mejorar la inteligibilidad del habla en ambientes ruidosos (véase, por ejemplo, Brown y Meddis, 2010; Yasin et al., 2018, 2020), estudios experimentales humanos han demostrado que el MOCR no es necesario para adaptarse al ruido (e.g., Marrufo-Pérez et al., 2018, 2019). El audífono MOC comparte características con el MOCR contralateral pero no es un modelo de la repuesta mecánica coclear. Por tanto, sería un error concluir que nuestros resultados apoyan la idea de que el MOCR natural sí mejora la inteligibilidad en ambientes ruidosos. Siendo rigurosos, los resultados obtenidos no aportan evidencia ni a favor ni en contra sobre el papel del MOCR para comprender el habla en ruido. De la misma manera, el hecho de que los usuarios del audífono mantengan, en mayor o menor grado los efectos del MOCR, no implica un mayor o menor beneficio del procesamiento binaural MOC. Simplemente se revindica que reproducir los efectos del MOCR contralateral en el funcionamiento audífonos binaurales es una opción prometedora para mejorar la inteligibilidad del habla en ruido de los usuarios de audífonos.

\subsubsection{Implicaciones psicoacústicas}

Los resultados obtenidos aquí y en anteriores estudios de la estrategia MOC (Lopez-Poveda et al., 2016b, 2017a, 2020) pueden ayudar a comprender algunos aspectos de la percepción binaural auditiva. La estrategia de codificación de sonidos MOC, mejora presumiblemente la representación de la información acústica en cada oído gracias al control contralateral de la compresión. La linealización de la respuesta realza las ILDs y facilita la segregación espacial de las fuentes sonoras, lo que puede mejorar el desenmascaramiento espacial y la localización de las fuentes sonoras. Al mismo tiempo, como el control contralateral de la compresión es dinámico 
(variable en tiempo), puede facilitar otros mecanismos como la escucha en los valles, ya que de forma local incrementa la relación señal ruido entre los oídos. Los resultados obtenidos con la estrategia MOC para audífonos e ICs reivindican que el procesamiento binaural MOC es una propuesta exitosa para el diseño de procesadores binaurales de sonidos.
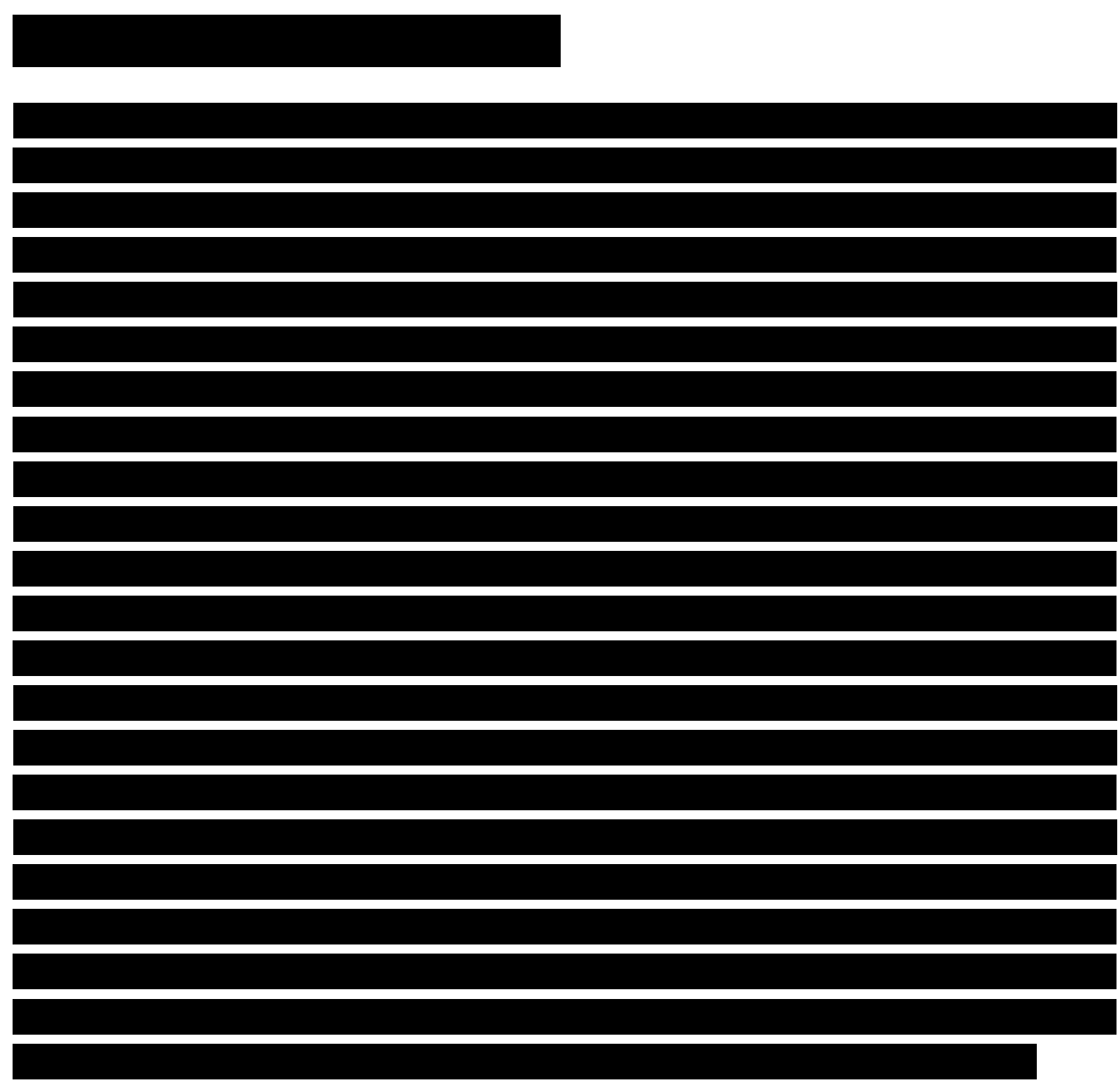


\section{VII - CONCLUSIONES}


VII - Conclusiones 


\section{VII - Conclusiones}

1. Es posible diseñar un compresor de amplitud de sonidos no instantáneo, multicanal y binaural inspirado en el MOCR contralateral y basado en los fundamentos de la estrategia MOC en el que la compresión que aplica cada audífono MOC cambie dinámicamente dependiendo de los sonidos contralaterales de forma similar a cómo el MOCR natural cambia la compresión coclear mecánica.

2. La implementación en formato software del prototipo del audífono MOC, así como la regla de prescripción de ganancia no lineal en función de la pérdida audiométrica, resultan adecuados para restaurar el rango dinámico auditivo de los participantes y establecer una inteligibilidad del habla en ambiente silencioso similar a la proporcionada por los audífonos comerciales.

3. En comparación con el uso de dos audífonos funcionalmente independientes entre sí, el audífono MOC, programado adecuadamente, mejora entre 1 y $2 \mathrm{~dB}$ los umbrales de recepción verbal del habla enmascarada por otro hablante (ruido fluctuante) y no deteriora el reconocimiento de habla en ruido estacionario. 



\section{Referencias}

AAO-HNS. (1993). American Academy of Otolaryngology - Head and Neck Surgery. Bulletin 1617.

Abrams, H. B., Kihm, J. (2015). An introduction to MarkeTrak IX: A new baseline for the hearing aid market. Hearing Review, 22(6), 16-21.

Aguilar E. (2013). Caracterización del efecto del reflejo olivococlear contralateral sobre la respuesta coclear humana. Tesis Doctoral. Universidad de Salamanca.

Aguilar, E., Eustaquio-Martin, A., Lopez-Poveda, E. A. (2013). Contralateral efferent reflex effects on threshold and suprathreshold psychoacoustical tuning curves at low and high frequencies. Journal of the Association for Research in Otolaryngology, 14(3), 341-357.

Aguilar, E., Johannesen, P. T., Lopez-Poveda, E. A. (2015). Contralateral efferent suppression of human hearing sensitivity. Frontiers in Systems Neuroscience, 8, 251.

Ainsworth, W. A. (1976). Mechanisms of Speech Recognition. (Pergamon press, Oxford, UK).

Akeroyd, M. A. (2006). The psychoacoustics of binaural hearing: La psicoacústica de la audición binaural. International Journal of Audiology, 45(sup1), 25-33.

ANSI, A. (1997). S3. 5-1997, Methods for the calculation of the speech intelligibility index. New York: American National Standards Institute, 19, 90-119.

ANSI, A. (2003). S3. 22-2003, Specification of hearing aid characteristics. New York: American National Standards Institute.

Arsenault, M. D., Punch, J. L. (1999). Nonsense-syllable recognition in noise using monaural and binaural listening strategies. Journal of the Acoustical Society of America, 105(3), 1821-1830.

Ashmore, J., Avan, P., Brownell, W. E., Dallos, P., Dierkes, K., Fettiplace, R., ... Lindner, B. (2010). The remarkable cochlear amplifier. Hearing Research, 266(1-2), 1-17.

Aubanel, V., Lecumberri, M. L. G., Cooke, M. (2014). The Sharvard Corpus: A phonemicallybalanced Spanish sentence resource for audiology. International Journal of Audiology, 53(9), 633-638.

Backus, B. C., Guinan Jr, J. J. (2006). Time-course of the human medial olivocochlear reflex. Journal of the Acoustical Society of America, 119(5), 2889-2904. 
Baer, T., Moore, B. C. J. (1993). Effects of spectral smearing on the intelligibility of sentences in noise. Journal of the Acoustical Society of America, 94(3), 1229-1241.

Baer, T., Moore, B. C. J., Gatehouse, S. (1993b). Spectral contrast enhancement of speech in noise for listeners with sensorineural hearing impairment: Effects on intelligibility, quality, and response times. Journal of Rehabilitation Research and Development, 30, 49-49.

Baer, T., Moore, B. C. J., Kluk, K. (2002). Effects of low pass filtering on the intelligibility of speech in noise for people with and without dead regions at high frequencies. Journal of the Acoustical Society of America, 112(3), 1133-1144.

Balfour, P. B., Hawkins, D. B. (1992). A comparison of sound quality judgments for monaural and binaural hearing aid processed stimuli. Ear and Hearing, 13(5), 331-339.

Best, V., Carlile, S., Jin, C., van Schaik, A. (2005). The role of high frequencies in speech localization. Journal of the Acoustical Society of America, 118(1), 353-363.

Bhagat, S. P., Carter, P. H. (2010). Efferent-induced change in human cochlear compression and its influence on masking of tones. Neuroscience Letters, 485(2), 94-97.

Bisgaard, N., Vlaming, M. S., Dahlquist, M. (2010). Standard audiograms for the IEC 60118-15 measurement procedure. Trends in Amplification, 14(2), 113-120.

Blamey, P. J. (2005). Adaptive dynamic range optimization (ADRO): a digital amplification strategy for hearing aids and cochlear implants. Trends in Amplification, 9(2), 77-98.

Bramhall, N. F., Konrad-Martin, D., McMillan, G. P., Griest, S. E. (2017). Auditory brainstem response altered in humans with noise exposure despite normal outer hair cell function. Ear and Hearing, 38(1), e1-e12.

Bramhall, N., Beach, E. F., Epp, B., Le Prell, C. G., Lopez-Poveda, E. A., Plack, C. J., ... Canlon, B. (2019). The search for noise-induced cochlear synaptopathy in humans: Mission impossible? Hearing Research, 377, 88-103.

Bronkhorst, A. W. (2000). The cocktail party phenomenon: A review of research on speech intelligibility in multiple-talker conditions. Acta Acustica united with Acustica, 86(1), 117-128.

Bronkhorst, A. W. (2015). The cocktail-party problem revisited: early processing and selection of multi-talker speech. Attention, Perception, Psychophysics, 77(5), 1465-1487.

Bronkhorst, A. W., Plomp, R. (1989). Binaural speech intelligibility in noise for hearing-impaired listeners. Journal of the Acoustical Society of America, 86(4), 1374-1383.

Bronkhorst, A. W., Plomp, R. (1989). Binaural speech intelligibility in noise for hearing-impaired listeners. Journal of the Acoustical Society of America, 86(4), 1374-1383. 
Bronkhorst, A., Plomp, R. (1992). Effect of multiple speechlike maskers on binaural speech recognition in normal and impaired hearing. Journal of the Acoustical Society of America, 92(6), 3132-3139.

Brown, G. J., Ferry, R. T., Meddis, R. (2010). A computer model of auditory efferent suppression: implications for the recognition of speech in noise. Journal of the Acoustical Society of America, 127(2), 943-954.

Brown, M. C., Nuttall, A. L. (1984). Efferent control of cochlear inner hair cell responses in the guinea-pig. Journal of Physiology, 354(1), 625-646.

Brownell, W. E. (1990). Outer hair cell electromotility and otoacoustic emissions. Ear and Hearing, 11(2), 82-92.

Byrne, D. (1991). Modified hearing aid selection procedures for severe/profound hearing losses. The Vanderbilt Hearing Aid Report II, 295-300.

Byrne, D., Cotton, S. (1988). Evaluation of the National Acoustic Laboratories' new hearing aid selection procedure. Journal of Speech, Language, and Hearing Research, 31(2), 178-186.

Byrne, D., Dillon, H. (1986). The National Acoustic Laboratories'(NAL) new procedure for selecting the gain and frequency response of a hearing aid. Ear and Hearing, 7(4), 257-265.

Byrne, D., Dillon, H., Ching, T., Katsch, R., Keidser, G. (2001). NAL-NL1 procedure for fitting nonlinear hearing aids: characteristics and comparisons with other procedures. Journal of the American Academy of Audiology, 12(1), 37-51.

Byrne, D., Noble, W. (1998). Optimizing sound localization with hearing aids. Trends in Amplification, 3(2), 51-73.

Byrne, D., Noble, W., LePage, B. (1992). Effects of long-term bilateral and unilateral fitting of different hearing aid types on the ability to locate sounds. Journal of the American Academy of Audiology, 3(6), 369-382.

Chabert, R., Magnan, J., Lallemant, J. G., Uziel, A., Puel, J. L. (2002). Contralateral sound stimulation suppresses the compound action potential from the auditory nerve in humans. Otology Neurotology, 23(5), 784-788.

Cheatham, M. A., Dallos, P. (2001). Inner hair cell response patterns: implications for lowfrequency hearing. Journal of the Acoustical Society of America, 110(4), 2034-2044.

Chen, J., Baer, T., Moore, B. C. J. (2010). Effects of enhancement of spectral changes on speech quality and subjective speech intelligibility. In INTERSPEECH 2010, 11th Annual Conference of the International Speech Communication Association, Makuhari, Chiba, Japan, September 26-30, 2010. 
Cherry, E. C. (1953). Some experiments on the recognition of speech, with one and with two ears. Journal of the Acoustical Society of America, 25(5), 975-979.

Clark, N. R., Brown, G. J., Jürgens, T., Meddis, R. (2012). A frequency-selective feedback model of auditory efferent suppression and its implications for the recognition of speech in noise. Journal of the Acoustical Society of America, 132(3), 1535-1541.

Clark, N. R., Lecluyse, W., Jürgens, T. (2018). Analysis of compressive properties of the BioAid hearing aid algorithm. International Journal of Audiology, 57(3), S130-S138.

Collet, L., Moulin, A., Morlet, T., Giraud, A. L., Micheyl, C., Chery-Croze, S. (1994). Contralateral auditory stimulation and otoacoustic emissions: a review of basic data in humans. British Journal of Audiology, 28(4-5), 213-218.

Cooper, N. P., Guinan Jr, J. J. (2003). Separate mechanical processes underlie fast and slow effects of medial olivocochlear efferent activity. Journal of Physiology, 548(1), 307-312.

Cooper, N. P., Guinan Jr, J. J. (2006). Efferent-mediated control of basilar membrane motion. Journal of Physiology, 576(1), 49-54.

de Boer, J., Thornton, A. R. D., Krumbholz, K. (2012). What is the role of the medial olivocochlear system in speech-in-noise processing? Journal of Neurophysiology, 107(5), 1301-1312.

Deng, L., Geisler, C. D. (1987). A composite auditory model for processing speech sounds. Journal of the Acoustical Society of America, 82(6), 2001-2012.

Dillon, H. (1996). Tutorial compression? Yes, but for low or high frequencies, for low or high intensities, and with what response times? Ear and Hearing, 17(4), 287-307.

Dillon, H. (2012). Hearing aids. (Thieme, New York, USA).

Dolan, D. F., Guo, M. H., Nuttall, A. L. (1997). Frequency-dependent enhancement of basilar membrane velocity during olivocochlear bundle stimulation. Journal of the Acoustical Society of America, 102(6), 3587-3596.

Drga, V., Plack, C. J., Yasin, I. (2016). Frequency tuning of the efferent effect on cochlear gain in humans. Advances in Experimental Medicine and Biolology, 894, 477-484.

Eisenberg, L. S., Dirks, D. D., Takayanagi, S., Martinez, A. S. (1998). Subjective judgments of clarity and intelligibility for filtered stimuli with equivalent speech intelligibility index predictions. Journal of Speech, Language, and Hearing Research, 41(2), 327-339.

Ernst, S. M., Kortlang, S., Grimm, G., Bisitz, T., Kollmeier, B., Ewert, S. D. (2018). Binaural modelbased dynamic-range compression. International Journal of Audiology, 57(3), S31-S42.

Eustaquio-Martín, A., Lopez-Poveda, E. A. (2011). Isoresponse versus isoinput estimates of cochlear filter tuning. Journal of the Association for Research in Otolaryngology, 12(3), 281299. 
Ferry, R. T., Meddis, R. (2007). A computer model of medial efferent suppression in the mammalian auditory system. Journal of the Acoustical Society of America, 122(6), 35193526.

Festen, J. M., Plomp, R. (1986). Speech-reception threshold in noise with one and two hearing aids. Journal of the Acoustical Society of America, 79(2), 465-471.

Festen, J. M., Plomp, R. (1990). Effects of fluctuating noise and interfering speech on the speechreception threshold for impaired and normal hearing. Journal of the Acoustical Society of America, 88(4), 1725-1736.

Fletcher, H. (1940). Auditory patterns. Reviews of Modern Physics, 12(1), 47.

Fletcher, H., Munson, W. A. (1933). Loudness, its definition, measurement and calculation. Bell System Technical Journal, 12(4), 377-430.

Fletcher, M. D., Krumbholz, K., de Boer, J. (2016). Effect of contralateral medial olivocochlear feedback on perceptual estimates of cochlear gain and compression. Journal of the Association for Research in Otolaryngology, 17(6), 559-575.

Francis, N. A., Guinan Jr, J. J. (2010). Acoustic stimulation of human medial olivocochlear efferents reduces stimulus-frequency and click-evoked otoacoustic emission delays: Implications for cochlear filter bandwidths. Hearing Research, 267(1-2), 36-45.

Frolenkov, G. I. (2006). Regulation of electromotility in the cochlear outer hair cell. Journal of Physiology, 576(1), 43-48.

Gardner, W. G., Martin, K. D. (1995). HRTF measurements of a KEMAR. Journal of the Acoustical Society of America, 97(6), 3907-3908.

Garinis, A., Werner, L., Abdala, C. (2011). The relationship between MOC reflex and masked threshold. Hearing Research, 282(1-2), 128-137.

Ghitza, O. (2007). Using auditory feedback and rhythmicity for diphone discrimination of degraded speech. In Proceedings of the International Conference on Phonetic Sciences ICPhS, Saarbrucken, Germany. 6-10 August 2007. 163-168.

Giannoulis, D., Massberg, M., Reiss, J. D. (2012). Digital dynamic range compressor design-A tutorial and analysis. Journal of the Audio Engineering Society, 60(6), 399-408.

Giannoulis, D., Massberg, M., Reiss, J. D. (2013). Parameter automation in a dynamic range compressor. Journal of the Audio Engineering Society, 61(10), 716-726.

Goldstein, J. L. (1990). Modeling rapid waveform compression on the basilar membrane as multiple-bandpass-nonlinearity filtering. Hearing Research, 49(1-3), 39-60. 
Grange, J. A., Culling, J. F. (2016). Head orientation benefit to speech intelligibility in noise for cochlear implant users and in realistic listening conditions. Journal of the Acoustical Society of America, 140(6), 4061-4072.

Gratton, M. A., Schmiedt, R. A., Schulte, B. A. (1996). Age-related decreases in endocochlear potential are associated with vascular abnormalities in the stria vascularis. Hearing Research, 102(1-2), 181-190.

Gregan, M. J., Nelson, P. B., Oxenham, A. J. (2013). Behavioral measures of cochlear compression and temporal resolution as predictors of speech masking release in hearingimpaired listeners. Journal of the Acoustical Society of America, 134(4), 2895-2912.

Grimm, G., Herzke, T., Berg, D., Hohmann, V. (2006). The master hearing aid: A PC-based platform for algorithm development and evaluation. Acta Acustica united with Acustica, 92(4), 618-628.

Guinan Jr, J. J. (2006). Olivocochlear efferents: anatomy, physiology, function, and the measurement of efferent effects in humans. Ear and Hearing, 27(6), 589-607.

Guinan Jr, J. J. (2010). Cochlear efferent innervation and function. Current Opinion in Otolaryngology Head and Neck Surgery, 18(5), 447.

Guinan Jr, J. J., Cooper, N. P. (2003). Fast effects of efferent stimulation on basilar membrane motion. In: The biophysics of the cochlea: molecules to models, 245-251. (World Scientific, Singapore).

Hansen, L. B. (2008). Epoq study measures user benefits. The Hearing Journal, 61(9), 47-49.

Hawley, M. L., Litovsky, R. Y., Culling, J. F. (2004). The benefit of binaural hearing in a cocktail party: Effect of location and type of interferer. Journal of the Acoustical Society of America, 115(2), 833-843.

Herzke, T., Hohmann, V. (2005). Effects of instantaneous multiband dynamic compression on speech intelligibility. EURASIP Journal on Advances in Signal Processing, 2005(18), 30343043.

Hochmuth, S., Brand, T., Zokoll, M. A., Castro, F. Z., Wardenga, N., Kollmeier, B. (2012). A Spanish matrix sentence test for assessing speech reception thresholds in noise. International Journal of Audiology, 51(7), 536-544.

Hogan, C. A., Turner, C. W. (1998). High-frequency audibility: Benefits for hearing-impaired listeners. Journal of the Acoustical Society of America, 104(1), 432-441.

Hohmann, V., Kollmeier, B. (1995). The effect of multichannel dynamic compression on speech intelligibility. Journal of the Acoustical Society of America, 97(2), 1191-1195. 
Hood, L. J., Berlin, C. I., Hurley, A., Cecola, R. P., Bell, B. (1996). Contralateral suppression of transient-evoked otoacoustic emissions in humans: intensity effects. Hearing Research, 101(1-2), 113-118.

Hopkins, K., Moore, B. C. J. (2007). Moderate cochlear hearing loss leads to a reduced ability to use temporal fine structure information. Journal of the Acoustical Society of America, 122(2), 1055-1068.

Huarte, A. (2008). The Castilian Spanish hearing in noise test. International Journal of Audiology, 47(6), 369-370.

Huss, M., Moore, B. C. J. (2005a). Dead regions and noisiness of pure tones. International Journal of Audiology, 44(10), 599-611.

Huss, M., Moore, B. C. J. (2005b). Dead regions and pitch perception. Journal of the Acoustical Society of America, 117(6), 3841-3852.

Irving, S., Moore, D. R. (2011). Training sound localization in normal hearing listeners with and without a unilateral ear plug. Hearing Research, 280(1-2), 100-108.

James, A. L., Mount, R. J., Harrison, R. V. (2002). Contralateral suppression of DPOAE measured in real time. Clinical Otolaryngology Allied Sciences, 27(2), 106-112.

Jennings, S. G., Strickland, E. A., Heinz, M. G. (2009). Precursor effects on behavioral estimates of frequency selectivity and gain in forward masking. Journal of the Acoustical Society of America, 125(4), 2172-2181.

Johannesen, P. T., Pérez-González, P., Kalluri, S., Blanco, J. L., Lopez-Poveda, E. A. (2016). The influence of cochlear mechanical dysfunction, temporal processing deficits, and age on the intelligibility of audible speech in noise for hearing-impaired listeners. Trends in Hearing, 20, 1-14.

Johannesen, P. T., Pérez-González, P., Lopez-Poveda, E. A. (2014). Across-frequency behavioral estimates of the contribution of inner and outer hair cell dysfunction to individualized audiometric loss. Frontiers in Neuroscience, 8, 214.

Jürgens, T., Clark, N. R., Lecluyse, W., Meddis, R. (2016). Exploration of a physiologicallyinspired hearing-aid algorithm using a computer model mimicking impaired hearing. International Journal of Audiology, 55(6), 346-357.

Kam, A. C., Wong, L. L. (1999). Comparison of performance with wide dynamic range compression and linear amplification. Journal of the American Academy of Audiology, 10(8), 445-457.

Kates, J. M. (2005). Principles of digital dynamic-range compression. Trends in Amplification, $9(2), 45-76$. 
Kates, J. M. (2008). Digital hearing aids. (Plural Publishing, San Diego, USA).

Kates, J. M. (2009). Binaural compression system. U.S. Patent No. 7,630,507. Washington, DC: U.S. Patent and Trademark Office.

Kates, J. M. (2010). Understanding compression: Modeling the effects of dynamic-range compression in hearing aids. International Journal of Audiology, 49(6), 395-409.

Kawase, T., Delgutte, B., Liberman, M. C. (1993). Antimasking effects of the olivocochlear reflex. II. Enhancement of auditory-nerve response to masked tones. Journal of Neurophysiology, 70(6), 2533-2549.

Kawase, T., Ogura, M., Sato, T., Kobayashi, T., Suzuki, Y. (2003). Effects of contralateral noise on the measurement of auditory threshold. Tohoku Journal of Experimental Medicine, 200(3), 129-135.

Keidser, G., Dillon, H., Carter, L., O’Brien, A. (2012). NAL-NL2 empirical adjustments. Trends in Amplification, 16(4), 211-223.

Keidser, G., Dillon, H., Flax, M., Ching, T., Brewer, S. (2011). The NAL-NL2 prescription procedure. Audiology Research, 1, 88-90.

Kim, D. O., Dorn, P. A., Neely, S. T., Gorga, M. P. (2001). Adaptation of distortion product otoacoustic emission in humans. Journal of the Association for Research in Otolaryngology, 2(1), 31.

Kim, S., Frisina, R. D., Frisina, D. R. (2006). Effects of age on speech understanding in normal hearing listeners: Relationship between the auditory efferent system and speech intelligibility in noise. Speech Communication, 48(7), 855-862.

Kluk, K., Moore, B. C. J. (2006). Dead regions in the cochlea and enhancement of frequency discrimination: Effects of audiogram slope, unilateral versus bilateral loss, and hearing-aid use. Hearing Research, 222(1-2), 1-15.

Kochkin, S. (2002). Consumers rate improvements sought in hearing instruments. Hearing Review, 9(11), 18-22.

Kochkin, S. (2007). MarkeTrak VII: Obstacles to adult non-user adoption of hearing aids. The Hearing Journal, 60(4), 24-51.

Koenig, W. (1950). Subjective effects in binaural hearing. Journal of the Acoustical Society of America, 22(1), 61-62.

Kollmeier, B., Kiessling, J. (2018). Functionality of hearing aids: State-of-the-art and future modelbased solutions. International Journal of Audiology, 57(3), S3-S28. 
Kowalewski, B., Zaar, J., Fereczkowski, M., MacDonald, E. N., Strelcyk, O., May, T., Dau, T. (2018). Effects of Slow-and Fast-Acting Compression on Hearing-Impaired Listeners' Consonant-Vowel Identification in Interrupted Noise. Trends in Hearing, 22, 1-12

Kreisman, B. M., Mazevski, A. G., Schum, D. J., Sockalingam, R. (2010). Improvements in speech understanding with wireless binaural broadband digital hearing instruments in adults with sensorineural hearing loss. Trends in Amplification, 14(1), 3-11.

Krull, V., Strickland, E. A. (2008). The effect of a precursor on growth of forward masking. Journal of the Acoustical Society of America, 123(6), 4352-4357.

Kryter, K. D. (1962). Methods for the calculation and use of the articulation index. Journal of the Acoustical Society of America, 34(11), 1689-1697.

Kujawa, S. G., Liberman, M. C. (2009). Adding insult to injury: cochlear nerve degeneration after "temporary" noise-induced hearing loss. Journal of Neuroscience, 29(45), 14077-14085.

Kuk, F. K. (2002). Considerations in modern multichannel nonlinear hearing aids. In Hearing Aids: Standards, Options and Limitations, 178-213. (Thieme Medical Publishers, New York, USA)

Kumar, U. A., Vanaja, C. S. (2004). Functioning of olivocochlear bundle and speech perception in noise. Ear and Hearing, 25(2), 142-146.

Launer S., Zakis J.A., Moore B.C.J. (2016) Hearing Aid Signal Processing. In: Hearing Aids. Springer Handbook of Auditory Research. (Springer, New York, USA).

Lee, C. C., Sherman, S. M. (2011). On the classification of pathways in the auditory midbrain, thalamus, and cortex. Hearing Research, 276(1-2), 79-87.

Leijon, A., Stadler, S. (2008). Fast amplitude compression in hearing aids improves audibility but degrades speech information transmission. In 16th European Signal Processing Conference, Lausanne, Switzerland, August 25-29, 1-5.

Levitt, H. (1971). Transformed up-down methods in psychoacoustics. Journal of the Acoustical Society of America, 49(2B), 467-477.

Levitt, H. (1987). Digital hearing aids: a tutorial review. Journal of Rehabilitation Research and Development, 24(4), 7-20.

Levitt, H. (2001). Noise reduction in hearing aids: A review. Journal of Rehabilitation Research and Development, 38(1), 111-122.

Levitt, H., Cudahy, E., Hwang, W. H., Kennedy, E., and Link, C. (1987). Towards a general measure of distortion. Journal of Rehabilitation Research and Development, 24, 283-292.

Liberman, M. C., Brown, M. C. (1986). Physiology and anatomy of single olivocochlear neurons in the cat. Hearing Research, 24(1), 17-36. 
Liberman, M. C., Dodds, L. W., Learson, D. A. (1986). Structure-function correlation in noisedamaged ears: A light and electron-microscopic study. In Basic and applied aspects of noiseinduced hearing loss ,163-177. (Springer, Boston, USA).

Liberman, M. C., Guinan Jr, J. J. (1998). Feedback control of the auditory periphery: anti-masking effects of middle ear muscles vs. olivocochlear efferents. Journal of Communication Disorders, 31(6), 471-82.

Lichtenhan, J. T., Wilson, U. S., Hancock, K. E., Guinan Jr, J. J. (2016). Medial olivocochlear efferent reflex inhibition of human cochlear nerve responses. Hearing Research, 333, $216-$ 224.

Lilaonitkul, W., Guinan Jr, J. J. (2009b). Reflex control of the human inner ear: a half-octave offset in medial efferent feedback that is consistent with an efferent role in the control of masking. Journal of Neurophysiology, 101(3), 1394-1406.

Lilaonitkul, W., Guinan Jr, J. J. (2012). Frequency tuning of medial-olivocochlear-efferent acoustic reflexes in humans as functions of probe frequency. Journal of Neurophysiology, 107(6), 1598-1611.

Lilaonitkul, W., Guinan, J. J. (2009a). Human medial olivocochlear reflex: effects as functions of contralateral, ipsilateral, and bilateral elicitor bandwidths. Journal of the Association for Research in Otolaryngology, 10(3), 459-470.

Lopez-Poveda, E. A. (2014). Sound enhancement for cochlear implants. Patente WO2015169649A1.

Lopez-Poveda, E. A. (2014). Why do I hear but not understand? Stochastic undersampling as a model of degraded neural encoding of speech. Frontiers in Neuroscience, 8, 348.

Lopez-Poveda, E. A. (2018). Olivocochlear efferents in animals and humans: From anatomy to clinical relevance. Frontiers in Neurology, 9, 197.

Lopez-Poveda, E. A. (2019.) Medial olivocochlear reflex sound coding with bandwidth normalization. Patente WO2019006059A1.

Lopez-Poveda, E. A., Eustaquio-Martín, A. (2018). Objective speech transmission improvements with a binaural cochlear implant sound-coding strategy inspired by the contralateral medial olivocochlear reflex. Journal of the Acoustical Society of America, 143(4), 2217-2231.

Lopez-Poveda, E. A., Eustaquio-Martín, A., Fumero, M. J., Stohl, J. S., Schatzer, R., Nopp, P, Wilson, B. S. (2019). Lateralization of virtual sound sources with a binaural cochlear-implant sound coding strategy inspired by the medial olivocochlear reflex. Hearing Research, 379, 103-116. 
Lopez-Poveda, E. A., Eustaquio-Martín, A., Stohl, J. S., Wolford, R. D., Schatzer, R., Wilson, B. S. (2016a). Roles of the contralateral efferent reflex in hearing demonstrated with cochlear implants. In Physiology, Psychoacoustics and Cognition in Normal and Impaired Hearing, 105-114. (Springer, New York, USA).

Lopez-Poveda, E. A., Eustaquio-Martín, A., Stohl, J. S., Wolford, R. D., Schatzer, R., Wilson, B. S. (2016b). A binaural cochlear implant sound coding strategy inspired by the contralateral medial olivocochlear reflex. Ear and Hearing, 37(3), e138.

Lopez-Poveda, E. A., Eustaquio-Martín, A., Stohl, J. S., Wolford, R. D., Schatzer, R., Gorospe, J. M., ... Wilson, B. S. (2017a). Intelligibility in speech maskers with a binaural cochlear implant sound coding strategy inspired by the contralateral medial olivocochlear reflex. Hearing Research, 348, 134-137.

Lopez-Poveda, E. A., Johannesen, P. T. (2012). Behavioral estimates of the contribution of inner and outer hair cell dysfunction to individualized audiometric loss. Journal of the Association for Research in Otolaryngology, 13(4), 485-504.

Lopez-Poveda, E. A., Johannesen, P. T., Merchán, M. A. (2009). Estimation of the degree of inner and outer hair cell dysfunction from distortion product otoacoustic emission input/output functions. Audiological Medicine, 7(1), 22-28.

Lopez-Poveda, E. A., Johannesen, P. T., Perez-González, P., Blanco, J. L., Kalluri, S., Edwards, B. (2017b). Predictors of hearing-aid outcomes. Trends in Hearing, 21, 1-28.

Lopez-Poveda, E. A., Meddis, R. (2001). A human nonlinear cochlear filterbank. Journal of the Acoustical Society of America, 110(6), 3107-3118.

Lopez-Poveda, E. A., Plack, C. J., Meddis, R., Blanco, J. L. (2005). Cochlear compression in listeners with moderate sensorineural hearing loss. Hearing Research, 205(1-2), 172-183.

Lopez-Poveda, E.A., Eustaquio-Martín, A., Fumero M.J., Gorospe J.M., Polo López R., Gutierrez Revilla M.A., Schatzer R., Nopp, P., Stohl, J.S. (2020). Speech-in-noise recognition with more realistic implementations of a binaural cochlear-implant sound coding strategy inspired by the medial olivocochlear reflex. Ear and Hearing.

Lorenzi, C., Gilbert, G., Carn, H., Garnier, S., Moore, B. C. J. (2006). Speech perception problems of the hearing impaired reflect inability to use temporal fine structure. Proceedings of the National Academy of Sciences, 103(49), 18866-18869.

Lupo, J. E., Koka, K., Thornton, J. L., Tollin, D. J. (2011). The effects of experimentally induced conductive hearing loss on spectral and temporal aspects of sound transmission through the ear. Hearing Research, 272(1-2), 30-41. 
Macrae, J. H., Dillon, H. (1996). Gain, frequency response, and maximum output requirements for hearing aids. Journal of Rehabilitation Research and Development, 33(4), 363.

Maison, S., Micheyl, C., Andéol, G., Gallégo, S., Collet, L. (2000). Activation of medial olivocochlear efferent system in humans: influence of stimulus bandwidth. Hearing Research, 140(1-2), 111-125.

Malmierca M. S., Merchán, M. (2004). The auditory system In G. Paxinos (Ed.), The rat nervous system, 997-1082. (Academic Press, San Diego, USA).

Marozeau, J., Florentine, M. (2007). Loudness growth in individual listeners with hearing losses: a review. Journal of the Acoustical Society of America, 122(3), EL81-EL87.

Marrufo-Pérez, M. I., Eustaquio-Martín, A., Lopez-Poveda, E. A. (2018). Adaptation to noise in human speech recognition unrelated to the medial olivocochlear reflex. Journal of Neuroscience, 38(17), 4138-4145.

Martín Méndez J. (2010). AudioAid: Modo Test. Trabajo de Fin de Grado. Ingeniería Informática. Universidad de Salamanca.

McCreery, R. W., Venediktov, R. A., Coleman, J. J., Leech, H. M. (2012a). An evidence-based systematic review of frequency lowering in hearing aids for school-age children with hearing loss. American Journal of Audiology. 21,313-328.

McCreery, R. W., Venediktov, R. A., Coleman, J. J., Leech, H. M. (2012b). An evidence-based systematic review of directional microphones and digital noise reduction hearing aids in school-age children with hearing loss. American Journal of Audiology. 21(2), 295-312.

Meddis, R., Clark, N. R., Lecluyse, W., Jürgens, T. (2013). BioAid - Ein Biologisch Inspiriertes Hörgerät, "(BioAid-A biologically inspired hearing aid). Zeitschrift für Audiologie Audiological Acoustics 52, 148-152.

Meddis, R., O'Mard, L. P., Lopez-Poveda, E. A. (2001). A computational algorithm for computing nonlinear auditory frequency selectivity. Journal of the Acoustical Society of America, 109(6), 2852-2861.

Micheyl, C., Collet, L. (1996). Involvement of the olivocochlear bundle in the detection of tones in noise. Journal of the Acoustical Society of America, 99(3), 1604-1610.

Moore, B. C. J. (1996). Perceptual consequences of cochlear hearing loss and their implications for the design of hearing aids. Ear and Hearing, 17(2), 133-161.

Moore, B. C. J. (2001). Dead regions in the cochlea: Diagnosis, perceptual consequences, and implications for the fitting of hearing aids. Trends in Amplification, 5(1), 1-34.

Moore, B. C. J. (2007). Cochlear hearing loss: physiological, psychological and technical issues, 1-332. (Wiley, Chichester, UK). 
Moore, B. C. J. (2008). The choice of compression speed in hearing aids: Theoretical and practical considerations and the role of individual differences. Trends in Amplification, 12(2), 103-112.

Moore, B. C. J. (2012). Effects of bandwidth, compression speed, and gain at high frequencies on preferences for amplified music. Trends in Amplification, 16(3), 159-172.

Moore, B. C. J., Glasberg, B. R. (1983). Suggested formulae for calculating auditory-filter bandwidths and excitation patterns. The Journal of the Acoustical Society of America, 74(3), 750-753.

Moore, B. C. J., Glasberg, B. R. (1988). A comparison of four methods of implementing automatic gain control (AGC) in hearing aids. British Journal of Audiology, 22(2), 93-104.

Moore, B. C. J., Glasberg, B. R. (2004). A revised model of loudness perception applied to cochlear hearing loss. Hearing Research, 188(1-2), 70-88.

Moore, B. C. J., Glasberg, B. R., Hopkins, K. (2006). Frequency discrimination of complex tones by hearing-impaired subjects: Evidence for loss of ability to use temporal fine structure. Hearing Research, 222(1-2), 16-27.

Moore, B. C. J., Glasberg, B. R., Plack, C. J., Biswas, A. K. (1988). The shape of the ear's temporal window. Journal of the Acoustical Society of America, 83(3), 1102-1116.

Moore, B. C. J., Glasberg, B. R., Stone, M. A. (2010). Development of a new method for deriving initial fittings for hearing aids with multi-channel compression: CAMEQ2-HF. International Journal of Audiology, 49(3), 216-227.

Moore, B. C. J., Peters, R. W., Stone, M. A. (1999). Benefits of linear amplification and multichannel compression for speech comprehension in backgrounds with spectral and temporal dips. Journal of the Acoustical Society of America, 105(1), 400-411.

Mott, J. B., Norton, S. J., Neely, S. T., Warr, W. B. (1989). Changes in spontaneous otoacoustic emissions produced by acoustic stimulation of the contralateral ear. Hearing Research, 38(3), 229-242.

Murugasu, E., Russell, I. J. (1996). The effect of efferent stimulation on basilar membrane displacement in the basal turn of the guinea pig cochlea. Journal of Neuroscience, 16(1), 325-332.

Musa-Shufani, S., Walger, M., von Wedel, H., Meister, H. (2006). Influence of dynamic compression on directional hearing in the horizontal plane. Ear and Hearing, 27(3), 279-285.

Nabelek, A. K., Mason, D. (1981). Effect of noise and reverberation on binaural and monaural word identification by subjects with various audiograms. Journal of Speech, Language, and Hearing Research, 24(3), 375-383. 
Ng, J. H. Y., Loke, A. Y. (2015). Determinants of hearing-aid adoption and use among the elderly: A systematic review. International Journal of Audiology, 54(5), 291-300.

Nieder, P., Nieder, I. (1970). Stimulation of efferent olivocochlear bundle causes release from low level masking. Nature, 227(5254), 184-185.

Organización Mundial de la Salud (2013). Millions of people in the world have hearing loss that can be treated or prevented. Obtenido de URL: https://www.who.int/pbd/deafness/news/Millionslivewithhearingloss.pdf?ua=1. Fecha de última descarga: 28/05/2020.

Organización Mundial de la Salud (2018). ¡La pérdida de audición va en aumento! Obtenido de URL: $\quad$ https://www.who.int/deafness/world-hearing-day/World-Hearing-Day-InfographicSP.pdf. Fecha de última descarga: 28/05/2020.

Otsuka, S., Nakagawa, S., Furukawa, S. (2020). Relationship between characteristics of medial olivocochlear reflex and speech-in-noise-reception performance. Acoustical Science and Technology, 41(1), 404-407.

Oxenham, A. J., Bacon, S. P. (2003). Cochlear compression: perceptual measures and implications for normal and impaired hearing. Ear and Hearing, 24(5), 352-366.

Oxenham, A. J., Simonson, A. M., Turicchia, L., Sarpeshkar, R. (2007). Evaluation of companding-based spectral enhancement using simulated cochlear-implant processing. Journal of the Acoustical Society of America, 121(3), 1709-1716.

Palmer, A. D., Newsom, J. T., Rook, K. S. (2016). How does difficulty communicating affect the social relationships of older adults? An exploration using data from a national survey. Journal of Communication Disorders, 62, 131-146.

Pascoe, D. P. (1988). Clinical measurements of the auditory dynamic range and their relation to formulas for hearing aid gain. Hearing aid Fitting: Theoretical and Practical Views, 129-152.

Pavlovic, C. V. (1987). Derivation of primary parameters and procedures for use in speech intelligibility predictions. Journal of the Acoustical Society of America, 82(2), 413-422.

Peissig, J., Kollmeier, B. (1997). Directivity of binaural noise reduction in spatial multiple noisesource arrangements for normal and impaired listeners. Journal of the Acoustical Society of America, 101(3), 1660-1670.

Pérez González P. (2009). AudioAid: Modo de Entrenamiento. Trabajo de Fin de Grado. Ingeniería Informática. Universidad de Salamanca.

Persson, K., Björkman, M., Rylander, R. (1990). Loudness, annoyance and dBA in evaluating low frequency sounds. Journal of Low Frequency Noise, Vibration and Active Control, 9(1), 3245. 
Plack, C. J., Barker, D., Prendergast, G. (2014). Perceptual consequences of "hidden" hearing loss. Trends in Hearing, 18:1-11.

Plack, C. J., Moore, B. C. J. (1990). Temporal window shape as a function of frequency and level. Journal of the Acoustical Society of America, 87(5), 2178-2187.

Plomp, R. (1978). Auditory handicap of hearing impairment and the limited benefit of hearing aids. Journal of the Acoustical Society of America, 63(2), 533-549.

Plomp, R. (1988). The negative effect of amplitude compression in multichannel hearing aids in the light of the modulation-transfer function. Journal of the Acoustical Society of America, 83(6), 2322-2327.

Plomp, R. (1994). Noise, amplification, and compression: considerations of three main issues in hearing aid design. Ear and Hearing, 15(1), 2-12.

Popelka, G. R., Moore, B. C. J., Fay, R. R., Popper, A. N. (Eds.). (2016). Hearing Aids. (Springer, New York, USA).

Rasetshwane, D. M., Gorga, M. P., Neely, S. T. (2013). Signal-processing strategy for restoration of cross-channel suppression in hearing-impaired listeners. IEEE Transactions on Biomedical Engineering, 61(1), 64-75.

Rayleigh, L. (1907). XII. On our perception of sound direction. The London, Edinburgh, and Dublin Philosophical Magazine and Journal of Science, 13(74), 214-232.

Rhode, W. S. (1971). Observations of the vibration of the basilar membrane in squirrel monkeys using the Mössbauer technique. Journal of the Acoustical Society of America, 49(4B), 12181231.

Rhode, W. S., Recio, A. (2000). Study of mechanical motions in the basal region of the chinchilla cochlea. Journal of the Acoustical Society of America, 107(6), 3317-3332.

Rhode, W. S., Robles, L. (1974). Evidence from Mössbauer experiments for nonlinear vibration in the cochlea. Journal of the Acoustical Society of America, 55(3), 588-596.

Robinson, C. E., Huntington, D. A. (1973). The Intelligibility of Speech Processed by Delayed Long-Time-Averaged Compression Amplification. Journal of the Acoustical Society of America, 54(1), 314-314.

Robinson, J. D., Stainsby, T. H., Baer, T., Moore, B. C. J. (2009). Evaluation of a frequency transposition algorithm using wearable hearing aids. International Journal of Audiology, 48(6), 384-393.

Robles, L., Ruggero, M. A. (2001). Mechanics of the mammalian cochlea. Physiological Reviews, 81(3), 1305-1352. 
Robles, L., Ruggero, M. A., Rich, N. C. (1986). Basilar membrane mechanics at the base of the chinchilla cochlea. I. Input-output functions, tuning curves, and response phases. Journal of the Acoustical Society of America, 80(5), 1364-1374.

Ruggero, M. A. (1992). Responses to sound of the basilar membrane of the mammalian cochlea. Current Opinion in Neurobiology, 2(4), 449-456.

Ruggero, M. A., Rich, N. C. (1991). Furosemide alters organ of corti mechanics: evidence for feedback of outer hair cells upon the basilar membrane. Journal of Neuroscience, 11(4), 1057-1067.

Ruggero, M. A., Rich, N. C., Robles, L., Shivapuja, B. G. (1990). Middle-ear response in the chinchilla and its relationship to mechanics at the base of the cochlea. Journal of the Acoustical Society of America, 87(4), 1612-1629.

Ruggero, M. A., Robles, L., Rich, N. C. (1992). Two-tone suppression in the basilar membrane of the cochlea: Mechanical basis of auditory-nerve rate suppression. Journal of Neurophysiology, 68(4), 1087-1099.

Sachs, M. B., Young, E. D. (1980). Effects of nonlinearities on speech encoding in the auditory nerve. Journal of the Acoustical Society of America, 68(3), 858-875.

Salorio-Corbetto, M., Baer, T., Stone, M. A., Moore, B. C. J. (2020). Effect of the number of amplitude-compression channels and compression speed on speech recognition by listeners with mild to moderate sensorineural hearing loss. Journal of the Acoustical Society of America, 147(3), 1344-1358.

Sammeth, C. A., Ochs, M. T. (1991). A review of current" noise reduction" hearing aids: rationale, assumptions, and efficacy. Ear and Hearing, 12(6), 116S-124S.

Schreurs, K. K., Olsen, W. O. (1985). Comparison of monaural and binaural hearing aid use on a trial period basis. Ear and Hearing, 6(4), 198-202.

Scollie, S., Seewald, R., Cornelisse, L., Moodie, S., Bagatto, M., Laurnagaray, D., ... Pumford, J. (2005). The desired sensation level multistage input/output algorithm. Trends in Amplification, 9(4), 159-197.

Sellick, P. M., Patuzzi, R. M. J. B., Johnstone, B. M. (1982). Measurement of basilar membrane motion in the guinea pig using the Mössbauer technique. Journal of the Acoustical Society of America, 72(1), 131-141.

Silman, S., Gelfand, S. A., Silverman, C. A. (1984). Late-onset auditory deprivation: Effects of monaural versus binaural hearing aids. Journal of the Acoustical Society of America, 76(5), 1357-1362. 
Simpson, A. (2009). Frequency-lowering devices for managing high-frequency hearing loss: A review. Trends in Amplification, 13(2), 87-106.

Smith, S. B., Lichtenhan, J. T., Cone, B. K. (2017). Contralateral inhibition of click-and chirpevoked human compound action potentials. Frontiers in Neuroscience, 11, 189.

Sockalingam, R., Holmberg, M., Eneroth, K., Shulte, M. (2009). Binaural hearing aid communication shown to improve sound quality and localization. The Hearing Journal, 62(10), 46-47.

Souza, P. E. (2002). Effects of compression on speech acoustics, intelligibility, and sound quality. Trends in Amplification, 6(4), 131-165.

Souza, P. E., Turner, C. W. (1999). Quantifying the contribution of audibility to recognition of compression-amplified speech. Ear and Hearing, 20(1), 12-20.

Sridhar, T. S., Liberman, M. C., Brown, M. C., Sewell, W. F. (1995). A novel cholinergic" slow effect" of efferent stimulation on cochlear potentials in the guinea pig. Journal of Neuroscience, 15(5), 3667-3678.

Steinberg, J. C., Gardner, M. B. (1937). The dependence of hearing impairment on sound intensity. Journal of the Acoustical Society of America, 9(1), 11-23.

Stone, M. A., Moore, B. C. J. (1992). Syllabic compression: Effective compression ratios for signals modulated at different rates. British Journal of Audiology, 26(6), 351-361.

Stone, M. A., Moore, B. C. J. (2003). Effect of the speed of a single-channel dynamic range compressor on intelligibility in a competing speech task. Journal of the Acoustical Society of America, 114(2), 1023-1034.

Stone, M. A., Moore, B. C. J. (2004). Side effects of fast-acting dynamic range compression that affect intelligibility in a competing speech task. Journal of the Acoustical Society of America, 116(4), 2311-2323.

Stone, M. A., Moore, B. C. J. (2007). Quantifying the effects of fast-acting compression on the envelope of speech. Journal of the Acoustical Society of America, 121(3), 1654-1664.

Stone, M. A., Moore, B. C. J. (2008). Effects of spectro-temporal modulation changes produced by multi-channel compression on intelligibility in a competing-speech task. Journal of the Acoustical Society of America, 123(2), 1063-1076.

Stone, M. A., Moore, B. C. J., Alcántara, J. I., Glasberg, B. R. (1999). Comparison of different forms of compression using wearable digital hearing aids. Journal of the Acoustical Society of America, 106(6), 3603-3619. 
Temchin, A. N., Rich, N. C., Ruggero, M. A. (2008). Threshold tuning curves of chinchilla auditory nerve fibers. II. Dependence on spontaneous activity and relation to cochlear nonlinearity. Journal of Neurophysiology, 100(5), 2899-2906.

Trine, T. D., Van Tasell, D. (2002). Digital hearing aid design: Fact vs. fantasy. The Hearing Journal, 55(2), 36-38.

Turicchia, L., Sarpeshkar, R. (2005). A bio-inspired companding strategy for spectral enhancement. IEEE Transactions on Speech and Audio Processing, 13(2), 243-253.

van Buuren, R. A., Festen, J. M., Houtgast, T. (1996). Peaks in the frequency response of hearing aids: Evaluation of the effects on speech intelligibility and sound quality. Journal of Speech, Language, and Hearing Research, 39(2), 239-250.

van Buuren, R. A., Festen, J. M., Houtgast, T. (1999). Compression and expansion of the temporal envelope: Evaluation of speech intelligibility and sound quality. Journal of the Acoustical Society of America, 105(5), 2903-2913.

Van den Bogaert, T., Doclo, S., Wouters, J., Moonen, M. (2008). The effect of multimicrophone noise reduction systems on sound source localization by users of binaural hearing aids. Journal of the Acoustical Society of America, 124(1), 484-497.

Vickers, D. A., Moore, B. C. J., Baer, T. (2001). Effects of low-pass filtering on the intelligibility of speech in quiet for people with and without dead regions at high frequencies. Journal of the Acoustical Society of America, 110(2), 1164-1175.

Von Békésy, G. (1960). Experiments in hearing. (McGraw-Hill, New York, USA).

Wagner, W., Frey, K., Heppelmann, G., Plontke, S. K., Zenner, H. P. (2008). Speech-in-noise intelligibility does not correlate with efferent olivocochlear reflex in humans with normal hearing. Acta Oto-laryngologica, 128(1), 53-60.

Walker, G., Dillon, H. (1982). Compression in hearing aids: An analysis, a review and some recommendations. National Acoustic Laboratories of Australia, Report 90.

Webster, D. B., Fay, R. R. (2013). The mammalian auditory pathway: neuroanatomy. (Springer, New York, USA).

Wiggins, I. M., Seeber, B. U. (2011). Dynamic-range compression affects the lateral position of sounds. Journal of the Acoustical Society of America, 130(6), 3939-3953.

Wiggins, I. M., Seeber, B. U. (2012). Effects of dynamic-range compression on the spatial attributes of sounds in normal-hearing listeners. Ear and Hearing, 33(3), 399-410.

Wiggins, I. M., Seeber, B. U. (2013). Linking dynamic-range compression across the ears can improve speech intelligibility in spatially separated noise. Journal of the Acoustical Society of America, 133(2), 1004-1016. 
Wightman, F. L., Kistler, D. J. (1993). Sound localization. In Human psychophysics, 155-192. (Springer, New York, USA).

Wightman, F., Kistler, D. (2005). Measurement and validation of human HRTFs for use in hearing research. Acta Acustica united with Acustica, 91(3), 429-439.

Wilson BS, Schatzer R, Lopez-Poveda EA, Sun X, Lawson DT, Wolford RD. (2005). Two new directions in speech processor design for cochlear implants. Ear and Hearing, 26, 73S-81S.

Winslow, R. L., Sachs, M. B. (1987). Effect of electrical stimulation of the crossed olivocochlear bundle on auditory nerve response to tones in noise. Journal of Neurophysiology, 57(4), 1002-1021.

Winslow, R. L., Sachs, M. B. (1988). Single-tone intensity discrimination based on auditory-nerve rate responses in backgrounds of quiet, noise, and with stimulation of the crossed olivocochlear bundle. Hearing Research, 35(2-3), 165-189.

Yang, J., Luo, F. L., Nehorai, A. (2003). Spectral contrast enhancement: Algorithms and comparisons. Speech Communication, 39(1-2), 33-46.

Yasin, I., Drga, V., Liu, F., Demosthenous, A., Meddis, R. (2020). Optimizing Speech Recognition Using a Computational Model of Human Hearing: Effect of Noise Type and Efferent Time Constants. IEEE Access, 8, 56711-56719.

Yasin, I., Drga, V., Plack, C. J. (2014). Effect of human auditory efferent feedback on cochlear gain and compression. Journal of Neuroscience, 34(46), 15319-15326.

Yasin, I., Liu, F., Drga, V., Demosthenous, A., Meddis, R. (2018). Effect of auditory efferent timeconstant duration on speech recognition in noise. Journal of the Acoustical Society of America, 143(2), EL112-EL115.

Young, E. D. (2008). Neural representation of spectral and temporal information in speech. Philosophical Transactions of the Royal Society B: Biological Sciences, 363(1493), 923-945.

Yund, E. W., Buckles, K. M. (1995). Multichannel compression hearing aids: Effect of number of channels on speech discrimination in noise. Journal of the Acoustical Society of America, 97(2), 1206-1223.

Zadeh, L. M., Silbert, N. H., Sternasty, K., Swanepoel, D. W., Hunter, L. L., Moore, D. R. (2019). Extended high-frequency hearing enhances speech perception in noise. Proceedings of the National Academy of Sciences, 116(47), 23753-23759.

Zhao, W., Dhar, S. (2010). The effect of contralateral acoustic stimulation on spontaneous otoacoustic emissions. Journal of the Association for Research in Otolaryngology, 11(1), 5367 
Zhao, W., Dhar, S. (2011). Fast and slow effects of medial olivocochlear efferent activity in humans. PLoS One, 6(4) e18725.

Zhao, W., Dhar, S. (2012). Frequency tuning of the contralateral medial olivocochlear reflex in humans. Journal of Neurophysiology, 108(1), 25-30. 
Esta(s) página(s) se han omitido porque contienen información confidencial de interés industrial 




\section{El audífono binaural MOC}

\section{○}

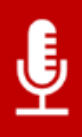

$(1)$

La pérdida de audición, que afecta 466 millones de personas en todo el mundo, deteriora la comunicación y la interacción social de las personas que la padecen. Para estas personas, el uso de audífonos puede ser una gran ayuda, ya que estos dispositivos mejoran la audibilidad de los sonidos suaves y la percepción de la sonoridad. Sin embargo, en situaciones cotidianas donde una persona está hablando en presencia de otros sonidos, los usuarios de audífonos tienen grandes dificultades para entender el habla. Esto podría deberse a que las personas con pérdida auditiva, que sufren un deterioro de sus células ciliadas externas cocleares, carecen de los beneficios 'desenmascarantes' que proporciona el reflejo olivococlear medial (MOCR). Este control reflejo, que el cerebro auditivo ejerce sobre la respuesta mecánica coclear, posiblemente facilita la escucha en ruido al reducir la adaptación de la respuesta al ruido de las fibras del nervio auditivo. Con el objetivo de mejorar la percepción del habla en ruido de los usuarios de audífonos, en la presente tesis se ha diseñado, implementado y evaluado un algoritmo de compresión de amplitud multicanal inspirado en el MOCR contralateral, denominado audífono MOC. Se trata de un audífono binaural en formato software donde la compresión que se aplica sobre los sonidos varía en el tiempo en función del sonido ipsilateral (compresión no instantánea) y contralateral (control contralateral de la compresión). Se demuestra que, de manera similar al efecto del MOCR natural en la compresión coclear, la compresión en cada canal del audífono MOC cambia dinámicamente dependiendo de las características de los sonidos ipsilaterales y contralaterales. La evaluación objetiva de la inteligibilidad del habla en personas con hipoacusia neurosensorial bilateral simétrica muestra que, en comparación al uso de dos audífonos funcionalmente independientes entre sí (audífono STD), el audífono binaural MOC mejora de 1-2 dB la inteligibilidad del habla en presencia de otro hablante. Este hallazgo implica que los 72 millones posibles usuarios de audífonos podrían mejorar entre un 20 y $40 \%$ el reconocimiento de frases en reuniones, fiestas o lugares de trabajo, donde los ruidos son otras personas hablando. En conclusión, el procesamiento binaural MOC, que simula los efectos del MOCR contralateral en el procesamiento de sonidos, puede mejorar la percepción del habla en ruido al reducir los efectos nocivos asociados a la compresión que aplican los audífonos tradicionales. 